Florida International University FIU Digital Commons

7-21-2005

\title{
Evaluating a participatory approach to diversity training with multicultural counseling trainees
}

Jenean Brown

Florida International University

DOI: $10.25148 /$ etd.FI14051857

Follow this and additional works at: https://digitalcommons.fiu.edu/etd

Part of the Psychology Commons

\section{Recommended Citation}

Brown, Jenean, "Evaluating a participatory approach to diversity training with multicultural counseling trainees" (2005). FIU Electronic Theses and Dissertations. 1874.

https://digitalcommons.fiu.edu/etd/1874 
FLORIDA INTERNATIONAL UNIVERSITY

Miami, Florida

EVALUATING A PARTICIPATORY APPROACH TO DIVERSITY TRAINING

WITH MULTICULTURAL COUNSELING TRAINEES

A thesis submitted in partial fulfillment of the

requirements for the degree of

MASTER OF SCIENCE

in

PSYCHOLOGY

by

Jenean Brown

2005 
To: Interim Dean Mark Szuchman

College of Arts and Sciences

This thesis, written by Jenean Brown, and entitled Evaluating a Participatory Approach to Diversity Training with Multicultural Counseling Trainees, having been approved in respect to style and intellectual content, is referred to you for judgment.

We have read this thesis and recommend that it be approved.

Raysá Richardson

William Kurtines

Marilyn Montgotnery, Major Professdr

Date of Defense: July 21, 2005

The thesis of Jenean Brown is approved.

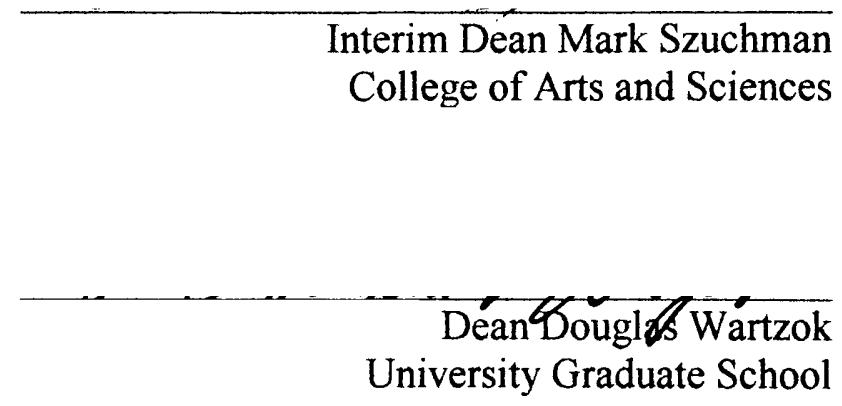

Florida International University, 2005 


\title{
ABSTRACT OF THE THESIS
}

\section{EVALUATING A PARTICIPATORY APPROACH TO DIVERSITY \\ TRAINING WITH MULTICULTURAL COUNSELING TRAINEES}

by

\author{
Jenean Brown
}

Florida International University, 2005

Miami, Florida

Professor Marilyn Montgomery, Major Professor

The purpose of this study was to gain knowledge about the impact and effectiveness of instructional practices used in teaching of multicultural diversity sensitivity courses at the graduate level. A participatory approach termed Transformative Diversity Training (TDT) was evaluated by examining how graduate students $(\mathrm{N}=41$ evaluated their own change in (a) awareness, knowledge, and skills for working with diverse clients, and (b) efforts to transform themselves, work settings, and/or communities toward more equitable practices. TDT impact was analyzed by examining participants' written responses to questions provided at pretest (start of semester), posttest (end of semester), and follow-up (one year later), using the qualitative data analytic method of Relational Data Analyses. Results indicated that most students (95\%) gained awareness, knowledge and skills related to multicultural competence, and these gains facilitated personal and professional transformation through empowerment. Students reported continued transformative activities and social action one year after the course had ended 
I. INTRODUCTION .................................................... 1

II. LITERATURE REVIEW

A. Accessibility and Quality of Mental health Services................... 5

B. The Diversity of Helping Professionals............................. 7

C. Professional Involvement.......................................... 9

D. Developing Diversity Training Approaches that Involve and Empower...................................................... 13

E. Transformative Pedagogy........................................ 15

F. A Transformative Diversity Training Program..................... 17

III. METHODOLOGY

1. Design..................................................... 26

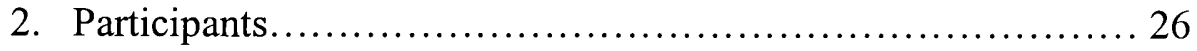

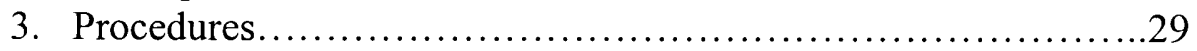

4. Data Analyses.......................................... 31

a) RDA Procedures.................................... 31

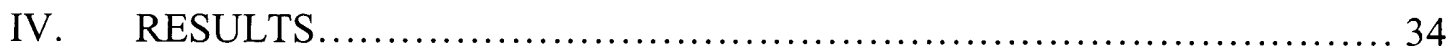

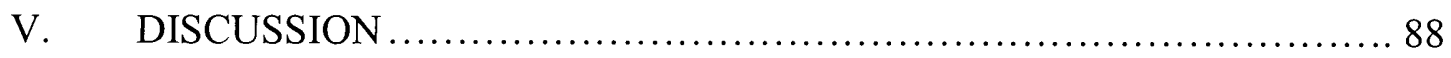

REFERENCES................................................... 104

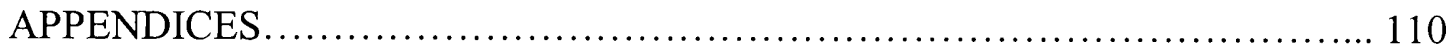




\section{LIST OF TABLES}

TABLE

PAGE

1. Summary of Studies on the Impact of Multicultural Education Programs on Counseling Trainees

2. Transformative Diversity Training Model

3. Participants' Background Information .28

4. Students' Hopes for Change at Pre-Test.

5. Students' Personal and Professional Actual Change at Post-Test

6. Students' Actual Change in Multicultural Competence. .48

7. Identified Impact on Multicultural Competence for each Conceptual Coding Category.

8. Impact of Participatory Activities

9. Impact of Change in Multicultural Competence on the Quality of Students' Professional Services/Activities.

10. Impact on Community and Professional Involvement.

11. Impact of Change in Community Involvement on the Quality of Students' Professional Services/Activities

12. Student Feedback and Suggestions for Transformative Diversity Training Course .71

13. Theoretical Coding of Students' Hopes for Change at Pre-Test. .76

14. Theoretical Coding of Students' Self-Perceptions of Changes at Post-Test. .77

15. Theoretical Coding of Students' Self-Perceptions of Changes in Multicultural Competencies at Post-Test.

16. Theoretical Coding of Students' Self-Appraisals of Change in Multicultural Competencies at 1-Year Follow-Up. 
17. Theoretical Coding of Students' Self-Appraisals of Impact on Professional Services at 1-Year Follow-Up

18. Theoretical Coding of Students' Self-Appraisals of Change in Involvement in Community/Professional at $1-$ Year Follow-Up...............................84

19. Theoretical Coding of Students' Self-Appraisals of Change in Quality of Services Resulting from Involvement in Community/Professional at 1-Year

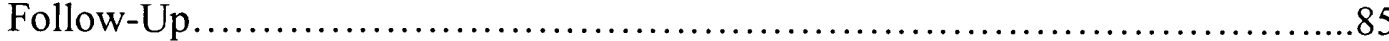

20. Percent of Responses in Each Category at Each Time of Assessment................87

21. Matching Actual Change with Sue's Multicultural Competencies.................91 


\section{LIST OF FIGURES}

FIGURE

PAGE

1. Students' Hopes for Change Conceptual Coding Categories.........................35

2. Personal and Professional Actual Change Conceptual Coding Categories............39

3. Cross-Matching of Hopes for Change with Actual Change (Personal \& Professional).

4. Conceptual Coding Categories for Students' Actual Change in Multicultural Competence.

5. Conceptual Coding Categories for the Impact of Participatory Activities

6. Conceptual Coding Categories for Impact on Quality of Professional Services/Activities

7. Conceptual Coding Categories for Class Impact on Community and Professional Involvement.

8. Conceptual Coding Categories for Impact of Change in Community Involvement on the Quality of Professional Services/Activities 


\section{CHAPTER I}

Introduction

The demographic composition of the United States is increasingly racially and ethnically diverse (United States Census Bureau, 2001). Conservative projections estimate that ethnic minorities will comprise over $50 \%$ of U.S. society by the year 2050 (U.S. Census Bureau, 2001). As echoed by Sue, 1998, as diversity within the United States population increases, the probability is higher that counselors will work with clients of differing cultural backgrounds. As communities continue to change, effective service delivery will require counsellors to be culturally competent-or face obsolescence (Hall, 1997). In response to this trend, one of the most notable developments has been the identification and definition of multicultural counseling competencies by leaders in the counselling profession (Sue et al., 1992; 1998).

By the 1990 's, approximately $88 \%$ of clinical and counseling psychology programs (APA), covered minority issues in general, over $50 \%$ taught one or two classes that specifically addressed multicultural issues (Quintana \& Bernal, 1995). Hence, it would seem that multiculturalism had become "one of the most important psychological constructs in this decade" (Nagayama, 1997).

As multiculturalism's acceptance grew, and the multicultural counseling competency literature expanded, the Sue et al. (1992) "competencies" gave rise to instruments that were designed to measure counsellor multicultural competence (cf. reviews by Ponterotto, Rieger, Barrett, \& Staples, 1994; Pope-Davis \& Dings, 1995). These included, for example, the Cross-Cultural Counseling Inventory - Revised (CCCIR; La Fromboise, Coleman, \& Hernandez, 1991), the Multicultural Counseling 
Awareness Scale- Form B (MCAS:B; Ponterotto et al., 1996), the Multicultural Counseling Inventory (MCI; Sodowsky, Taffe, Gutkin, \& Wise, 1994), and the Multicultural Awareness-Knowledge-Skills Survey (MAKSS; D’Andres, Daniels, \& Heck, 1991). Much of the early research on multiculturalism focused on multicultural counselling competence and identifying effective ways to assess such competence.

However, relative to the total amount of literature on multicultural issues, little has been done to evaluate the effectiveness of graduate training in helping students to achieve multicultural competence. Ridley, Mendoza \& Kanitz, 1997 noted that "the evaluation of multicultural counseling training is critical if the goal of providing quality services to all clients is to be effectively met" (p. 274). Despite this need, there has been minimal attention directed toward developing consistently sound and conceptually anchored training programs, and instruments for evaluating these programs. A central question is still paramount: with increased exposure to multicultural issues, will students gain the appropriate awareness, knowledge and skills for working with diverse populations? Specifically, do the courses offered thus far, result in changes in awareness, knowledge and skills that are tangible and pragmatically useful? Are students' changes lasting and sustainable beyond the classroom? What formats and instructional strategies foster student gains in the multicultural competencies?

Until training efforts and the multicultural competence level of psychology trainees are evaluated, it will not be clear if the required infusion of multicultural goals and programs into psychology training programs and internship sites do result in culturally sensitive psychologists (Jones, 1985). It is therefore essential to articulate the process through which counsellors-in-training become more culturally competent. 
The purpose of this study is to gain knowledge about the impact and effectiveness of instructional practices used in the teaching of multicultural or diversity sensitivity courses at the graduate level, in particular a participatory approach to diversity training designated here as Transformative Diversity Training (TDT). The aim of this study is to investigate the way in which students in a TDT course evaluate their own change in awareness, knowledge, and skills for working with diverse clients, their own efforts in transforming themselves, their work settings, and/or their communities toward more equitable practices, and the utility and sustainability of such changes. 


\section{CHAPTER II}

\section{Literature Review}

The growth of diversity training programs represents a response to some basic inequities that have existed in the field of counseling psychology. One inequity is the disproportionately low numbers of non-majority people participating in counseling as clients. Many racial and ethnic minorities, particularly American Indians, Asian Americans, African Americans and Hispanics tend to underutilize traditional outpatient mental health services (Cheung \& Snowden, 1990), despite the fact that prevalence rates for mental health/psychiatric disorders are analogous across ethnic groups (Hough et al, 1987: U.S. Department of Health and Human Services, 2000, 2001; Weissman, Livingston, Leaf, Florio, \& Holzer, 1991). Among ethnic minorities who do use mental health services (Rogler, Malgady, Constantino, \& Blumenthal, 1987; Sue, 1977) there are often high drop out rates after one session (Wierzbicki \& Pekarik, 1993), infrequent use of therapy sessions (Krebs, 1971; O’Sullivan \& Lasso, 1992;Solomon, 1988), and poor levels of functioning at the end of treatment (Jerrell \& Wilson, 1997; Rosenheck, Leda, Frisman, \& Gallup, 1997; Zane, Enomoto, \& Chun, 1994). Evidently, although "guidance for all" has long been a value of the profession (Robinson, 1953; Hoyt, 1967), there are, in fact, neglected segments of the population whose needs are not met by counselors (for a review, see Jackson, 1995).

Some have asserted that the unequal treatment of some clients served by the profession is due to the lack of cultural competence of providers. The Surgeon General's Report on culture and mental health (USDHHS, 2000, 2001) suggests that "cultural misunderstanding or communication problems between clients and therapists may 
prevent minority group members from using services and receiving appropriate care" ( $p$. 42). Without awareness and considerable skill, the counselor who works with a culturally different client may engage unknowingly in harmful practices (Sue, Arredondo, \& McDavis, 1992) and provide a standard of care below what is usually obtained by majority individuals.

\section{Accessibility and Quality of Mental Health Services}

Generally, the profession has been proactive in responding to these inequities, reflecting concern about the accessibility and quality of mental health services available for diverse people. Professional association divisions (Division 45 of APA and the Association for Multicultural Counseling and Development (AMCD), journals (Cultural Diversity and Ethic Minority Psychology and Journal of Multicultural Counseling and Development) and special offices (APA's Office of Ethnic Minority Affairs) have done much to raise professionals' awareness of particular needs and issues and to increase their competence in working with diverse people. However, a special charge is given to those who are responsible for the education of professionals, as many have asserted that the major reason for therapeutic ineffectiveness lies in the training of mental health professionals (Sue, Akutsu, \& Higashi, 1985; Parham, 1999). For example, in an attempt to address concerns with respect to both accessibility and quality, the AMCD worked for two decades to refine and adopted a set of 31 cross-cultural competencies and standards (i.e., in the three areas of multicultural awareness, knowledge, and skills) for multicultural training in counseling (Sue, Arredondo, \& McDavis, 1992). In this document, the authors argued that teaching these competencies would enhance the 
accessibility and quality of mental health services for diverse people by helping professionals identify and overcome racial and ethnocentric biases in their understanding and treatment of others. Another recent example of the profession's response to the challenge is the set of "Guidelines for Practice, Education and Training, and Research" that includes an array of multicultural competencies endorsed by a growing number of divisions (American Psychological Association, 2003; Fouad, 1999). Both documents reflect the growing recognition of the importance of training in cultural competence in order for high quality counseling interventions to be accessible for non-majority people.

In response to these challenges, diversity training programs have been developed and widely adopted, but they vary a great deal with respect to their focus (Hills \& Strozier, 1992). Although the need for training in cultural competence and the need to make the profession more inclusive have both been widely acknowledged, it is training in cultural competence that has tended to dominate diversity-training programs.

Multicultural training efforts typically use approaches that focus on changing some aspects of individual participants' cultural competence (awareness, knowledge, and skills). Reynolds (1995), for example, identified three such distinct teaching approaches:

1. Awareness approaches concentrate on participants' discovery of personal biases, exploration of personal racial and ethnic identity, increased sensitivity to multicultural issues, and development of greater tolerance and acceptance of cultural differences.

2. Oppression-focused models utilize a socio-political framework to help participants "unlearn" oppression. Such training confronts participants' world-views and 
perceptions, challenging their notions of power and the status quo, and sensitizing them to the realities of racism, sexism, heterosexism, and classism.

3. An integrative training focus seeks to foster multicultural attitudes, knowledge, and specific skills in the participants. Often incorporating features of both of the previous models, an integrative focus also aims to have changes in attitudes and knowledge result in changed (more culturally appropriate) behavior, such as seeking consultation from indigenous helpers, accurately comprehending non-verbal cues and conversational metamessages, etc. (e.g., Brown, Parham, \& Yonker, 1996; Lee, 1996; Pedersen, 19XX).

\section{The Diversity of Helping Professionals}

The training efforts of the past three decades have been constructive and have contributed substantially toward the goal of rendering high quality counseling interventions more accessible to non-majority people. As noted, however, non-majority individuals remain (despite many efforts) underrepresented in the profession. For example, according to the most recent survey (Norcross, Hedges \& Castle, 2002), only $2 \%$ of the membership of the American Psychological Association lists themselves as Hispanic, and only $1 \%$ of the Psychotherapy Division of APA do. Hence, the focus of most existing training programs has been on increasing the multicultural sensitivity and awareness of middle class white counselor trainees (e.g., Ridley, Mendoza, Kanitz, Angermeier, \& Zenck, 1994; Nuttal, Sanchez, \& Webber, 1996). Systematic analyses of the results of training programs in achieving their aims have, almost without exception, analyzed samples comprised of European American trainees (Vinson \& Neimeyer, 2000). See Table 1, for a summary of studies on the impact of multicultural education programs on counseling trainees. 
Table 1.

Summary of Studies on Impact of Multicultural Education Programs

On Counseling Trainees

\begin{tabular}{|c|c|c|}
\hline Authors & Participants & Results \\
\hline $\begin{array}{l}\text { D'Andrea, } \\
\text { Daniels, \& Heck } \\
\text { (1991) }\end{array}$ & $\begin{array}{l}90 \text { "Predominantly } \\
\text { White" and } \\
\text { "Predominantly Asian" } \\
\text { counselor trainees }\end{array}$ & $\begin{array}{l}\text { Training increased self-assessment of } \\
\text { multicultural awareness, knowledge, } \\
\text { and skills }\end{array}$ \\
\hline $\begin{array}{l}\text { Parker, Moore, \& } \\
\text { Neimeyer (1998) }\end{array}$ & $\begin{array}{l}54 \text { White counselor } \\
\text { trainees }\end{array}$ & $\begin{array}{l}\text { Training resulted in significant } \\
\text { increases on three dimensions of } \\
\text { White racial consciousness, and } \\
\text { enhanced expressed interracial } \\
\text { comfort. }\end{array}$ \\
\hline $\begin{array}{l}\text { Steward, Wright, } \\
\text { Jackson, \& Jo } \\
\text { (1998) }\end{array}$ & $\begin{array}{l}54 \text { White counselor } \\
\text { trainees }\end{array}$ & $\begin{array}{l}\text { Training contributed significantly to } \\
\text { participants' discrimination of } \\
\text { culturally sensitive counseling skills. }\end{array}$ \\
\hline $\begin{array}{l}\text { Steward, Morales, } \\
\text { Bartell, Miller, \& } \\
\text { Weeks (1998) }\end{array}$ & $\begin{array}{l}39 \text { White counselor } \\
\text { trainees }\end{array}$ & $\begin{array}{l}\text { Training efforts did not result in the } \\
\text { same degree of sensitivity for all } \\
\text { trainees; one third of the students } \\
\text { perceived exposure to multicultural } \\
\text { literature as meaningless and } \\
\text { unnecessary. }\end{array}$ \\
\hline
\end{tabular}


Thus, "knowledge development" efforts with respect to the efficacy of

multicultural training have unwittingly perpetuated a monocultural focus to the research, even though non-European American trainees comprise a small but growing proportion of counseling trainees $(21 \%$, according to the most recent Council of Counseling Psychology Training Programs Survey, 1998). The important role that diversity training can play in increasing non-majority participation in the profession has tended to be overshadowed by the emphasis on increasing cultural awareness and sensitivity among majority trainees.

Consequently, this study focuses on the impact of multicultural training for nonmajority students. Realizing the profession's goal of meeting the needs of an increasingly culturally diverse population (both in terms of accessibility and quality) requires that efforts to enhance individuals' multicultural awareness, knowledge, and skills in providing services be balanced by efforts to get non-majority trainees included and invested in the profession through participatory and transformative activities whereby they are empowered to "make a difference."

\section{Professional Involvement}

Despite some advances in recent years, a relatively small proportion of nonmajority individuals participate in the counseling psychology profession as collaborators and colleagues, raising a concern with respect to the inclusion of diverse individuals in the profession (D’Andrea \& Daniels, 1994; 1995). As noted previously, data from the U. S. Census Bureau, indicates that $25 \%$ of all Americans were non-white minorities in 2000 (an estimate projected to increase to $50 \%$ by 2050). Yet this substantial proportion of diversity is not reflected in our profession: for example, in the latest report from the 
National Centre for Education Statistics (NCES), 2001, 74, 060 bachelor's degrees were awarded in psychology in 2001, 14,465 master's degrees were awarded in psychology in 2001, and 4310 doctoral degrees were awarded in psychology. Of these degrees the majority were awarded to Whites (72\% of all bachelor's and master's degrees and $77 \%$ of all doctoral degrees). African Americans received 10\% of both bachelor's and master's degrees and $5 \%$ of doctoral degrees; Asian/Pacific Islanders received $6 \%$ of bachelor's degrees, $3 \%$ of master's, and $4 \%$ of doctoral degrees in psychology. American Indians received less than $1 \%$ of all the degrees in psychology. Similarly, as of 2000 , APA's membership was $77 \%$ white and $6 \%$ ethnic minority (although $17 \%$ did not specify) (APA, 2000). Thus, in comparison to population percentages for these minority groups, racial/ethnic minority students are underrepresented at all levels of psychology but most particularly at the doctoral level: the primary entry point for becoming a psychologist. These continuing inequities and imbalances within the profession itself have resulted in repeated calls to the profession to remedy its active neglect of culture and oppression and instead "take a proactive stance in incorporating standards of practice that reflect the diversity of our society" (Sue, Arredondo, \& McDavis, 1992, p. 479; see also APA, 2002).

A reason that inclusion in the profession is so important is to remedy the unwitting monocultural focus that "guidance for all" carried with it. Theories of counseling were derived from a Western European perspective and adapted for use in the United States when most ethnic group members were segregated and experienced discrimination and racism in schools, communities, workplaces, and society at large (Jackson, 1995). Because most minority ethnic groups were not a part of "mainstream" 
society, the needs and cultural concerns of these groups were not brought into focus. As a result, the counseling techniques and strategies that emerged in operationalizing these theories were relatively monocultural and thus of unknown relevance for groups from which they were not derived (Speight, Meyers, Cox, \& Highlen, 1991). In order to increase the likelihood that future professional helping theories or models and the practices derived from existing and future theories/models are culturally relevant and sensitive, culturally diverse individuals must be represented in the profession and in professional decision-making bodies. Indeed, increasing the involvement of diverse people who are active in the profession is seen as essential, or "professional associations will put themselves in a dinosaur position" (Sanders, 1999).

The profession's response to the inequity of minority representation has also been overall positive but far less focused and direct than its response to the concerns about accessibility and quality of care. Steps have been taken to make the profession more inclusive of non-majority individuals, such as minority student recruitment and minority faculty and staff hiring (Ridley, Mendoza, \& Kanitz, 1994; Sue \& Zane, 1987). Strategies for increasing ethnic-minority involvement have been suggested (Diaz, 1990; APA, 2002), including one-on-one personal invitations to get involved in professional organizations, issued over lunch (Suinn, 1999). However, no systematic effort has addressed the issue of how to empower non-majority individuals once they have been recruited into the profession.

As an increasing number of non-majority trainees enter the profession (as is currently the case in many larger, multicultural urban communities), the need to address issues that arise in diversity training for non-majority trainees has come to the 
foreground. For example, the issues that confront the counselor educator who is training or teaching sensitivity and awareness to racial and ethnic biases to middle class white trainees, it turns out, are quite different from those that confront the counselor educator covering the same topics with a class of non-majority individual who have been exposed, sometime quite painfully, to these effects everyday of their life.

There is an urgent need for approaches that welcome marginalized and/or underrepresented trainees and create contexts that foster proactive participation by such trainees. This type of program can be found at the confluence of non-majority individuals entering into the mainstream of the profession, such as in the greater Miami area. Recently, Montgomery, Marbley, Contreras, \& Kurtines (2000) undertook a systematic program of research to develop, refine, and evaluate an approach to diversity training that not only specifically targets the training of diverse counseling trainees for work in multicultural contexts, but is also designed to provide them with the types of experiences that believed to ultimately foster their proactive participation in the profession (see Table 2 for a summary of the model). They assert that fostering trainees' proactive participation in their professional lives and the life of their communities is essential if the goal of increasing the presence of non-majority individuals as proactive participants in the profession is to be taken seriously (Montgomery \& Kottler, 2004; McAuliffe et al., 2002). This type of approach can be referred to as a Transformative Diversity Training model, or "TDT."

However, the implications of multicultural training, including a TDT model, extend beyond programs with large percentages of minority students to all training programs that find themselves in a complex and pluralistic cultural milieu. "Cross- 
cultural counseling" increasingly includes virtually all individuals, regardless of cultural or ethnic origin. In very diverse communities, traditional categories defined by race, culture, and class have little utility as guides for practice. Rather, multiculturalism is foremost a philosophical framework that encompasses the experiences of various peoples - including, but not limited to, racial and ethnic minorities (Leach \& Carlton, 1997). Jackson (1995, p. 3) defines multicultural counseling as counseling that takes place between or among individuals from different cultural backgrounds, underscoring the observation that virtually every counseling-therapy interaction is at least slightly crosscultural (Sue et al., 1982, p. 47). A Transformative Diversity Training approach goes beyond training for encounters between individuals who differ from one another to training students to bring about positive change at broader levels, incorporating notions of broader change that are often termed "social action" (Lee \& Walz, 1998).

\section{Developing Diversity Training Approaches that Involve and Empower}

The Transformative Diversity Training approach has emancipation and empowerment goals in addition to multicultural competence goals. Montgomery, et al. (2002) developed a TDT model out of experiences in teaching diversity training courses in an urban, multicultural context. This approach grew out of efforts to develop a theoretically grounded approach with ideas for using participatory learning and transformative activities in diversity training with both majority and non-majority trainees.

These scholars, like others (e.g., Steward, Morales, Bartell, Miller, \& Weeks, 1998), noticed that students were resistant to diversity training when they sensed that facilitators (who ostensibly teach the value of openness and diversity) insist that everyone 
adopt a particular value, even a "multicultural" value. They found that both majority and minority students found aspects of the multicultural "canon" to be narrow and limiting from the perspective of their own experience. Through interactions with diverse trainees, these scholars began to pose provocative questions: Who should determine the diversity training curriculum, when students are predominantly minority students? If the instructor determines the curriculum and sets forth the competencies that will be achieved, is this an implicitly "oppressive method"? If so, what would ensure that the "local and particular" voice was heard?

To fully address this paradox and the questions it raises, we need approaches to diversity training in which our students are active co-participants in the creation of the learning context and process. The use of a "participatory learning" process helps to resolve this paradox because it offers a model of teaching and learning that is collaborative rather than didactic. In keeping with the notions of "parallel process," it is consonant with the collaborative counseling relationship that is most empowering for clients (Steward, 1998). Rather than using a fixed curriculum model that dictates the endpoint, participatory learning processes directly involve students in determining what is to be included in the training curriculum. As part of promoting (and exemplifying) the value of inclusiveness, students' voices are heard. This approach also seems arguably more likely to transform the profession into one that is truly inclusive. Additionally, such an approach represents an opportunity to empower students for transformative action.

Minority trainees are urged to consider the possibility of transforming (rather than enduring) the circumstances that negatively impact their personal and professional lives and the life of their communities. Majority trainees are urged to consider the possibility 
of taking social action to reduce the injustices that continue to exist in contemporary social forms. The goal is to allow all students to acquire a greater critical understanding of themselves (as racial, cultural persons) and of the contexts (of privilege or marginalization, or both) in which they live. This, as a step toward liberating individual students, ourselves, and our profession from both subtle and overt forms of oppression (Ivey, 1995).

\section{Transformative Pedagogy}

Transformative pedagogy is adopted from the pedagogy of liberation in general and the transformative pedagogy of Paulo Freire (1970/1983) in particular. Freire's approach was found to be useful in developing a non-oppressive, participatory learning process in recent work at the Youth Development Program at Florida International University (Ferrer-Wreder, Cass Lorente, Kurtines, Briones, Bussell, Berman, \& Arrufat, 1999; Milnitsky, Ferrer-Wreder, Briones, Berman, \& Kurtines, 1997). His work was adapted to provide a guide for the Tranformative Diversity Training approach.

Freire sought to empower the marginalized by offering them the opportunity to enhance their "critical consciousness" about their own exclusion from mainstream normative institutions (political, economic, legal, etc.). While working to empower marginalized peasants in Brazil, he found, for example, that the individuals who were disempowered and marginalized by poverty did not learn well from classic lecture formats that were detached from their reality. According to Freire, the use of a didactic approach only served to emphasize in the peasants' sense of "incompetence," in contrast to the "competence" of the knowledgeable expert who was dictating the lesson. In his 
book, Pedagogy of the Oppressed (Freire, 1970/1983), Freire offers an alternative: an approach that is participatory and transformative.

Freire referred to such a transformative pedagogy as a pedagogy of dialogue and considered it distinct from a pedagogy of instruction. It is a "problem-posing" and participatory learning model in which the marginalized take an active role in the educational process. The teacher works with the students to collaboratively explore and critically examine the meaning and significance of their marginalization.

Transformative pedagogy extends beyond identifying problems to action-oriented problem solving. It does not seek to carry out constructive transformations for the oppressed, but with the oppressed. While intentionally identifying problems and following through by engaging in successful "transformative activities" to solve these problems, students learn "to see a closer correspondence between their goals and a sense of how to achieve them, gain greater access to and control over resources and gain mastery over their lives" (Zimmerman, 1995; p. 583). As a consequence of these experiences, they not only become the experts on their own "local and particular" situation but they also take control of their transformative activities. They become empowered as they develop a greater sense of control and responsibility in their lives and the life of their communities.

In drawing on Friere to create participatory and transformative learning experiences, our goal with minority trainees has been to open them to the possibility of transforming (rather than enduring) the circumstances that negatively impact their personal and professional lives and the life of their communities. Our goal with majority trainees has been to open them to the possibility of taking social action to reduce the 
injustices that continue to exist in contemporary social forms. Thus, in posing problems and in following through with transformative activities to solve these problems, students acquire a greater critical understanding of themselves (as racial, cultural persons) and of the contexts (of privilege or marginalization, or both) in which they live. Doing so in the context of the training program empowers students to continue transforming themselves and to eventually transform their profession and their communities.

\section{A Transformative Diversity Training Program}

This section describes the basic elements of the multiphasic Transformative Diversity Training Program developed by Montgomery et al. (2000; 2001). The training program was designed to be flexibly adapted to diverse populations and problems, goals, and institutional and cultural settings. As described elsewhere, the program consists of three phases: (1) group cohesion building, (2) participatory learning experiences, and (3) student-directed transformative activities (Montgomery et al, 2000; 2001; see Table 2). The duration of the program and sequence of the phases can be adapted to specific course formats. In addition, as discussed below, the program can be adapted to focus on individual, social, or institutional change.

\section{Group Cohesion Building}

During the preliminary phase of the training, we work at developing cohesion within the training group (for example, use ice breakers, mutually establish group rules, etc.). This process is influenced by the ethnicity, academic level, and personal styles of the group members. Training groups are similar to other groups in that genuine cohesiveness results from the ongoing building of connections between people in ways that are culturally and contextually most appropriate. The strength of the cohesion in the 
group contributes to the subsequent depth of genuine exploration of self and the world of others. Once cohesion has been sufficiently established, the focus shifts from cohesion development to the participatory learning phase. 
Table 2.

Transformative Diversity Training Model

\begin{tabular}{|c|c|c|}
\hline \multicolumn{3}{|c|}{ Transformative Diversity Training 1} \\
\hline Intervention Phase & Targets Increases In: & Intervention Strategy: \\
\hline 1. Preliminary & Training group cohesion & Cohesion-building activities \\
\hline 2. Participatory Learning & Awareness & $\begin{array}{l}\text { Active exploration of self and } \\
\text { the perceptual world of others }\end{array}$ \\
\hline & Knowledge & $\begin{array}{l}\text { Active exploration of local } \\
\text { cultural contexts; professional } \\
\text { knowledge base }\end{array}$ \\
\hline & Skills & $\begin{array}{l}\text { Problem posing/identification } \\
\text { (in self, profession, or } \\
\text { community) }\end{array}$ \\
\hline $\begin{array}{l}\text { 3. Transformative } \\
\text { Activities }\end{array}$ & $\begin{array}{l}\text { Personal empowerment } \\
\text { Proactive participation } \\
\text { in the community } \\
\text { and the profession }\end{array}$ & $\begin{array}{l}\text { Student-directed transformative } \\
\text { activities (in personal, } \\
\text { professional, or community } \\
\text { contexts) }\end{array}$ \\
\hline
\end{tabular}

\footnotetext{
'Montgomery, M. J., Marbley, A. F, Contreras, R., \& Kurtines, W. M. (2000). Transforming diversity training in counselor education. In McAuliffe, G., \& Eriksen, K. (eds.), Preparing Counselors: Creating constructivist and developmental programs. Washington, D. C.: Donning Publishers
} 
During the second phase of the program, students engage in participatory learning experiences aimed at enhancing multicultural awareness, knowledge, and skills. In contrast to training approaches relying on directive and didactic processes, participatory learning experiences emphasize cooperative and mutual learning contexts. In this phase, we use exploration and problem posing to accomplish the training goal of increasing multicultural awareness, knowledge, and skills. The class group becomes a starting point from which both students and the teacher can explore their own cultural competence. As the group becomes more cohesive and inclusive, members identify and pose problems for consideration, challenging one another to think critically about (1) their awareness of and sensitivity to diversity and inequity, (2) their assumptions, motivations, and cultural agendas they bring to the counseling context, (3) their level of knowledge about cultural issues that are "local and particular" such as immigration and acculturation issues, disenfranchisement of particular groups, and local ethnic politics, and (4) their level of general cultural skills, local and particular cultural skills, and competencies for dealing with a variety of clients. The members of the group support one another as they gather information, uncover surprising (distressing or encouraging) facts, encounter resistance, and draw new conclusions.

Problem Posing

After group members explore their own cultural awareness and knowledge, they engage in problem posing as a means for identifying cultural problems in themselves, their community, or the profession. Freire (1970/1984) draws on the tradition of critical theory in stressing problem posing as the foundation for transformative activities. $\mathrm{He}$ 
recognized that deciding on what the problem is was necessary if problem-solving, transformative activities were to be effective. That is, he recognized the need to solve the "right" problem and to not be deflected or distracted by solving the wrong problem. "Problem solving" skills alone, consequently, would not be sufficient for successful transformative activities.

Each student poses a specific problem or set of problems for the group's consideration. We find it helpful to focus on problems for which the group might genuinely contribute to a solution. Specifically, we suggest that members of the group focus on the negative consequences of intolerance of diversity for themselves personally (as members of marginalized groups, e.g., ethnic, gender, social class, etc.), their profession (e.g., as students, as future counselors, etc.), or their community in the broadest sense (e.g., neighborhood, city, nation). We find that many students experience the process of problem posing as extremely meaningful and also often find the problems they identify to be personally compelling. As a result, they learn to take a proactive stance. As we nurture a proactive, critical, and reflective perspective in our students, they sometimes direct these critical competencies toward the profession for which they are training. Offering opportunities for choices in participation, however, allows students to locate the level of challenge where they are optimally "stretched," rather than bored or broken.

Transformative Activities

AMCD's cross-cultural competencies and objectives for counselors include institutional intervention skills and active efforts to eliminate biases, prejudices, and 
discriminatory practices. Thus, in this third phase of the program, participants do more than talk about problems; they do something about them.

During this phase, students choose to intervene in their communities and their profession in ways that are personally most meaningful to them, as a group or as individuals. The class provides a supportive context for students who tackle the problems that have an impact on their lives, the profession, and the life of their community.

The focus of the class sessions and assignments targeted different areas of multicultural competency. The first assignments and exercises focused on developing Cultural Awareness, the second on developing Cultural Knowledge, and the third on developing Transformative Skills. Assignments and exercises were sequenced so that students had the option to select Cultural Knowledge (II) assignments that built upon areas that became salient to them as they developed increased Cultural Awareness (I). In turn, it was suggested that the Transformative Skills assignment build upon their experiences in I and II.

Specifically, for the Transformative Skills assignment, students were instructed to choose either a) a project wherein they employed advocacy skills, systemic intervention skills, and/or collaborative skills in order to change an aspect of a system toward greater equity, or b) a paper wherein they critiqued an existing psychological theory, model, or intervention strategy for its applicability to diverse populations, and submitted this paper for publication in an appropriate journal. (Additional instructions regarding these assignments are available from the first author.) Students worked individually or in small groups. 
The inclusion of the Transformative Skills project in the training addresses several issues of importance in multicultural education. First, students, minority and majority alike, gain exposure to and opportunities to practice with systemic intervention and advocacy skills, both of which have been highlighted as of key importance in the training of new professionals. Second, because students choose the areas that are of the greatest importance to them, they have both a sense of control over the project and a sense of responsibility for the outcome of the project. This allows them to address cultural issues that they find most important. The effect of this is that the phenomenon of student resistance in multicultural training is greatly reduced. Third, when students choose their own transformative projects, their classroom experience parallels the liberating or empowering stance that counsellors typically take toward their clients, thus there are fewer contradictions for students between what we teach them is "good for clients" and what we offer them as trainees (implicitly, what is "good for students"). This consistency between our actual classroom practice and our pedagogy of therapeutic intervention further reduces the double binds that foster students' confusion, reluctance and resistance to diversity training.

\section{Research Objectives}

According to Pope-Davis \& Dings (1995), culturally competent counselors are counselors who have "moved from being culturally unaware to being aware and sensitive to their own cultural issues and to the ways that their own values and biases affect culturally diverse clients." These authors go on to further state that a culturally competent counselor tries to understand the different experiences of people within a particular group, has an understanding of potential barriers to communication that exist as a result 
of cultural differences and possess a set of skills that make the counselor potentially culturally skilled. D.W. Sue, Arredondo and Mc Davis (1992) identified a culturally competent counselor as someone who:
a. is aware of one's own cultural assumptions, values and biases
b. understands the worldview of the culturally different client, and
c. continually develops appropriate ways of working with clients.

Thus in light of these definitions, multicultural advocates have recommended a fundamental transformation of graduate and professional training that would require trainees to demonstrate their comprehension and application of multicultural competencies.

With this in mind, the overall purpose of this study was to gain knowledge about the impact and effectiveness of instructional practices used in the teaching of multicultural or diversity sensitivity courses at the graduate level, in particular the participatory approach to diversity training designated in this thesis as Transformative Diversity Training (TDT).

Thus, the first aim of the study was to investigate and describe the way in which diverse students in a TDT course evaluated their own change in the awareness, knowledge, and skills for working with diverse clients, and how they evaluated their own efforts in transforming themselves, their work settings, and/or their communities toward more equitable practices. Hence, the first aim of the study was to gather ideas from a predominantly minority group of students and describe, in their words, their perceptions of the course's impact on their personal and professional development. 
The second aim of the study was to assess whether the Transformative Diversity Training course accomplished its goals in (a) increasing students' cultural awareness, knowledge, and skills in enduring ways, and (b) empowering students to transform their work settings, communities, and/or the profession toward more equitable practices. To investigate this aim, students' perceptions of salient change in the short term (pre-test to end of semester post-test) and the long term (post-test to one year follow-up) were compared. Because the key components of the Transformative Diversity Training Model could be seen as forming a functional developmental sequence (Snarey \& Bell, 2003), it was expected that the pattern of responses with respect to the types of change students mentioned would differ across time points. Specifically, it was expected that more students would mention that important change had occurred in knowledge and empowerment at post test (end of course) than at pretest (beginning of course). It was expected more students would mention that change had occurred in skills and in becoming a transformative stakeholder (local and global or professional) at one-year follow-up than at the end of the course. 


\section{CHAPTER III}

\section{Methodology}

\section{Design}

The data reported in this study was collected using a short-term longitudinal (post course evaluation and one year follow-up evaluation) research design. The impact of the Transformative Diversity Training program on the students was evaluated in terms of both short (end of semester) and long (one year follow-up) term impact utilising an openended questionnaire requesting information about the effects of the diversity training program.

The strategy for the short-term outcome was to evaluate the impact of the TDT course on increasing students' multicultural awareness, knowledge, and skills as well as increasing their involvement in the community and the profession by the end of the course. With respect to the long-term outcome (one year follow-up), the impact of the TDT course was evaluated in terms of the impact of the key phases (co-participatory learning experiences and student-directed transformative activities) on the three-targeted domains of increased awareness, knowledge, and cross-cultural skills. The overall goal was to conduct qualitative research investigating the impact of the TDT Program on the students' personal and professional developmental trajectory.

\section{Participants}

The sample included 38 graduate level counseling students, 1 undergraduate and 2 special students enrolled in the Diversity Training course - CYP 6766, "Cross-Cultural Sensitization in a Multicultural Context". Consent to participate in the project was 
obtained at the beginning of the course, and at the one-year follow-up data collection. The response rate for follow-up was $59 \%$.

As Shown in Table 3, a total of 41 students between the ages of 21 and 49 were included in the final group of participants. The mean age of the students ( 7 men and 34 women) was 28 . Most (93\%) of the students were at the graduate level, with $42 \%$ enrolled in a master's program and $51 \%$ in a doctoral program. On average, students had completed 24 hours of graduate course work. Approximately half of the students (53\%) were born in the US and Puerto Rico, and about half (47\%) of foreign birth, primarily in countries in or near Central/South America and the Caribbean basin. These included Brazil, Colombia, Cuba, Grenada, Jamaica, Nicaragua, Peru, and Trinidad. Other native countries indicated by participants included Canada, China, Germany, Israel, Korea and Taiwan. A smaller portion , $42 \%$, of the students were US citizens by virtue of birth, $40 \%$ were permanent US residents, and $15 \%$ were temporarily here while $3 \%$ were unsure as to their immigrant status. Eleven students ( $27 \%$ of the sample) identified themselves as first-generation immigrants (born outside the United States), 17 ( $42 \%$ of the sample) as second-generation immigrants (U.S. born but raised by parents born outside the U.S.), and $12(29 \%$ of the sample) as third or later generation (both participant and parents born in the U.S.). The modal reported family income $(n=10)$ was less than $\$ 30,000$ per annum. For additional details regarding the sample's characteristics, see Table 3. 
Table 3

Participants' Background Information

\section{Variable}

$(N=41)$

$n$

\section{Ethnicity}

Census Identified

White (Non-Hispanic)

Black (Non-Hispanic) or African American

Asian or Pacific Islander

White Hispanic

Hispanic Not Specified

Other

20

$49 \%$

3

3

1

$7 \%$

$2 \%$

11

$27 \%$

3

$7 \%$

Self-Described
White/Caucasian/Non Hispanic

Jewish

Cuban Hispanic

Non-Cuban Hispanic

Caribbean Islander

Asian

Other/Biracial/Mixed

$\begin{array}{cc}13 & 33 \% \\ 2 & 5 \% \\ 5 & 13 \% \\ 6 & 15 \% \\ 2 & 5 \% \\ 3 & 8 \% \\ 8 & 21 \%\end{array}$

Gender

Male

7

$17 \%$

Female

\section{Student US Born}

Yes

No

\section{Parent US Born}

Mother

Yes

12

$30 \%$

No

28

$70 \%$

Father

$$
\begin{aligned}
& \text { Yes } \\
& \text { No }
\end{aligned}
$$

$33 \%$ 
Table 3 continued

\section{Citizenship}

Permanently

Temporarily

Unsure

N/A (US Citizens)

Yearly Household Income

Below $\$ 30,000$

$\$ 30,000$ to $\$ 50,000$

9

$\$ 50,000$ to $\$ 100,000$

9

$28 \%$

More than $\$ 100,000$

$4 \quad 13 \%$

\section{Student Residency}

On Campus

With Parents

$\begin{array}{cc}2 & 5 \% \\ 7 & 18 \% \\ 23 & 57 \% \\ 8 & 20 \%\end{array}$

Other

\section{Academic Program}

Special Student

Undergraduate

Mental Health Masters

Psych Masters not Specified

$13 \%$

I/O Psych PhD

Developmental Psych PhD

Psych PhD Not Specified

$6 \quad 16 \%$

$12 \%$

\section{Procedure}

Students in CYP 6766, "Cross-Cultural Sensitization in a Multicultural Context," were requested to participate in a research project evaluating the short and long-term impact of such a course. Students who agreed were given consent forms to document their agreement to be included in the study and to be re-contacted by the professor or other investigator one year after the course concluded. They were also asked to complete 
a demographics information form (indicating race/ethnicity, gender, age, level of graduate training completed, country of birth, languages spoken, etc.).

Short-term impact of the TDT course on students' multicultural awareness, knowledge, and skills, as well as their involvement in the community and the profession, was evaluated. This was accomplished by coding for markers of qualitative change in (a) each individual's articulation of their personal goals for the course at its beginning and (b) their evaluation of personal progress and plans for future growth as a result of the course at its ending. The articulation of personal goals was routinely obtained in writing from students in the course at the beginning of the semester; the evaluation of personal progress and plans for future growth were routinely obtained in writing from each student as a part of their final examination. Only students who agreed to participate in the study had their material analyzed.

Students were contacted by email or phone one year later by this investigator (not the course instructor) and asked to participate in the follow-up phase of the project. They were asked to respond to the "The Effects of Transformative Diversity Training Survey." They had the option of emailing or mailing their responses to the investigator. Long-term impact of the TDT course on students' multicultural awareness, knowledge, and skills, as well as their involvement in the community and the profession, was evaluated by coding responses to "The Effects Of Transformative Diversity Training Survey" for markers of qualitative change in (a) each individual's articulation of the personal impact of the course one year later, and (b) their evaluation of personal progress in attaining transformative goals since the ending of the course. 


\section{Data Analysis}

Relational Data Analysis.

The qualitative analytic strategy of Relational Data Analysis (Kurtines, Montgomery, Lewis-Arango, and Kortsch, 2004), was used to identify types of shortlong-term responses to TDT. Relational Data Analysis (RDA) is a multidimensional, multi-phasic framework for unifying the use of data analytic strategies across dimensions of analysis (in this case, qualitative and quantitative) and phases of analysis (conceptual, theoretical and research analysis). RDA is explained in detail below and in the Appendix. In addition, the computer package SPSS Windows was utilized to summarize information about the participants using descriptive statistics.

Conceptual Analysis Phase. The first aim of the study was to investigate and describe the way in which diverse students in a TDT course evaluated their own change in the awareness, knowledge, and skills for working with diverse clients, and how they evaluated their own efforts in transforming themselves, their work settings, and/or their communities toward more equitable practices. RDA Conceptual analysis used to identify all qualitatively different categories in the data set which were obtained from The Effects of Transformative Diversity Training Survey, using open coding and the method of constant comparison.

Undergraduate psychology students were recruited through the psychology department at Florida International University and served as coders following a brief training in conducting a Conceptual Analysis. (See Appendix B for a more detailed description of the procedure for conducting RDA conceptual analysis.) These theoretically neutral content coders (i.e., coders who did not represent any particular 
theoretical perspective) used grounded theory "open" coding using the method of "constant comparison" for similarities and differences (i.e., the process of the comparison of content properties of participant response data for creating and eliminating categories) in order to identify all qualitatively different (non-overlapping) content categories in the data set. Content coders also formulated and documented an explicit description of the specific property that makes each content category in the response data conceptually unique (qualitatively different from all other categories).

Theoretical Analysis Phase. The second aim of the study was to assess whether the Transformative Diversity Training course accomplished its goals in (a) increasing students' cultural awareness, knowledge, and skills in enduring ways, and (b) empowering students to transform their work settings, communities, and/or the profession toward more equitable practices. To investigate this aim, students' perceptions of salient change in the short term (pre-test to end of semester post-test) and the long term (posttest to one year follow-up) were compared.

The theoretical Analysis phase of RDA was conducted by two "theory laden" coders. For this step, the data was coded according to the theoretical coders' consensual multicultural training perspective, which included the conceptual framework used to design the TDT course (e.g., both the "multicultural competencies" of awareness, knowledge, and skills, and the "transformative competencies" of empowerment and social action). The two theoretical coders independently coded the data and then compared their results. The overall agreement across all categories was $88.1 \%$, providing strong evidence for concurrence across types of coders. Items involving disagreement were discussed until a consensus was reached. Next, the theoretical categories were 
assigned subcategories drawn from those specified by the conceptual coding phase of the analysis. For example, the theoretical category of "awareness" included "self-awareness" and "other awareness" (see Table 4). From the conceptual coding phase, the theoretical coders drew subcategories formulated by the naïve coders that further organized responses and illuminated the theory. For example, the theoretical category of "selfawareness" was elaborated to include "biased self" and "valuing own culture" subcategories, which were distinctions drawn by the categorical coders. The results of the theoretical analysis presented in the next chapter are based on the complete and consensually derived coding categories.

Research Analysis Phase. For this phase, analytic methods from both the qualitative and quantitative research traditions were used. Because the data were collected using a longitudinal design, it was possible to evaluate the research hypotheses about changes in the pattern of students responses across time. To do so, students' perceptions of salient change in the short term (pre-test to end of semester post-test) and the long term (post-test to one year follow-up) were compared. The strength of the association between Pre-Test categories, Post-Test categories, and Follow-up categories was analyzed using chi-square analyses, thereby permitting conclusions about student change. 


\section{CHAPTER IV}

\section{Results}

This chapter describes the results of the Relational Data Analysis undertaken to assess the research questions for this study. First, the results from the Conceptual Coding procedures will be described. The Conceptual Coding categories are primarily descriptive, and reflect the content of the participant responses that seemed most salient across the naïve groups of coders. The results from the Theoretical Coding are next described. The results of the Theoretical Coding permit a comparison of the student's hopes for the impact of the course and their perspectives on the actual impact of the course (both immediately following and one year later) with the instructor's objectives for course impact. Finally, the results of the Research Analyses are presented. The Research Analyses allow for an empirical examination of changes, across the three times of assessment, of how frequently various categories were named, thus permitting the conclusions about a developmental pattern of change.

\section{The Conceptual Coding Analysis}

Pre-TDT Hopes for Change

During the first week of class, students completed the demographic survey and also completed a pretest which included the question, "In what ways would you like to be different (personally, professionally, etc.) by the time we complete this course?" The aim of the question was to evaluate the students' hope for change and learn what students hoped to obtain from the course. Additionally, the question served as a "baseline" benchmark for change described at Post TDT and at the one-year follow-up. As shown in Figure 1, conceptual coding revealed that students' hopes for change fell 
under two main categories, Cultural Awareness and Societal Change/Social Advocacy. The Cultural Awareness category was comprised of expressed desires to "gain in other culture knowledge," (General), to increase racial appreciation, and for personal development which specifically entailed "understanding other cultures and coming to terms with one's own biases and prejudices." Students hoped these gains would lead them to become more open-minded and enhance their positive development as an individual.

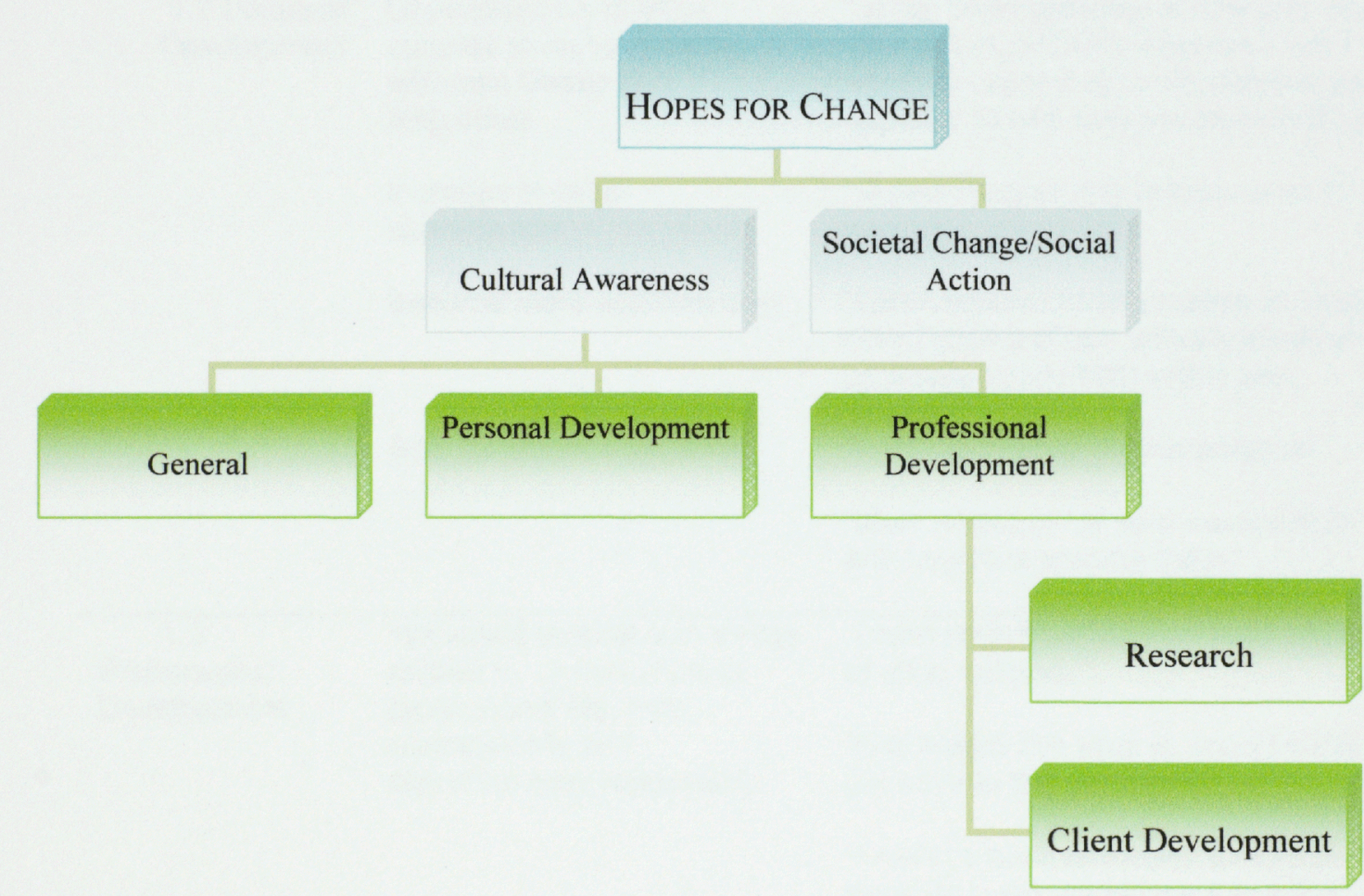

Figure 1. Student Hopes for Change Conceptual Coding Categories.

In addition to describing general knowledge gain and personal development, this category included answers describing students' desires to become more aware of or increase their knowledge of the client/therapist issues and research related to 
multiculturalism and other cultures. This was given a sub-category title of Professional Development and further sub-categorized to describe students' expression of Cultural Professional Development in areas of both client/therapist relationship and multicultural research. See Table 4, which gives descriptions of each category along with subcategories and student response examples. 
Table 4.

Student Hopes for Change at Pretest

\begin{tabular}{ll}
\hline Category & \multicolumn{1}{c}{ Description } \\
\hline 1. Cultural & Gain in "other culture" general knowledge. \\
Awareness & Increase in racial appreciation. \\
& Understand other cultures to come to terms with own biases/prejudices, \\
& to become more open-minded. (Personal Development) \\
& Awareness with respect to dealing with clients. (Client Development) \\
& Research related to multiculturalism, other cultures.
\end{tabular}

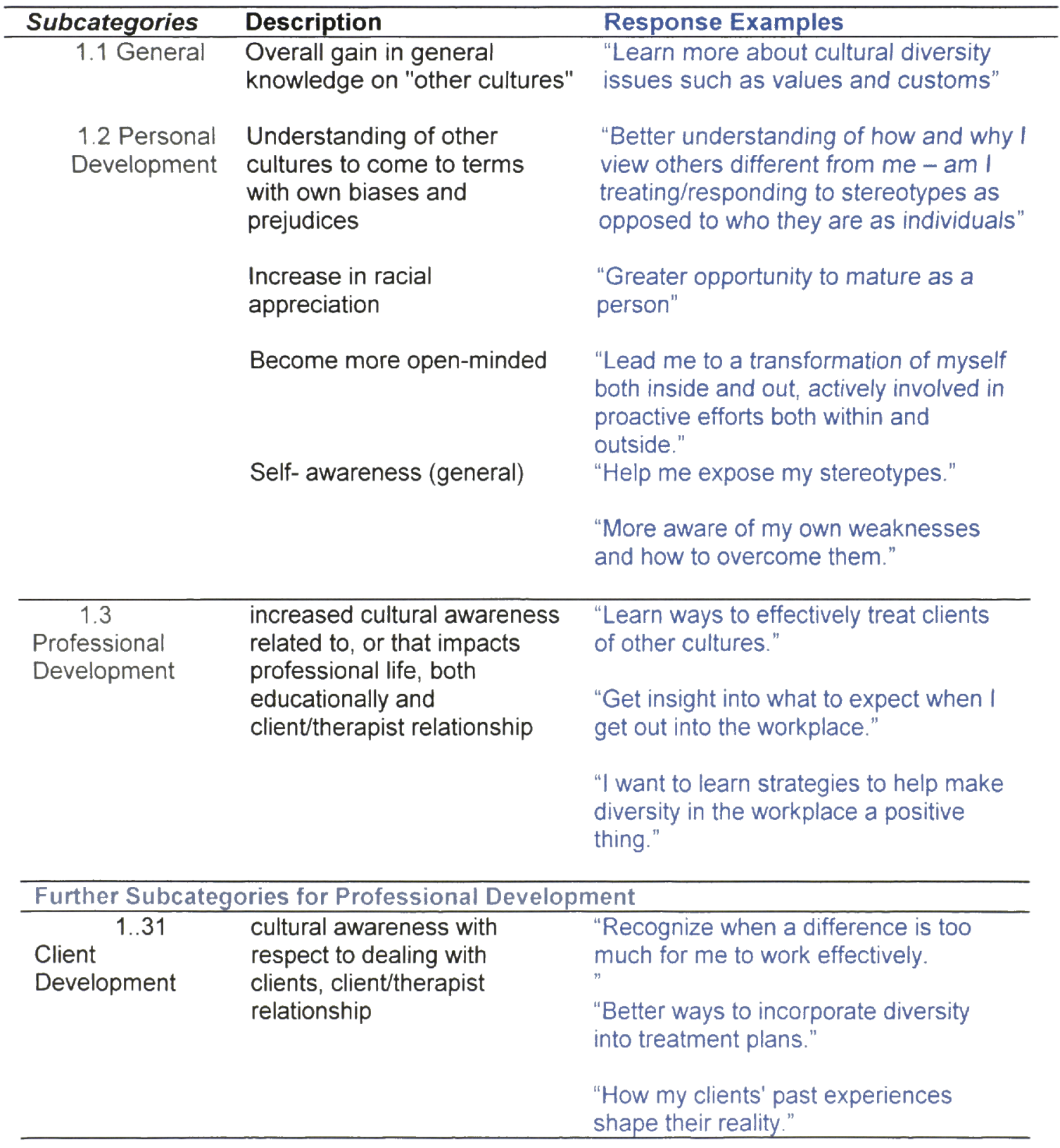


Table 4. continued

1.32 learn more about diversity

Research

research
"I hope to get an idea of what are the research areas that are being pursued, as well as not being pursued within diversity research."
2. Societal

Change

Social Action

Social

Advocacy
"Learn things I can do in everyday life to bring about change."

"social advocacy/action"

"I hope to be able to draw upon my experiences to make the world a more peaceful place." 
Post TDT: Actual Change-Personal and Professional

At the last session of the course, students provided with a copy to their answers to the pretest "hopes for change" question, and were asked to write their responses to the following prompt: "At the beginning of the course you answered the following question: "How would you like to be different (personally, professionally, etc.) by the time you finish this course?" A) In general, how are you different now? B) Compare these differences to the goals you had at the beginning of the course. Did you achieve your goals? More? Less? Explain." The aim of this question was to collect information about whether change did occur for each student (personally and professionally), what form the change took, and how similar and/or different was change from "hopes for change." For purposes of this study, only the information about what form the change took was examined in the conceptual coding.

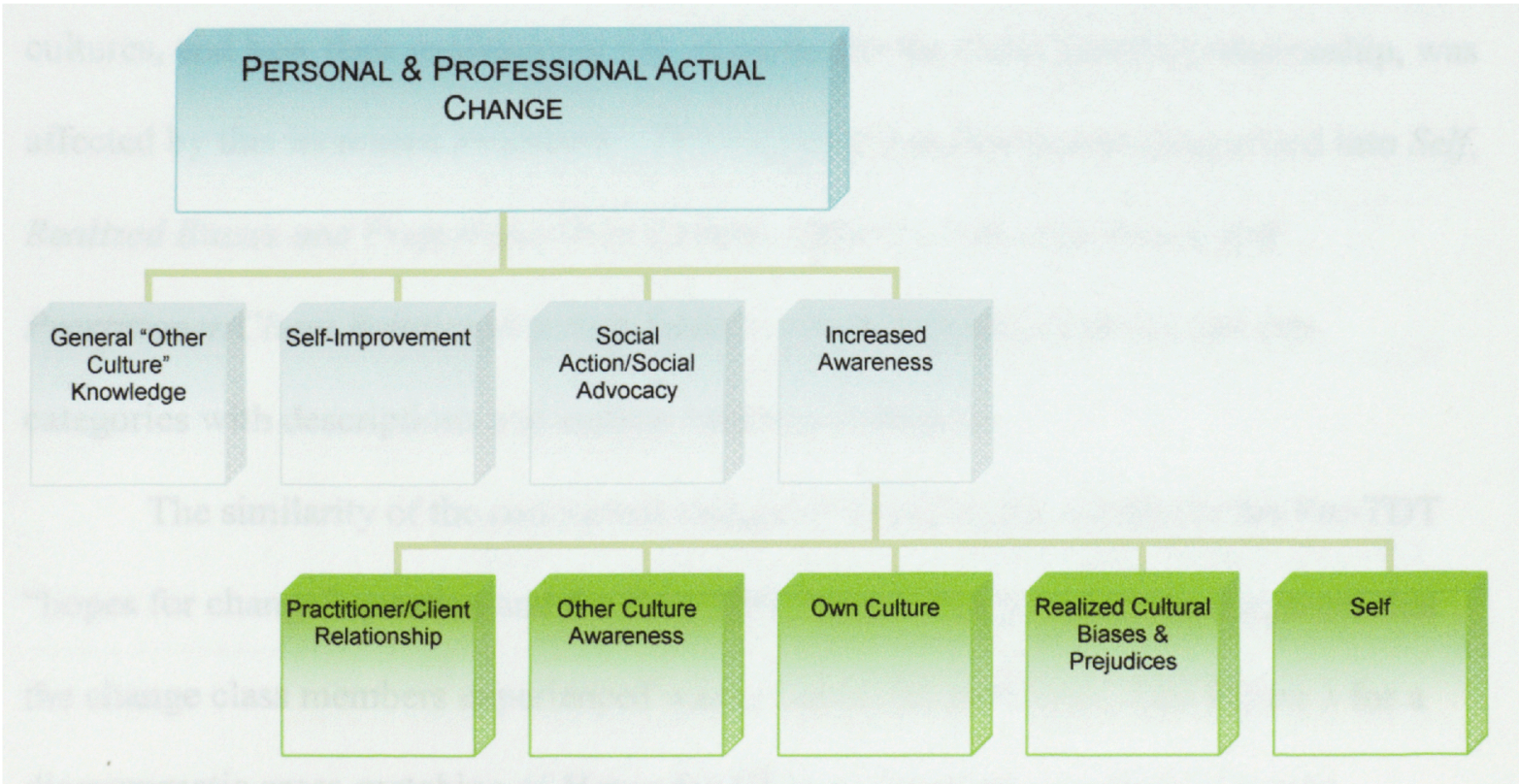

Figure 2. Students' Personal and Professional Actual Change Conceptual Coding Categories. 
As shown in Figure 2, conceptual coding revealed that students expressed that change did occur. As found by the coders, change was experienced in the following areas.

Gaining General "Other Culture" Knowledge. This category entailed having learned about aspects of cultures such as history, values, customs, religion, and education. This category also included gains in professional knowledge and research with respect to other cultures.

Self-Improvement. This entailed moving from "one's comfort zone" to increased self-empowerment, increased open-mindedness, personal and professional growth.

Social Action/Advocacy. This category included responses wherein students reported wanting to make use of the knowledge gained to affect change, reduce prejudice and/or empower minorities.

Increased Awareness. This category included responses denoting that students felt they had become more aware of how they saw, felt and related to their own and other cultures, and how their professional life, in particular the client/therapist relationship, was affected by this increased awareness.. This category was further sub-categorized into Self, Realized Biases and Prejudices, Own Culture, Other Culture Awareness, and Practitioner/Client Relationship. See Table 5, which lists all categories and subcategories with descriptions and student response examples.

The similarity of the conceptual categories found by the coders for the Pre-TDT "hopes for change" question and the Post-TDT "actual change" question suggested that the change class members experienced was in hoped-for directions. See Figure 3 for a diagrammatic cross-matching of Hopes for Change Categories to Actual Change (Personal and Professional) Categories. 
Table 5.

Students' Personal and Professional Actual Change at Post-Test

\begin{tabular}{|c|c|c|}
\hline Category Name & Description & Response Examples \\
\hline \multirow{4}{*}{$\begin{array}{l}\text { 1. General "Other } \\
\text { Culture" Knowledge } \\
\text { Gain }\end{array}$} & $\begin{array}{l}\text { increased general knowledge } \\
\text { base about other cultures }\end{array}$ & $\begin{array}{l}\text { "Became more aware of "other" } \\
\text { culture issues" }\end{array}$ \\
\hline & $\begin{array}{l}\text { learned more about other } \\
\text { aspects of culture such as } \\
\text { history, religion, education }\end{array}$ & $\begin{array}{l}\text { "I have come to realize the } \\
\text { factors that led to diversity } \\
\text { within the US are complex." }\end{array}$ \\
\hline & $\begin{array}{l}\text { gain in knowledge specifically } \\
\text { related to work or profession. } \\
\text { (Professional) }\end{array}$ & $\begin{array}{l}\text { "I've also learned about the } \\
\text { cultural utility and sensitivity of } \\
\text { taking a technical eclecticism in } \\
\text { theory and practice when } \\
\text { dealing with culturally different } \\
\text { clients." }\end{array}$ \\
\hline & $\begin{array}{l}\text { learned about academic } \\
\text { aspects of psychology of other } \\
\text { cultures and its use (Research) }\end{array}$ & $\begin{array}{l}\text { "Learn more about people from } \\
\text { different countries and } \\
\text { cultures." }\end{array}$ \\
\hline
\end{tabular}

2. Self - Improvement

gains in knowledge (both personal and professional) helped them grow, change positively as a person.

empowering self

use of gained knowledge for own progress, to become a better person.

learning about other cultures pushed them to become more open-minded

Moved from their "comfortzone"
"To increase my self-awareness and change, in daily life, has been achieved and is significant."

"My awareness will continue to develop throughout my life and impact my personal and professional growth."

"I didn't put empowerment in my goal list, yet that's probably where I've made the most progress."

"This course pushed me out of my comfort zone."

"This class has conquered a huge issue with me, and I did not think it could." 


\begin{tabular}{lll}
\hline Category & Description & Response Examples \\
\hline $\begin{array}{l}\text { 3. Social } \\
\text { Action/Advocacy }\end{array}$ & $\begin{array}{l}\text { wanted to do something with } \\
\text { the knowledge gained; be } \\
\text { proactive; wanting to do actions } \\
\text { for change }\end{array}$ & $\begin{array}{l}\text { "I am now more aware and look } \\
\text { forward to being able to } \\
\text { facilitate changes within } \\
\text { institutions." }\end{array}$ \\
& $\begin{array}{l}\text { actions directed at reducing } \\
\text { prejudice; actions directed at } \\
\text { empowering minorities. }\end{array}$ & $\begin{array}{l}\text { "I really desire on working to be } \\
\text { tolerant and promote } \\
\text { tolerance." }\end{array}$ \\
& & \\
\hline
\end{tabular}

\section{Increased}

Awareness became more aware of how they see, feel and relate to/with other cultures
"The family genogram was very helpful to me in finding out about where my family came from and what influences they have had on me."

\section{Subcategories for Increased Awareness}

4.1 Self-Awareness became more aware of their own feelings and how they felt about other cultures (beyond biases \& prejudices)

awareness of personal behaviors (actions) towards others of different cultures

awareness pf personal beliefs (thoughts) towards/about people of different cultures
"I've become more aware of my beliefs, and views, and how they can affect the way I treat and view others."

"I am on my way to thinking less ethnocentrically than I did before."

"I think I have come to a greater understanding of my privileges."

"This class has challenged me to step up to the plate each and everyday and to realize that being multicultural sensitive is a daily decision."
4.2 Realized Biases \& prejudices learned about own

biases/prejudices that they had towards other cultures

course brought to light unrealized biases

initial denial/lack of realization of having/holding biases/prejudices, these were brought to light by course

\section{"I feel more aware of my} biases."

"Sought out a non-racist identity."

"I had been denying to myself how much discrimination I have internalized over my lifetime.

"Although I was able to acknowledge and admit my biases toward very religious individuals, I cannot say I conquered my bias."

"Acknowledging my own racist attitudes and beliefs." 


\begin{tabular}{|c|c|c|}
\hline \multirow[t]{5}{*}{$\begin{array}{l}4.3 \text { Other Culture } \\
\text { Awareness }\end{array}$} & $\begin{array}{l}\text { learned cultural aspects of } \\
\text { other cultures }\end{array}$ & $\begin{array}{l}\text { "I've learned a new way to } \\
\text { appreciate and respect "other" } \\
\text { cultures." }\end{array}$ \\
\hline & $\begin{array}{l}\text { gained greater appreciation for } \\
\text { other cultures, customs and } \\
\text { values. }\end{array}$ & $\begin{array}{l}\text { "Allowed me greater awareness } \\
\text { of those around me." }\end{array}$ \\
\hline & $\begin{array}{l}\text { how to deal with differences } \\
\text { more effectively \& positively } \\
\text { (Skills) }\end{array}$ & $\begin{array}{l}\text { "I am more aware of others' } \\
\text { differences." }\end{array}$ \\
\hline & $\begin{array}{l}\text { became more tolerant of others } \\
\text { and their differences }\end{array}$ & \\
\hline & $\begin{array}{l}\text { able to relate and interact with } \\
\text { people who are culturally } \\
\text { different in a much more } \\
\text { positive way. }\end{array}$ & \\
\hline $\begin{array}{l}4.4 \\
\text { Practitioner/Client } \\
\text { Relationship }\end{array}$ & $\begin{array}{l}\text { awareness of the importance of } \\
\text { multicultural awareness in the } \\
\text { practitioner/client relationship. }\end{array}$ & $\begin{array}{l}\text { "Awareness of the importance } \\
\text { multicultural awareness has in } \\
\text { the practitioner/client } \\
\text { relationship." }\end{array}$ \\
\hline \multirow[t]{2}{*}{4.5 Own Culture } & $\begin{array}{l}\text { awareness of own cultural } \\
\text { heritage }\end{array}$ & $\begin{array}{l}\text { "I am more aware of my own } \\
\text { cultural heritage." }\end{array}$ \\
\hline & $\begin{array}{l}\text { learned about self and own } \\
\text { culture as it relates to other } \\
\text { cultures }\end{array}$ & $\begin{array}{l}\text { "I'm much better aware of my } \\
\text { own cultural background and } \\
\text { experiences." }\end{array}$ \\
\hline
\end{tabular}




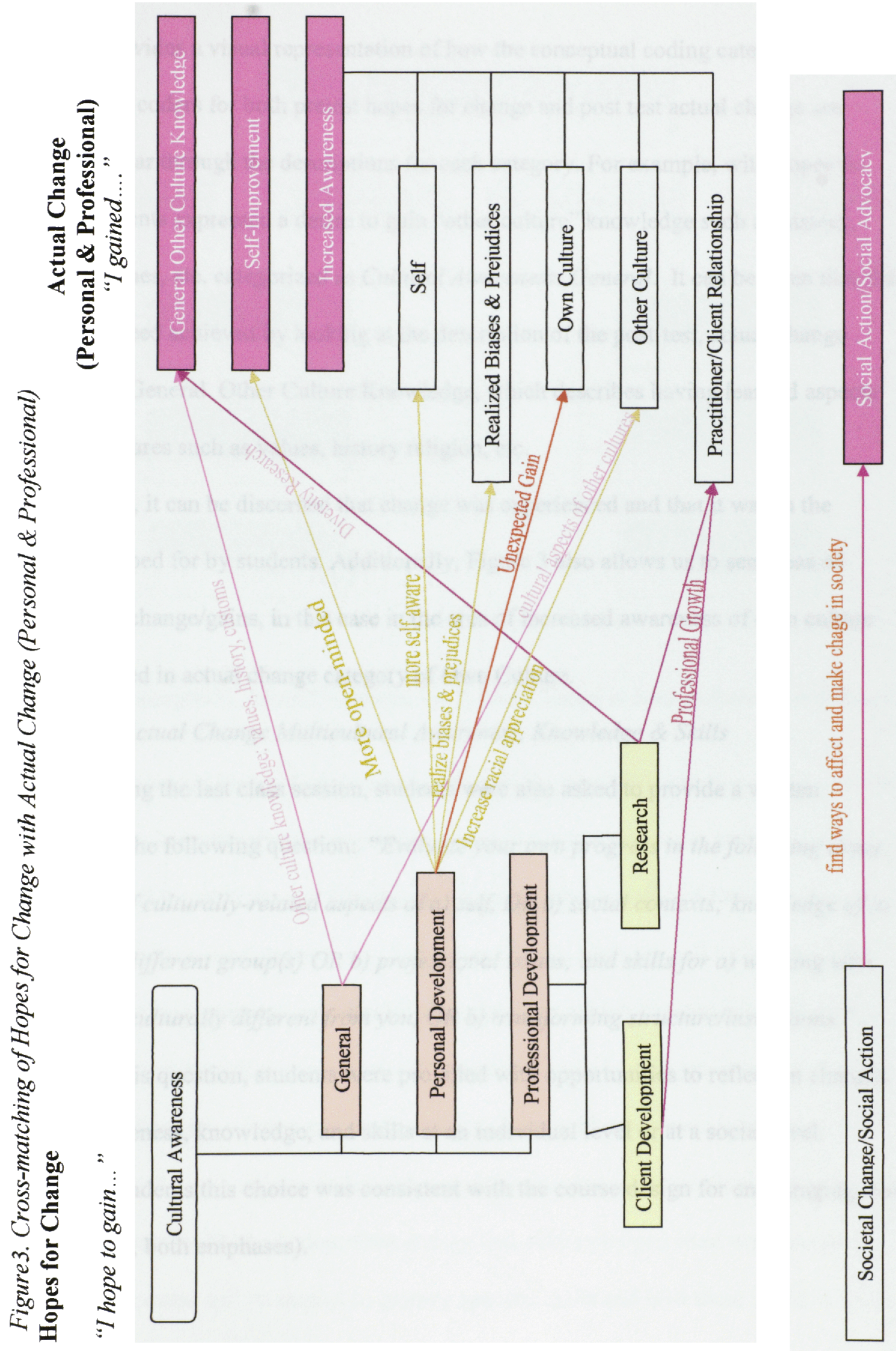


Figure 3 provides a visual representation of how the conceptual coding categories derived by the naïve coders for both pretest hopes for change and post test actual change are linked/ similar through the descriptions for each category. For example, with hopes for change students expressed a desire to gain "other culture" knowledge such as history, customs values, etc. categorized as Cultural Awareness: General. It can be seen that that this was indeed achieved by looking at the description of the post-test, actual change category of General Other Culture Knowledge, which describes having learned aspects of other cultures such as values, history religion, etc.

Thus, it can be discerned that change was experienced and that it was in the direction hoped for by students. Additionally, Figure 3 also allows us to see areas of unexpected change/gains, in this case in the area of increased awareness of own culture as categorized in actual change category of Own Culture. Post-TDT: Actual Change Multicultural Awareness, Knowledge \& Skills

During the last class session, students were also asked to provide a written response to the following question: "Evaluate your own progress in the following areas: awareness of culturally-related aspects of a) self, OR b) social contexts; knowledge of a) a culturally different group(s) OR b) professional issues; and skills for a) working with populations culturally different from you, OR b) transforming structure/institutions." Hence, for this question, students were provided with opportunities to reflect on changes in their awareness, knowledge, and skills at an individual level or at a social level. (Allowing students this choice was consistent with the course design for encouraging, but not requiring, both emphases). 
ACTUAL CHANGE IN MUlticUltural

COMPETENCE

Future Improvement

Open-Minded

Increased Awareness

Client-Involvement

Method
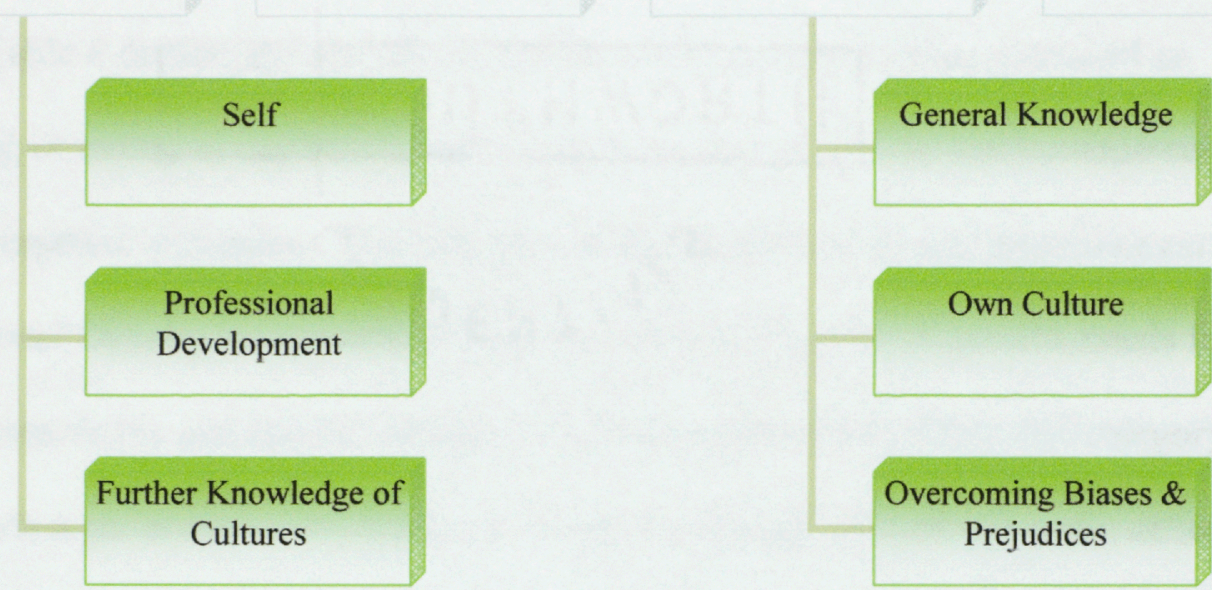

Figure 4. Conceptual Coding Categories for Actual Change in Multicultural Competence.

As shown in Figure 4, conceptual coding of the post TDT question that probed for actual change in multicultural competence revealed that change was experienced and reported by all the students and this change was categorized as that of Future Improvement, Increased Awareness, Client-Involvement Methods, and Open-Minded.

Future Improvement was described as change in which the students realized that despite the gains from the course, they still perceived a need for improvement in both self, other culture knowledge and professionally. Increased Awareness involved change that represented a gain in knowledge about self, other cultures and professional issues. Client Involvement Methods described change that acknowledged what was learned or gained from course and its impact in gaining specific skills and how these could be used. 
Finally, Open-Minded described change that involved a change of mindset of the students. The students described decreases in biased views and values, actively working to change any biases, and becoming more comfortable in dealing with culturally different groups.

Table 6 depicts the specific categories students expressed or identified as impacting or aiding in implementing change in an area of multicultural competence, with student response examples. For example, in the category of Future Improvement: Professional Development, students described their realization of specific needs for intervention skills, assessment, research, client therapist issues. Thus, this category portrays change/ progress in awareness of self, knowledge of both culturally different groups and professional issues and skills in working with other populations. Across the whole group of responses, all change that was reported was perceived as positive and enlightening, even if sometimes unsettling. 
Table 6.

Students' Actual Change in Multicultural Competence

\begin{tabular}{ll}
\hline Category Name & Description \\
\hline 1. Future Improvement & -Despite gains from class, still see a need for improvement in \\
& self, other culture general knowledge and professionally. \\
& -Course/class was not enough to fulfill personal improvement \\
& requirements, still need improvement in/for future \\
& -Concentration on gaining, improving self professionally beyond \\
course.
\end{tabular}

\begin{tabular}{|c|c|c|}
\hline \multicolumn{2}{|c|}{ Subcategories for Future Improvement: } & \multirow{2}{*}{$\begin{array}{l}\text { Response Examples } \\
\text { "I would like to acquire more } \\
\text { intervention skills." } \\
\text { "I recognize the limits of my } \\
\text { competencies and expertise." }\end{array}$} \\
\hline $\begin{array}{l}\text { 1.1 Professional } \\
\text { Development }\end{array}$ & $\begin{array}{l}\text { specific need for improvement } \\
\text { in intervention skills, } \\
\text { assessment, research, } \\
\text { client/therapist issues. }\end{array}$ & \\
\hline 1.2 Self & $\begin{array}{l}\text { desired future improvement in } \\
\text { self ( not in professional } \\
\text { capacity) }\end{array}$ & $\begin{array}{l}\text { "Work on getting past my } \\
\text { own discomfort concerning } \\
\text { lifestyles with which I strongly } \\
\text { disagree." }\end{array}$ \\
\hline \multirow[t]{2}{*}{$\begin{array}{l}\text { 1.3 Further Knowledge } \\
\text { of Other Cultures }\end{array}$} & $\begin{array}{l}\text { continue to learn about } \\
\text { various cultures }\end{array}$ & $\begin{array}{l}\text { "Familiarizing myself with } \\
\text { research and other findings } \\
\text { regarding mental health and } \\
\text { mental disorders of various } \\
\text { ethnic and racial groups." }\end{array}$ \\
\hline & & $\begin{array}{l}\text { "Further educate myself with } \\
\text { regards to specific cultures } \\
\text { and historical contexts of } \\
\text { ethnicity." }\end{array}$ \\
\hline
\end{tabular}

2. Increased Awareness

gain in knowledge about self, other cultures, professional issues.
"This course gave me a love for my culture."

"I believe I made significant progress in gaining knowledge about my own culture."

\section{Subcategories for Increased Awareness:}

2.1 Own Culture became more aware of their

own culture, cultural heritage.

learned about aspects of their own culture
"I have become more knowledgeable about my heritage's stereotypes and attitudes towards certain people."

"I feel I have improved in being more aware of my own culture, my cultural experiences and background.." 


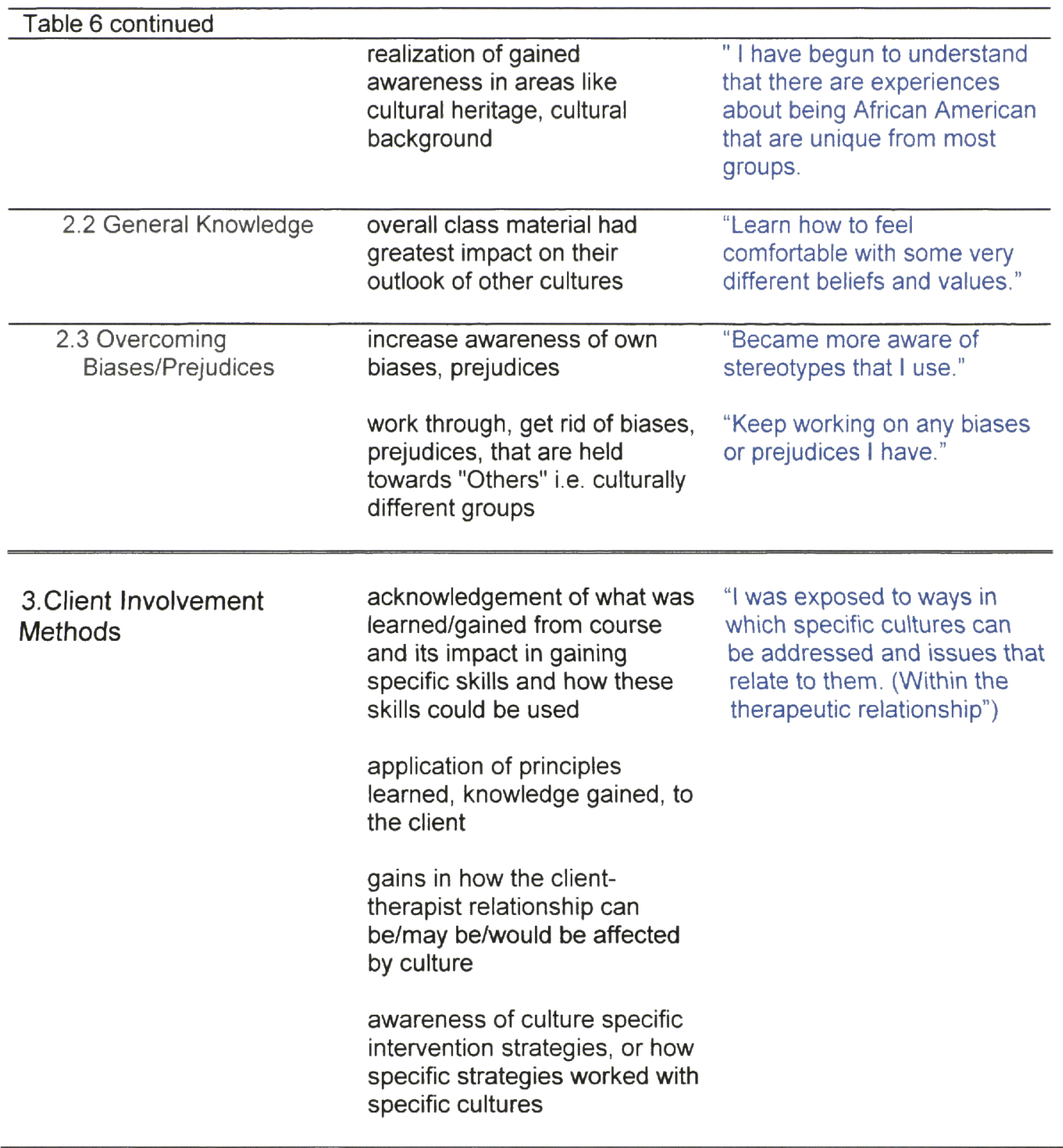

\section{Open Minded}

change of mindset, prejudices, "I think outside the box." discriminatory practices, biases to more positive one

able to now view other cultures in a more positive light

increased awareness of unknown/unrealized bias to active unbiased change

"I have become more aware of subtle biases around me."

"I thought I was fairly enlightened before beginning this course, but I quickly became aware of how prejudiced and biased I was towards others." 
decrease in culturally biased

views, values, decreased

prejudices

have become more comfortable in dealing with culturally different groups
"Less judgmental stance."

"I no longer feel that hate in the pit of my stomach."

It was through the "categorized changes" shown in Table 6 that students expressed perceiving a change in awareness of self and social contexts, knowledge of culturally different groups and professional issues, and skills for working with "other" populations and transforming structure/ institutions. Table 7 depicts students' gains by placing stars in the appropriate areas (awareness, knowledge and skills). As can be seen in the table, students did feel that they were improving in the multicultural competencies first articulated by Sue, Arredondo, \& McDavies (1992). Additionally, awareness was gained both in terms of self-awareness and awareness of social contexts, knowledge was gained both in terms of knowledge about different social groups and knowledge about professional issues, and skills were gained both for working with "other" populations and for transforming structures and institutions. 
Table 7:

Identified Impact on Multicultural Competence for each Conceptual Coding Category.

Category Name

Awareness

Knowledge

Skills

Culturally

Working Transforming

1. Future Improvement

$\begin{array}{ccccc}\text { Self Cocial } & \text { Different } & \text { Professional with "Other" } & \text { Structure/ } \\ \text { Issues } & \text { Populations } & \text { Institutions }\end{array}$

Subcategories:

1.1

Professional
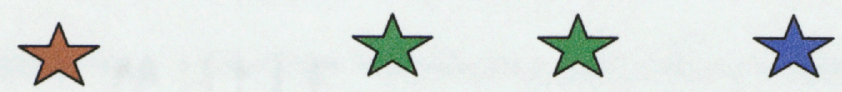

Development

1.2 Self

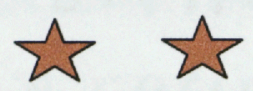

1.3 Further

Knowledge of Other

Cultures

2. Increased

Awareness

Subcategories:

2.1 Own

Culture

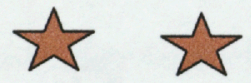

Knowledge

2.2 General

2.3 Overcoming Biases/Prejudices
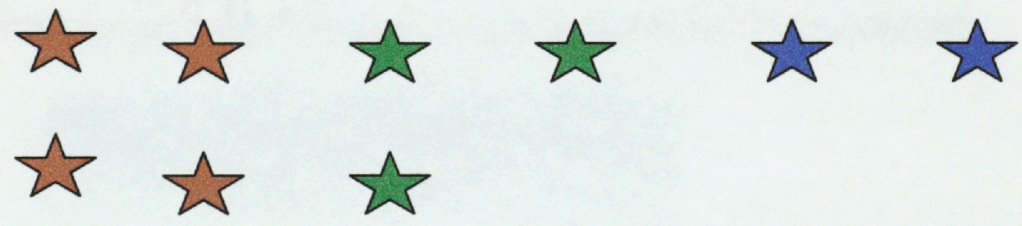

3.Client Involvement

Methods
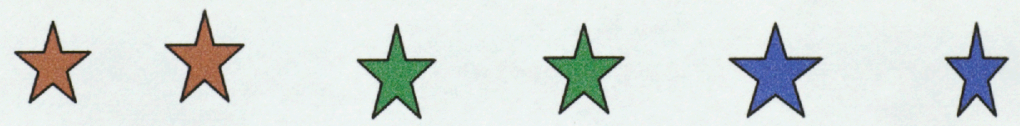

4. Open Minded
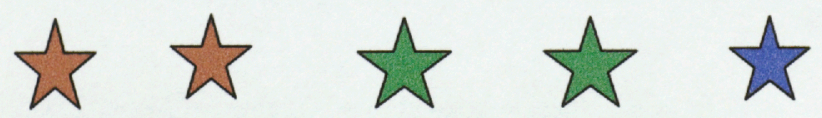
When students were re-contacted approximately one year after the conclusion of the TDT course, they were again asked to respond in writing, this time to a series of questions. The first prompt requested "Describe what, if any, change in your multicultural competence, (i.e., awareness, knowledge, and/or skills) resulted from the inclass participatory activities (e.g., readings, discussions, participatory learning experiences, etc.), and the meaning and significance of that change). The aim of this question was to evaluate the effect that the participatory activities, specifically, had on changes in awareness, knowledge and/or skills, and how meaningful these changes were, from the vantage point of one more year of training and counseling experience. As shown in Figure 5, conceptual coding revealed that students perceived that the participatory activities of the course impacted their awareness with Increased Awareness, Therapy Skills" and General Knowledge Gain. Some students (5\%), however, felt that the participatory activities had not prompted change in their multicultural competence.

\section{IMPACT OF PARTICIPATORY \\ ACTIVITIES}

No Change

Increased

Awareness
Therapy Skills
General Knowledge Gain
Cultural Sensitivity

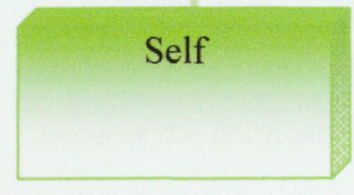

General

Figure 5. Conceptual Coding Categories for Impact of Participatory Activities. 
When students were re-contacted approximately one year after the conclusion of the TDT course, they were again asked to respond in writing, this time to a series of questions. The first prompt requested "Describe what, if any, change in your multicultural competence, (i.e., awareness, knowledge, and/or skills) resulted from the inclass participatory activities (e.g., readings, discussions, participatory learning experiences, etc.), and the meaning and significance of that change). The aim of this question was to evaluate the effect that the participatory activities, specifically, had on changes in awareness, knowledge and/or skills, and how meaningful these changes were, from the vantage point of one more year of training and counseling experience. As shown in Figure 5, conceptual coding revealed that students perceived that the participatory activities of the course impacted their awareness with Increased Awareness, Therapy Skills" and General Knowledge Gain. Some students (5\%), however, felt that the participatory activities had not prompted change in their multicultural competence.

IMPACT OF PARTICIPATORY

ACTIVITIES

No Change

Increased

Awareness
Therapy Skills

General Knowledge

Gain

Cultural Sensitivity

Self

General

Figure 5. Conceptual Coding Categories for Impact of Participatory Activities. 
Table 8 gives a full description of all the conceptual coding categories along with student response examples.

Increased Awareness. In the category of Increased Awareness, the participants noted that the participatory activities allowed for gains in awareness of self and others, which allowed for personal change which was perceived as positive. This change was reported as "a shift from being passive to more proactive with respect to beliefs and/or awareness." Increased Awareness of self was depicted as becoming more open-minded, realizing ones' limitations and biases, and discovering that despite believing self to be somewhat culturally competent before course, the participatory activities revealed to some students that they still had a lot more to learn with respect to multicultural competence.

Increased awareness of others was sub-categorized as Cultural Sensitivity and depicted the participatory activities aiding in greater understanding of other cultures and facilitating more appreciation of difference. As voiced by one student, the activities allowed students to recognize the "importance of viewing/ looking at perspectives of other cultures.” The participatory activities also provided for overall increased awareness; e.g., "It [the course and its activities] enhanced my understanding and awareness of multiculturalism." 
Table 8.

Impact of Participatory Activities.

\begin{tabular}{ll}
\hline Category Name & Description \\
\hline 1. No Change & $\begin{array}{l}\text { no perceived change resulting from } \\
\text { the "In-class participatory activities" } \\
\text {-change occurred that was } \\
\text { perceived as positive }\end{array}$ \\
\hline 2. Increased & $\begin{array}{l}\text {-shifted from being passive to more } \\
\text { proactive with respect to beliefs/ } \\
\text { awareness } \\
\text {-gains in awareness of self and } \\
\text { "others" }\end{array}$
\end{tabular}

Response Examples

"No Change"

Subcategories of Increased Awareness:

\begin{tabular}{|c|c|c|}
\hline \multicolumn{3}{|c|}{ Subcategories of Increased Awareness: } \\
\hline \multirow{4}{*}{$\begin{array}{l}2.1 \text { Of Others } \\
\text { (Cultural Sensitivity) }\end{array}$} & $\begin{array}{l}\text {-awareness gained is focused on } \\
\text { aspect of "others" }\end{array}$ & $\begin{array}{l}\text { "I am more aware of } \\
\text { multicultural differences." }\end{array}$ \\
\hline & $\begin{array}{l}\text {-having a greater understanding of } \\
\text { other cultures }\end{array}$ & $\begin{array}{l}\text { "Other awareness: be } \\
\text { sensitive to others' } \\
\text { differences, and allows others } \\
\text { to educate you on their unique } \\
\text { differences.' }\end{array}$ \\
\hline & -more appreciative of difference & $\begin{array}{l}\text { "Increased awareness into } \\
\text { cultural differences and the } \\
\text { experiences of others." }\end{array}$ \\
\hline & $\begin{array}{l}\text {-importance of viewing/looking at } \\
\text { perspective of other cultures. }\end{array}$ & $\begin{array}{l}\text { "I am more aware of different } \\
\text { groups of people." }\end{array}$ \\
\hline 2.2 Self & $\begin{array}{l}\text {-became more open-minded, more } \\
\text { understanding of client(s) as well as } \\
\text { "other people" }\end{array}$ & $\begin{array}{l}\text { "What changed was my short- } \\
\text { sightedness." }\end{array}$ \\
\hline & $\begin{array}{l}\text {-perceived self as already } \\
\text { somewhat culturally competent, but } \\
\text { realized that they had a lot more to } \\
\text { learn. }\end{array}$ & "Has increased my openness." \\
\hline & $\begin{array}{l}\text {-shifted from being passive to more } \\
\text { proactive with respect to } \\
\text { awareness/beliefs }\end{array}$ & \\
\hline 2.3 General & $\begin{array}{l}\text { increased awareness is broad, not } \\
\text { focused on one specific aspect of } \\
\text { self, other cultures, therapy - } \\
\text { awareness encompasses all } \\
\text { aspects }\end{array}$ & $\begin{array}{l}\text { "Enhanced my understanding } \\
\text { of and awareness of } \\
\text { multiculturalism." }\end{array}$ \\
\hline
\end{tabular}


Table 8. continued

\begin{tabular}{|c|c|c|}
\hline \multirow[t]{6}{*}{ 3. Therapy Skills } & $\begin{array}{l}\text { increased awareness of impact of } \\
\text { culture in client-therapist } \\
\text { relationship }\end{array}$ & $\begin{array}{l}\text { "Improved my professional } \\
\text { relationship with clients." }\end{array}$ \\
\hline & $\begin{array}{l}\text { possible improvement in therapeutic } \\
\text { (client-therapist) relationship }\end{array}$ & $\begin{array}{l}\text { "Better able to recognize } \\
\text { cultural competence and } \\
\text { sensitivity to other cultures } \\
\text { and how much it can affect the } \\
\text { therapeutic process." }\end{array}$ \\
\hline & $\begin{array}{l}\text { increased awareness applied to } \\
\text { client diagnosis and treatment } \\
\text { specifically }\end{array}$ & $\begin{array}{l}\text { "Working with multicultural } \\
\text { clients, I am more aware of } \\
\text { how their culture shapes their } \\
\text { cognition and behavior and } \\
\text { being able to differentiate } \\
\text { between pathology and } \\
\text { customs is very important.' }\end{array}$ \\
\hline & $\begin{array}{l}\text { gains in skills in working with } \\
\text { diverse people } \\
\text { (Competence/Professional Skills) }\end{array}$ & $\begin{array}{l}\text { "Opened my eyes to the } \\
\text { narrowness of studies." }\end{array}$ \\
\hline & $\begin{array}{l}\text { gains in knowledge about Research } \\
\text { as it relates to diverse cultures in } \\
\text { therapy/ professional arena }\end{array}$ & $\begin{array}{l}\text { "I now attempt to understand } \\
\text { the client's background. I find } \\
\text { this enhances rapport and } \\
\text { puts the client more at ease } \\
\text { " }\end{array}$ \\
\hline & $\begin{array}{l}\text { possible improvement in relating to } \\
\text { students of different cultures }\end{array}$ & $\begin{array}{l}\text { "Overall awareness of the } \\
\text { impact that culture plays in the } \\
\text { diagnosis and treatment of } \\
\text { mental health for my clients." }\end{array}$ \\
\hline
\end{tabular}

Therapy Skills included responses denoting that the participatory nature of the TDT course resulted in an increased awareness of the impact of culture in/on the client/therapist relationship. For these students, the participatory activities facilitated a more positive therapeutic relationship, through increased awareness applied to client diagnosis and treatment. The course participatory activities were reported to provide for gains in skills in working with diverse people, as well as knowledge about research as it relates to diverse cultures in therapy and the professional arena in general. 
General Knowledge Gain of other cultures was the category for responses indicating that the activities allowed students to see "what life is like for certain ethnicities." For these students, the knowledge gained through the participatory activities allowed for a perceived broad enhancement of awareness, which provided a better overall picture of multiculturalism as it impacts self, own culture, other cultures, personal and professional issues. Thus, the knowledge gained through the participatory activities provided for a greater understanding and appreciation of the role and relevance of multiculturalism in everyday life.

One-Year TDT Follow-Up: Change in Multicultural Competence

The second question students responded to at the one-year follow-up was based on the first question, and asked: "Do you believe that this change in your multicultural awareness, knowledge, and/or skills had an impact on the quality of your professional services/activities in a multicultural context? Describe this impact on the quality of your professional services/activities." Thus, the purpose of this question was to learn how students felt the quality of their professional services/activities had been impacted by the "perceived change" in multicultural competencies described in Question I. 
Figure 6. Conceptual Coding Categories for the Impact on the Quality of Professional Services/Activities.

As shown by Figure 6, the conceptual coding revealed that for some students $(8 \%)$ there was no impact on the quality of their professional services as a result of perceived change in multicultural competence. These students reported that this was either due to the perception that they had not attained any change in multicultural competence or that even with change in multicultural competence; it did not seem to alter the quality of their professional services/activities.

For the remainder of students, their improvements in multicultural competence impacted the quality of their professional services/activities in the areas of Cultural Sensitivity, Professional Incorporation, Comfort/Mindset, General Knowledge Gain, and Future Benefit. 
Responses classified as being in the Cultural Sensitivity category described impact on the quality of professional services and activities that resulted from students becoming more aware of and more sensitive to multicultural issues and difference. Responses in the Professional Incorporation described understanding and utilization of how the knowledge gained through the course, which changed some aspect of their multicultural competence, and has/can/will/may impact the quality of service to their clients. Responses in the Comfort/Mindset described an impact on professional activities/services as a result of students becoming more comfortable in dealing with people of different cultures. General Knowledge Gain responses described how overall gain in general knowledge affected the quality of their professional services and activities. Finally, responses in the Future Benefit category expressed the feeling of the $5 \%$ of the students who had no chance to incorporate their perceived change in multicultural competence, but foresaw that this change in competence, once incorporated, would indeed affect/impact the quality of their professional services/activities. See Table 9, which gives a full description of categories with student response examples. 
Table 9.

Impact of Change in Multicultural Competence on Professional Services.

\begin{tabular}{lll}
\hline Category Name & Description & Response Examples \\
\hline 1. No Impact & $\begin{array}{l}\text { change in multicultural awareness, } \\
\text { Knowledge \& skills had no impact } \\
\text { on the quality of their } \\
\text { professional/services/activities }\end{array}$ & "No change" \\
\hline \hline
\end{tabular}

2. Cultural Sensitivity

became more aware, more sensitive to multicultural issues, "difference"

mainly affected their degree of sensitivity towards "others"

increased empathy towards

"others", difference

became more compassionate, empathetic, understanding to/of "others"
"Made me aware of values and scripts of their culture every client brings."

"Allows me to be more empathetic."

"I've become more comfortable with others' differences and more sensitive to these differences."

"I am a more sensitive counselor."

"Work with them in a sensitive manner."

"I am more understanding, non-judgmental and objective when my clients speak about their life concerns."

"Become more sensitive to a wide range of individual perspectives and viewpoints. "

"Increased my sensitivity when working with clients."

"I recognize the extent to which perspectives can differ culturally; I take more care to actively discuss such issues. "

"I try to step into my client's shoes" 


\begin{tabular}{lll}
\hline Category Name & Description & Response Examples \\
\hline $\begin{array}{l}\text { 3. Professional } \\
\text { Incorporation }\end{array}$ & $\begin{array}{l}\text { understanding \& utilization of how } \\
\text { the knowledge gained through } \\
\text { course, has/can/ will/ may impact } \\
\text { the quality of service to their clients }\end{array}$ & $\begin{array}{l}\text { "I have also gone on to teach } \\
\text { of diversity." }\end{array}$ \\
$\begin{array}{ll}\text { incorporated the lessons learnt into } \\
\text { their professional lives }\end{array}$ & "I strive to incorporate the \\
& $\begin{array}{l}\text { lessons l've learned into my } \\
\text { gains/improvessional career." }\end{array}$ \\
that were positive & "l am learning to incorporate \\
& $\begin{array}{l}\text { a more eclectic cultural } \\
\text { approach." }\end{array}$ \\
& "I am better at preserving a \\
& client's original intent. \\
& "The quality of my \\
& $\begin{array}{l}\text { professional activities has } \\
\text { definitely benefited from my } \\
\text { increased multicultural }\end{array}$ \\
& awareness."
\end{tabular}

4. Comfort/mind- set

became more comfortable in dealing with people of different cultures

became more open-minded, less judgmental

became more non-judgmental of others

became more open-minded to how aspects of culture, difference is relevant
"I feel more confident in my competence to serve my clients."

"Conscious efforts to maintain a more openminded approach to things."

I am more conscious of the complexity in treatment regarding cultural differences.

"

"I have become more open to my clients' differences."

\section{Future Benefit}

No chance to incorporate change, but perceive/foresee incorporation as being potentially beneficial to self , client professional environment
"I believe that the knowledge I acquired will have an impact, but I have not yet had an opportunity to work with new groups of people."

"This awareness I believe will have a great impact on the quality of my professional services to clients, etc." 


\begin{tabular}{lll}
\hline Category & Description & Response Examples \\
$\begin{array}{l}\text { 6. General } \\
\text { Knowledge Gain }\end{array}$ & $\begin{array}{l}\text { gain in overall knowledge of other } \\
\text { cultures }\end{array}$ & $\begin{array}{l}\text { "More aware of the lack of } \\
\text { multicultural knowledge in the } \\
\text { literature." }\end{array}$ \\
& $\begin{array}{l}\text { gain in knowledge with respect to } \\
\text { diversity, culture, research in this } \\
\text { area }\end{array}$ & $\begin{array}{l}\text { "There still seems to be a } \\
\text { paucity of multicultural } \\
\text { research." }\end{array}$ \\
& $\begin{array}{l}\text { increased awareness of research as } \\
\text { it relates to diversity }\end{array}$ &
\end{tabular}


The third prompt at one-year follow up asked students to respond to the following: "Describe what, if any, change in your involvement in the community (local or global) and/or in the profession (e.g., affiliation with professional groups, conferences, etc.) resulted from the class (e.g., your transformative project or other experience).Please elaborate the meaning and significance of these changes." Thus, the purpose of this question was to learn if students believed the TDT course had resulted in any change in their "social action" or involvement in the local or global community, or in changes in their professional involvement.

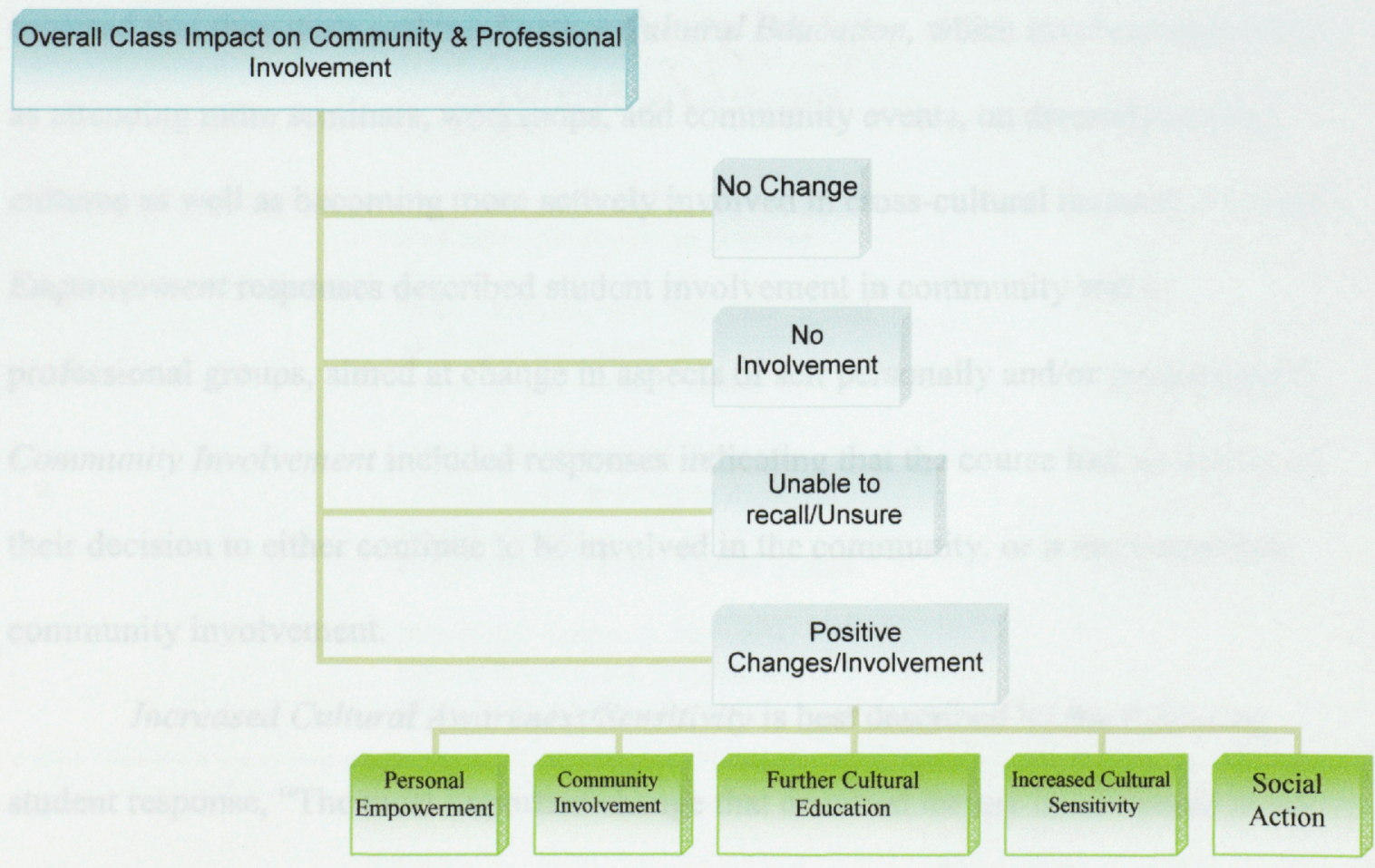

Figure 7. Conceptual Coding Categories for Class Impact on Community and Professional Involvement. 
As shown in Figure 7, conceptual coding revealed that for $13 \%$ of the students who took the course, despite the gains from the DT course, one-year follow-up revealed that there was no change in community or professional involvement. This group included $8 \%$ of the students, who noted that it was difficult to gauge if any change had occurred to their community and/or professional involvement as a result of the DT course because they were not presently involvement in community activity. This group also included 5\% of the students, who noted difficultly in recalling any change in their community and/or professional involvement, so they were uncertain as to whether change had occurred.

For the remainder of the students, all reported some aspect of community and/or professional involvement, and they all deemed this change as positive. See Table 10 for category codes with descriptions and student response examples. For example, some reported that they were seeking Further Cultural Education, which involved such things as attending more seminars, workshops, and community events, on diversity or other cultures as well as becoming more actively involved in cross-cultural research. Personal Empowerment responses described student involvement in community and or professional groups, aimed at change in aspects of self personally and/or professionally. Community Involvement included responses indicating that the course had an impact on their decision to either continue to be involved in the community, or it increased their community involvement.

Increased Cultural Awareness/Sensitivity is best described by the following student response, "The most important change that occurred for my involvement in my profession would again be the awareness of cultural impact." Within this category 
Table 10

Impact on Community and Professional Involvement

\begin{tabular}{lll}
\hline Category Name & Description & Response Examples \\
\hline 1. No Change & $\begin{array}{l}\text { No change in involvement in the } \\
\text { community and/or in the profession }\end{array}$ & "I have had no change in my \\
& community involvement." \\
& Involvement remained the same & \\
\hline
\end{tabular}

2. No Involvement

3. Unable to recall/Unsure not presently involved in community activity, therefore hard to tell if there has been any change
"I am not involved in community activities."

"I have not become involved in the community, nor in the profession."
4.Positive Changes /Involvement not certain if any change occurred

can't recall any changes, if any
"I am not sure if my involvement with the community has changed as a result of the Cross-Cultural Sensitization course." actual involvement in community \& professional activities which resulted in positive change for both self \& community

change in professional involvement that was perceived as positive

active involvement that was aimed at change, in aspects of self, personally \& professionally

increased interest in diversity related to community issues \& professionally social responsibility, social action

increased desire to face any personal demons, biases, with respect to culture, diversity 
4.1 Seeking Further Cultural Education increased interest in diversity related to community issues, research \& professionally
"There has been a huge impact on my research interests and activities."

"I have frequently attended seminars and workshops on diversity and other cultures."

"I have become more open to attending talks, performances, etc. that highlight different cultural histories and lives "

"More active in my involvement with crosscultural issues in my research."
4.2 Personal Empowerment active involvement that was aimed at change, in aspects of self, personally \& professionally

increased desire to face any personal demons, biases, with respect to culture, diversity
"I now feel more educated and more empowered to contribute in the small ways that I can.'

"Change my thoughts about my potential impact in the mental health field."
4.3 Community Involvement continued and /or increased community involvement
"I did some volunteer work for a non-profit organization."

"I very much enjoyed the component of the class that required us to seek out and participate in community events. As a result, I am currently still participating in more cultural community events."

"The most important change that occurred for my involvement in my profession would again be the awareness of cultural impact."

"Clearer understanding of the experiences of others." 
"I know to be more attuned to others' individuality and paradoxically those characteristics that bond them to their culture and ethnicity

4.5 Social Action Desire to make in change in society

"Interest and desire to want to help improve "others" lives.

were student responses indicating that the overall class impact on their community and/or professional involvement was the gain in a "clearer understanding of the experiences of others."

Social Action described the desire of students to make a change in society or the world, which they hoped could be attained somewhat through community and/or professional involvement.

One Year TDT Follow-Up: Quality of Professional Services/Activities

The fourth prompt at one year follow-up asked students to respond to the following: "Do you believe that this change in your involvement in the community and/or in the profession has had an impact on the quality of your professional services/activities in a multicultural context? Describe this impact on the quality of your professional services/activities." The purpose of this question was to learn if students believed that their described changes in community and professional involvement from question three had any perceived effect on the quality of their professional services/activities. 


\author{
No Change \\ Future Change \\ General Knowledge Gain \\ Client Empowerment \\ Professional Awareness \\ Self-Improvement \\ Not Applicable
}

Figure 8. Conceptual Coding Categories for Impact of Community Involvement on Quality of Professional Services

As shown in Figure 8, conceptual coding revealed that for $5 \%$ of the students, there was no perceived change in the quality of their professional services/activities that they believed was (directly or indirectly) influenced by any change in community involvement. No perceived change was described as either the result of previously describing no change in community involvement, hence none in quality of professional services, (nb. that this also applied to the $10 \%$ of students in the category of Not Applicable), or even with change in community involvement, they perceived the quality of their professional services/activities are remaining relatively unchanged.

For $2 \%$ of the students, change in quality of professional services could not be gauged at the time mainly due to no community involvement, but these students foresaw change in the quality of their professional services/activities to occur when given a chance to become involved in the community and apply what they had learned. Seven 
percent (7\%) of the students described their community involvement as impacting the quality of their professional activities through gaining in general knowledge about multicultural issues. This was categorized as General Knowledge Gain, as these students expressed that they had learned more about the general aspects of diversity within their community and globally through their community involvement.

For $2 \%$ of the students, community involvement impacted their professional services/activities by providing them with tools and skills necessary to foster Client Empowerment. This involved being able to give clients knowledge, both personal and practical, that allowed them to be better able to express, understand and face obstacles.

According to $17 \%$ of the students, changes in community involvement also brought changes in the professional areas of services, skills and sensitivity - categorized as Professional Awareness. This category described changes in professional services such as being more efficient, having increased empathy, compassion in dealing with clients, taking the background and culture of the client more into consideration, and generally perceiving self as being better able to work with culturally diverse clients.

Self Change/Self Improvement described the impact of change in community involvement on the quality of professional services/activities for $12 \%$ of students and entailed a perception of change within self. This category depicted students' perception of change with some aspect of self which they saw as crucial to allow for their provision of best quality of service to their clients. See Table 11, which gives a full description of each category with student response examples. 
Table 11

Impact of Change in Community Involvement on the Quality of Professional Services/Activities

\begin{tabular}{lll}
\hline Category Name & Description & Response Examples \\
\hline 1. No Change & no apparent change & "I don't think the class had a \\
significant impact."
\end{tabular}

Did not change anything for better or worse, stayed the same

2. Future Change impact/change in their involvement is expected later (in the future)

change has yet to occur, but perceived/foreseen to occur when they have a chance to apply what they have learned
"Most of the impact due to this change is yet to come."

"I will be more sensitive not only to the way I interact with clients, but in the manner I conduct research."

\section{General Knowledge Gain \\ learned more about general aspects of diversity/multiculturalism}

gain in general knowledge about multicultural issues
"I have understood the narrowness of certain earlier research and the tools it used."

"I have become aware of various kinds of people." 4. Client
Empowerment give client knowledge both personal and practical to allow them to be better able to express, understand and face obstacles
"I feel motivated to empower clients who are directly being affected by these issues.

\section{Professional Awareness \\ (Professional Services/Skills/ Sensitivity)}

changed the way they worked with "other"

became more efficient in their services

increased empathy, compassion in viewing, dealing with clients
"I am a lot more cautious of drawing conclusions about my clients and their families/situations."

"I ask more questions and listen more carefully and sensitively to others styles and meanings of their experiences."

"I am less likely to make assumptions." 
take the background, culture of the

client more into consideration

better ability to work with culturally diverse clients
"I feel more of a responsibility to insure that my professional services coincide with my multicultural awareness."
6. Self Change/Self impacted/ changed some aspect of Improvement self

changed their feelings, views with respect to some, certain aspects of self

gained knowledge about self
Has had an impact on my personal perspective of the world."

"Has helped me interpersonally, - increasing my confidence, ability to network.

I think it makes me more sensitive."

7. Not Applicable

Did not believe that question asked applied to them/ their life/experience
"Does not apply"

"N/A" 
One Year TDT Follow-Up: Feedback

The final prompt at the one year follow-up asked students to respond to the following: "Now that more than a year has gone by since the course ended, are there any other comments you would like to make about the impact the class had on you and your development as a person and as a professional?" The aim of this question was to provide general feedback about multicultural instruction, suggestions about the overall course itself, specific aspects of the course and any personal highlights. See Table 12, which gives a breakdown and description of the feedback and suggestions provided by the students.

Table 12

Student Feedback and Suggestions for Transformative Diversity Training Course

\begin{tabular}{lll}
\hline Category Name & Description & Response Examples \\
\hline 1. No comment & $\begin{array}{l}\text { Had no comment(s) to make in } \\
\text { response to question }\end{array}$ & "No comment" \\
\hline
\end{tabular}

2. Increased Awareness

became more aware of how class

impacted self, in general,

personally and professionally

\begin{tabular}{|c|c|c|}
\hline \multicolumn{3}{|c|}{ Subcategories for Increased Awareness: } \\
\hline 2.1 General & $\begin{array}{l}\text { general increase in awareness of } \\
\text { both self and "others" }\end{array}$ & $\begin{array}{l}\text { "I gained increased } \\
\text { multicultural awareness and } \\
\text { appreciation." }\end{array}$ \\
\hline & $\begin{array}{l}\text { increased awareness not specific } \\
\text { to any one aspect of self or "other" } \\
\text { or concept }\end{array}$ & $\begin{array}{l}\text { "Awareness of the issues, } \\
\text { problems and concerns that } \\
\text { people from other cultures } \\
\text { experience often daily." }\end{array}$ \\
\hline & $\begin{array}{l}\text { gain in knowledge and awareness } \\
\text { of how minority culture, both as it } \\
\text { pertains to self and others } \\
\text { impacted life }\end{array}$ & $\begin{array}{l}\text { "It made me realize that for } \\
\text { may therapists working in } \\
\text { the field, multiculturalism is } \\
\text { not known." }\end{array}$ \\
\hline 2.2 Self & $\begin{array}{l}\text { increased awareness related } \\
\text { directly to some aspect of self, as } \\
\text { it relates to diversity, } \\
\text { multiculturalism }\end{array}$ & $\begin{array}{l}\text { "This course made me } \\
\text { more aware of my biases." }\end{array}$ \\
\hline
\end{tabular}




\begin{tabular}{|c|c|c|}
\hline \multicolumn{3}{|l|}{ Table 12 continued } \\
\hline \multirow[t]{5}{*}{2.2 Self cont'd } & $\begin{array}{l}\text { became more aware, of } \\
\text { "unearned privileges" as a } \\
\text { sheltered individual }\end{array}$ & $\begin{array}{l}\text { "Impacted my development } \\
\text { as a person and as a } \\
\text { student of the course." }\end{array}$ \\
\hline & $\begin{array}{l}\text { became more aware of biases and } \\
\text { prejudices }\end{array}$ & $\begin{array}{l}\text { "I feel like I am a more } \\
\text { integrated and empowered } \\
\text { person that can contribute } \\
\text { to my community and } \\
\text { profession in a positive and } \\
\text { important way." }\end{array}$ \\
\hline & & $\begin{array}{l}\text { "It was helpful for me to } \\
\text { apply all the concepts and } \\
\text { skills we covered in class to } \\
\text { my life and experiences." }\end{array}$ \\
\hline & & "Made me more aware." \\
\hline & & $\begin{array}{l}\text { "I believe this course } \\
\text { opened my eyes and mind } \\
\text { to differences and gave me } \\
\text { tools to facilitate } \\
\text { development of my } \\
\text { sensitivity to them." }\end{array}$ \\
\hline \multirow[t]{7}{*}{ 3.Feedback/Suggestions } & General comments on class & $\begin{array}{l}\text { "I very much liked the } \\
\text { interactive nature of the } \\
\text { course." }\end{array}$ \\
\hline & $\begin{array}{l}\text { no real comment on impact to self, } \\
\text { just gave suggestions }\end{array}$ & $\begin{array}{l}\text { "The class was a positive } \\
\text { experience." }\end{array}$ \\
\hline & $\begin{array}{l}\text { specific examples from class, } \\
\text { assigned course work, that were } \\
\text { helpful and highly recommended, } \\
\text { thus suggested for continued use }\end{array}$ & $\begin{array}{l}\text { "My only suggestion would } \\
\text { be to have more } \\
\text { participatory activities." }\end{array}$ \\
\hline & in course & $\begin{array}{l}\text { "It was a very influential } \\
\text { class." }\end{array}$ \\
\hline & $\begin{array}{l}\text { suggestions as to how to apply } \\
\text { what was learned to make } \\
\text { boundaries between/among } \\
\text { cultures smaller }\end{array}$ & $\begin{array}{l}\text { "This course is important for } \\
\text { all students interested in } \\
\text { working with diverse } \\
\text { populations." }\end{array}$ \\
\hline & & $\begin{array}{l}\text { "I suggest including more } \\
\text { activities that will force } \\
\text { students to confront and } \\
\text { attempt to conquer their } \\
\text { personal demons regarding } \\
\text { views on race or creed." }\end{array}$ \\
\hline & & $\begin{array}{l}\text { "People outside the clinical } \\
\text { field could gain greatly from } \\
\text { such a course." }\end{array}$ \\
\hline
\end{tabular}




\begin{tabular}{|c|c|c|}
\hline \multicolumn{3}{|l|}{ Table 12 continued } \\
\hline & & $\begin{array}{l}\text { "I feel that the course is } \\
\text { incredibly important for the } \\
\text { development of clinical } \\
\text { skills." }\end{array}$ \\
\hline 4. Not relevant & $\begin{array}{l}\text { response provided did not seem } \\
\text { to answer question asked }\end{array}$ & \\
\hline $\begin{array}{l}\text { 5. Improvement/Life } \\
\text { Application }\end{array}$ & $\begin{array}{l}\text { class made an improvement in } \\
\text { how they react to and interact with } \\
\text { culturally different people }\end{array}$ & $\begin{array}{l}\text { "Step out of our cozy } \\
\text { boundaries and embrace } \\
\text { diversity." }\end{array}$ \\
\hline
\end{tabular}

In response to this question, many students again returned to themes of awareness and the importance of it in their development, both personally and with respect to clinical skills. For some, the most salient aspect of the course experiences was the opportunity to "step out of cozy boundaries" and confront difficult aspects of their own views. One person felt the course should do even more in "forcing students to confront and attempt to conquer their personal demons regarding views on race or creed."

Many also connected their gains from the class to expectations for future growth, indicating that in addition to learning course content, they now had tools to keep on directing their own learning. For example, one student noted, "I believe this course opened my eyes and mind to differences and gave me tools to facilitate development of my sensitivity to them." Some mentioned specifically that they now had tools for effecting transformative action: "I feel like I am a more integrated and empowered person that can contribute to my community and profession in a positive and important way." In conclusion, the Conceptual Coding phase of the analyses highlighted students' perspectives on their gains from the course. These categories of gains were essentially 
parallel to common curricular aims for diversity courses in terms of increased awareness, knowledge, and skills. They were also more nuanced, and illustrate, for example, how students perceived gains that blended multiple aspects of competence, or applied them in a very personal way. Finally, the results of the Conceptual Coding phase provided detailed information on how diverse students enrolled in a Transformative Diversity Training course responded to the counseling profession's call for greater cultural competence and readiness for social action. 


\section{Theoretical Coding}

For the second phase of coding the data was coded according to the theoretical coders consensual understanding of the particular theoretical perspective that they exemplify. For this study this included the conceptual framework used to design the TDT course, both the "multicultural competencies" of awareness, knowledge, and skills, and the "transformative competencies" of empowerment and becoming a transformative stakeholder. The later category was divided to include both (a) local, community involvement, and (b) professional involvement. The two theoretical coders independently coded the data and then compared their results. The overall agreement across all categories was $88.1 \%$, providing strong evidence for concurrence across types of coders. Items involving disagreement were discussed until a consensus was reached.

Tables 13 through 19 present the results of the theoretical coding for all questions across pre-test, post-test, and one year follow-up. The questions for which the responses were given are noted at the bottom of the table. As can be seen, students' characterizations of their own growth provided articulate and nuanced examples of all categories, although some questions "pulled" for answers in certain types of categories. Nevertheless, it is noteworthy that while questions requesting students to evaluate the impact of classroom participatory experiences on their multicultural competencies of awareness, knowledge and skills resulted largely in responses in each of those categories, empowerment was a theme for some, in response to all questions. Additionally, questions requesting students' analysis of the impact of their transformative project elicited responses across all categories, thus illustrating the value of a "social action" component in diversity training for enhancing multicultural competencies overall. 
Table 13.

Theoretical Coding of Student Hopes for Change at Pre-Test

\begin{tabular}{|c|c|c|c|c|c|}
\hline \multicolumn{3}{|c|}{$\begin{array}{c}\text { COUNSELOR } \\
\text { DEVELOPMENT }\end{array}$} & $\begin{array}{l}\text { EMPOWER- } \\
\text { MENT }\end{array}$ & \multicolumn{2}{|c|}{$\begin{array}{c}\text { BECOMING A } \\
\text { TRANSFORMATIVE } \\
\text { STAKEHOLDER }\end{array}$} \\
\hline Awareness & Knowledge & Skills & & $\begin{array}{c}\text { Community } \\
\text { (Local; Global) }\end{array}$ & Profession \\
\hline $\begin{array}{l}\text { Better } \\
\text { understand } \\
\text { how and } \\
\text { why I view } \\
\text { others } \\
\text { different } \\
\text { from me- } \\
\text { am I } \\
\text { treating/ } \\
\text { responding } \\
\text { to } \\
\text { stereotypes } \\
\text { as opposed } \\
\text { to } \\
\text { individuals? }\end{array}$ & $\begin{array}{l}\text { Learn more } \\
\text { about cultural } \\
\text { diversity } \\
\text { issues such as } \\
\text { values and } \\
\text { customs }\end{array}$ & $\begin{array}{l}\text { Learn ways } \\
\text { to } \\
\text { effectively } \\
\text { treat clients } \\
\text { of other } \\
\text { cultures. }\end{array}$ & $\begin{array}{l}\text { I seek a } \\
\text { transformation } \\
\text { of myself both } \\
\text { inside and out, } \\
\text { I want to be } \\
\text { involved in } \\
\text { proactive } \\
\text { efforts both } \\
\text { within and } \\
\text { outside. }\end{array}$ & $\begin{array}{l}\text { Draw upon my own } \\
\text { experiences to } \\
\text { make the world a } \\
\text { more peaceful } \\
\text { place. }\end{array}$ & $\begin{array}{l}\text { Learn } \\
\text { strategies to } \\
\text { help make } \\
\text { diversity in the } \\
\text { workplace a } \\
\text { positive thing. }\end{array}$ \\
\hline $\begin{array}{l}\text { Help me } \\
\text { expose my } \\
\text { stereotypes. }\end{array}$ & $\begin{array}{l}\text { Get insight } \\
\text { into what to } \\
\text { expect when I } \\
\text { get out into the } \\
\text { work-place. }\end{array}$ & $\begin{array}{l}\text { Recognize } \\
\text { when a } \\
\text { difference } \\
\text { is too much } \\
\text { for me to } \\
\text { work } \\
\text { effectively. }\end{array}$ & $\begin{array}{l}\text { I want to make } \\
\text { this an } \\
\text { opportunity to } \\
\text { mature as a } \\
\text { person. }\end{array}$ & $\begin{array}{l}\text { Learn things I can } \\
\text { do in everyday life } \\
\text { to bring about } \\
\text { change. }\end{array}$ & $\begin{array}{l}\text { Learn what } \\
\text { research areas } \\
\text { are being } \\
\text { pursued, as } \\
\text { well as not } \\
\text { being pursued, } \\
\text { within } \\
\text { diversity } \\
\text { research. }\end{array}$ \\
\hline $\begin{array}{l}\text { Become } \\
\text { more aware } \\
\text { of my own } \\
\text { weaknesses } \\
\text { and how to } \\
\text { overcome }\end{array}$ & $\begin{array}{l}\text { Learn better } \\
\text { ways to } \\
\text { incorporate } \\
\text { diversity into } \\
\text { treatment } \\
\text { plans. }\end{array}$ & & & & \\
\hline $\mathrm{n}=15$ & $\begin{array}{l}\text { Learn how my } \\
\text { clients' past } \\
\text { experiences } \\
\text { shape their } \\
\text { reality. } \\
\quad \mathrm{n}=6\end{array}$ & $\mathrm{n}=9$ & $\mathrm{n}=2$ & $\mathrm{n}=2$ & $\mathrm{n}=2$ \\
\hline
\end{tabular}

Note: Data was missing for five students. Students responded to this question: "In what ways would you like to be different (personally, professionally, etc.) by the time we complete this course?" 
Table 14.

Theoretical Coding of Student Self-Perceptions of Change at Post-Test

\begin{tabular}{|c|c|c|c|}
\hline \multicolumn{2}{|c|}{$\begin{array}{c}\text { COUNSELOR } \\
\text { DEVELOPMENT }\end{array}$} & \multirow[t]{2}{*}{$\begin{array}{l}\text { EMPOWER- } \\
\text { MENT } \\
\end{array}$} & \multirow{2}{*}{$\begin{array}{c}\begin{array}{c}\text { TRANSFORMATIVE } \\
\text { STAKEHOLDER }\end{array} \\
\begin{array}{c}\text { Community } \\
\text { (Local; Global) }\end{array} \\
\end{array}$} \\
\hline Awareness & Knowledge & & \\
\hline $\begin{array}{l}\text { "The family } \\
\text { genogram was very } \\
\text { helpful to me in } \\
\text { finding out about } \\
\text { where my family } \\
\text { came from and } \\
\text { what influences } \\
\text { they have had on } \\
\text { me." }\end{array}$ & $\begin{array}{l}\text { "I learned about the } \\
\text { utility and sensitivity } \\
\text { of technical and } \\
\text { theoretical } \\
\text { eclecticism when } \\
\text { dealing with } \\
\text { culturally different } \\
\text { clients." }\end{array}$ & $\begin{array}{l}\text { "I didn't put } \\
\text { empowerment on my } \\
\text { goal list, yet that's } \\
\text { probably where I've } \\
\text { made the most } \\
\text { progress." }\end{array}$ & $\begin{array}{l}\text { "I really desire to work on } \\
\text { being tolerant and promoting } \\
\text { tolerance." }\end{array}$ \\
\hline $\begin{array}{l}\text { "Became more } \\
\text { aware of 'other' } \\
\text { culture social } \\
\text { issues." }\end{array}$ & $\begin{array}{l}\text { "Learned more about } \\
\text { people from different } \\
\text { countries and } \\
\text { cultures." }\end{array}$ & $\begin{array}{l}\text { "I am on my way to } \\
\text { thinking less ethno- } \\
\text { centrically than before." }\end{array}$ & $\begin{array}{l}\text { "I am now more aware and } \\
\text { look forward to being able to } \\
\text { facilitate changes within } \\
\text { institutions." }\end{array}$ \\
\hline $\begin{array}{l}\text { "I've become more } \\
\text { aware of my beliefs } \\
\text { and views and how } \\
\text { they can affect the } \\
\text { way I treat and } \\
\text { view others." }\end{array}$ & $\begin{array}{l}\text { "Awareness of the } \\
\text { importance } \\
\text { multicultural } \\
\text { awareness has in the } \\
\text { practitioner/ client } \\
\text { relationship." }\end{array}$ & $\begin{array}{l}\text { "Increasing my self- } \\
\text { awareness and change, } \\
\text { in daily life, has been } \\
\text { achieved and is } \\
\text { significant." }\end{array}$ & \\
\hline $\begin{array}{l}\text { "I am more aware } \\
\text { of automatic } \\
\text { feelings and } \\
\text { thoughts." }\end{array}$ & $\begin{array}{l}\text { "I have come to } \\
\text { realize that factors } \\
\text { that led to diversity } \\
\text { within the US are } \\
\text { complex." }\end{array}$ & $\begin{array}{l}\text { "I ...realize how much I } \\
\text { have changed towards } \\
\text { 'different' people." }\end{array}$ & \\
\hline $\begin{array}{l}\text { "Although I was } \\
\text { able to } \\
\text { acknowledge and } \\
\text { admit my biases } \\
\text { toward very } \\
\text { religious people, I } \\
\text { cannot say I } \\
\text { conquered my } \\
\text { bias." }\end{array}$ & & $\begin{array}{l}\text { "I've become very } \\
\text { quick at catching } \\
\text { myself, either making } \\
\text { awful comments or just } \\
\text { thinking a certain way." }\end{array}$ & \\
\hline $\begin{array}{l}\text { "I am more aware } \\
\text { of others' } \\
\text { differences." }\end{array}$ & & $\begin{array}{l}\text { "My awareness will } \\
\text { continue to develop } \\
\text { throughout my life and } \\
\text { impact my personal and } \\
\text { professional growth." }\end{array}$ & \\
\hline
\end{tabular}


"I feel more aware of my biases."
"This class has conquered a huge issue with me, and I did not think it could."

\begin{tabular}{|c|c|c|}
\hline $\begin{array}{l}\text { "I had been } \\
\text { denying to myself } \\
\text { how much } \\
\text { discrimination I } \\
\text { have internalized } \\
\text { over my lifetime. } \\
\text { " }\end{array}$ & & $\begin{array}{l}\text { "This course pushed me } \\
\text { out of my comfort } \\
\text { zone." }\end{array}$ \\
\hline $\begin{array}{l}\text { "I'm much more } \\
\text { aware of my own } \\
\text { cultural } \\
\text { background and } \\
\text { experiences." }\end{array}$ & & $\begin{array}{l}\text { "This class has } \\
\text { challenged me to step } \\
\text { up to the plate each and } \\
\text { ever day and to realize } \\
\text { that being culturally } \\
\text { sensitive is a daily } \\
\text { decision." }\end{array}$ \\
\hline $\begin{array}{l}\text { "Acknowledging } \\
\text { my own racist } \\
\text { attitudes and } \\
\text { beliefs." }\end{array}$ & & $\begin{array}{l}\text { "I've learned a new } \\
\text { way to appreciate and } \\
\text { respect "other' } \\
\text { cultures." }\end{array}$ \\
\hline $\begin{array}{l}\text { "I have come to a } \\
\text { greater } \\
\text { understanding of } \\
\text { my privileges." }\end{array}$ & & $\begin{array}{l}\text { "I have sought out a } \\
\text { non-racist identity." }\end{array}$ \\
\hline $\begin{array}{l}\text { "Allowed me } \\
\text { greater awareness } \\
\text { of those around } \\
\text { me." }\end{array}$ & & \\
\hline $\mathrm{n}=13$ & $\mathrm{n}=4$ & $\mathrm{n}=11$ \\
\hline
\end{tabular}

Note: Students responded to the question: "At the beginning of the course you answered the following question: [pretest question]. In general, how are you different now? Compare these differences to the goals you had at the beginning of the course." 
Table 15.

Theoretical Coding of Student Self-Perceptions of Change in Multicultural Competencies

at Post-Test

\begin{tabular}{|c|c|c|c|}
\hline & $\begin{array}{c}\text { COUNSELOR } \\
\text { DEVELOPMENT }\end{array}$ & & EMPOWERMENT \\
\hline Awareness & Knowledge & Skills & Personal Growth \\
\hline $\begin{array}{l}\text { "I have improved in } \\
\text { being more aware of } \\
\text { my own culture, my } \\
\text { cultural experiences } \\
\text { and background." } \\
\text { "This course gave me } \\
\text { a love for my culture." }\end{array}$ & $\begin{array}{l}\text { "I made significant } \\
\text { progress in gaining } \\
\text { knowledge about my } \\
\text { own culture." }\end{array}$ & $\begin{array}{l}\text { "I am working on } \\
\text { acquiring more } \\
\text { intervention skills." }\end{array}$ & $\begin{array}{l}\text { "I will keep working on } \\
\text { getting past my own } \\
\text { discomfort concerning } \\
\text { lifestyles with which I } \\
\text { strongly disagree." }\end{array}$ \\
\hline $\begin{array}{l}\text { "I thought I was } \\
\text { fairly enlightened } \\
\text { before this course, but } \\
\text { I quickly became } \\
\text { aware of how } \\
\text { prejudiced and biased } \\
\text { I was toward others." }\end{array}$ & $\begin{array}{l}\text { "I want to continue } \\
\text { familiarizing myself } \\
\text { with research and other } \\
\text { findings regarding } \\
\text { mental health and } \\
\text { mental disorders of } \\
\text { various ethnic and } \\
\text { racial groups." }\end{array}$ & $\begin{array}{l}\text { "I am better at } \\
\text { assessment of 'other' } \\
\text { clients, but still want to } \\
\text { improve." }\end{array}$ & $\begin{array}{l}\text { "I want to keep } \\
\text { working on any biases } \\
\text { and prejudices that I } \\
\text { find I have." }\end{array}$ \\
\hline $\begin{array}{l}\text { "I learned how to feel } \\
\text { comfortable with } \\
\text { some very different } \\
\text { beliefs and values." }\end{array}$ & $\begin{array}{l}\text { "I want to further } \\
\text { educate myself with } \\
\text { respect to specific } \\
\text { culture and historical } \\
\text { contexts of ethnicity." }\end{array}$ & & $\begin{array}{l}\text { "I think outside the } \\
\text { box." }\end{array}$ \\
\hline \multicolumn{4}{|l|}{$\begin{array}{l}\text { "I take a less } \\
\text { judgmental stance." }\end{array}$} \\
\hline $\begin{array}{l}\text { "I have become more } \\
\text { aware of my } \\
\text { heritage's stereotypes } \\
\text { and attitudes toward } \\
\text { certain people." }\end{array}$ & $\begin{array}{l}\text { "I have begun to } \\
\text { understand that there } \\
\text { are experiences about } \\
\text { being African } \\
\text { American that are } \\
\text { unique from most } \\
\text { groups." }\end{array}$ & & $\begin{array}{l}\text { "I no longer feel that } \\
\text { hate in the pit of my } \\
\text { stomach." }\end{array}$ \\
\hline $\begin{array}{l}\text { "I have become more } \\
\text { aware of subtle biases } \\
\text { around me." }\end{array}$ & $\begin{array}{l}\text { "I was exposed to ways } \\
\text { in which specific } \\
\text { cultures can be } \\
\text { addressed and issues } \\
\text { that relate to them." }\end{array}$ & & \\
\hline \multicolumn{4}{|l|}{$\begin{array}{l}\text { "I recognize the limits } \\
\text { of my competencies } \\
\text { and expertise." }\end{array}$} \\
\hline $\mathrm{N}=13$ & $\mathrm{~N}=9$ & $\mathrm{~N}=4$ & $N=6$ \\
\hline
\end{tabular}


Note: Question asked: "Evaluate our own progress in the following areas: (a) awareness of culturally-related aspects of self or of social contexts, (b) knowledge of culturally different groups or professional issues, and (c) skills for working with populations different from you, or for transforming structures/institutions." No student responses were classified in the two categories of "Becoming a Transformative Stakeholder." 
Table 16.

Theoretical Coding of Students' Self-Appraisals of Change in Multicultural

Competencies at 1-Year Follow-up

\begin{tabular}{|c|c|c|c|}
\hline & $\begin{array}{c}\text { COUNSELOR } \\
\text { DEVELOPMENT }\end{array}$ & & EMPOWERMENT \\
\hline Awareness & Knowledge & Skills & \\
\hline $\begin{array}{l}\text { "I am more aware of } \\
\text { cultural differences." }\end{array}$ & $\begin{array}{l}\text { "I see that culture has } \\
\text { an impact on the } \\
\text { diagnosis and } \\
\text { treatment of my } \\
\text { clients." }\end{array}$ & $\begin{array}{l}\text { "While interviewing } \\
\text { clients I am better able } \\
\text { to probe to determine } \\
\text { what their experiences } \\
\text { mean to them." }\end{array}$ & $\begin{array}{l}\text { "I take a firmer stance for } \\
\text { what I believe in...the shift } \\
\text { gives me confidence to } \\
\text { express my beliefs to others, } \\
\text { which was a daunting task } \\
\text { in the past." }\end{array}$ \\
\hline $\begin{array}{l}\text { "Being sensitive to } \\
\text { others' differences; } \\
\text { allowing them to } \\
\text { educate you on their } \\
\text { unique differences." }\end{array}$ & $\begin{array}{l}\text { "I'm better able to } \\
\text { recognize cultural } \\
\text { competence and } \\
\text { sensitivity ... and see } \\
\text { how much it can affect } \\
\text { the therapeutic } \\
\text { process." }\end{array}$ & $\begin{array}{l}\text { "I am much more are } \\
\text { of how culture shapes } \\
\text { cognition and behavior } \\
\text { and I'm better at being } \\
\text { able to differentiate } \\
\text { between pathology and } \\
\text { customs." }\end{array}$ & $\begin{array}{l}\text { "Increased my openness to } \\
\text { discussing prejudice...I seek } \\
\text { out advice from others about } \\
\text { how to handle situations...it } \\
\text { is the seeking out that I } \\
\text { would not have done prior } \\
\text { to this class." }\end{array}$ \\
\hline $\begin{array}{l}\text { "I am more attuned } \\
\text { to "others' } \\
\text { reactivity." }\end{array}$ & $\begin{array}{l}\text { "Opened my eyes to } \\
\text { the narrowness of } \\
\text { published [treatment] } \\
\text { studies; how } \\
\text { minorities have been } \\
\text { left out of RCTs." }\end{array}$ & $\begin{array}{l}\text { "I now actively try to } \\
\text { understand the client's } \\
\text { background. I find this } \\
\text { enhances rapport and } \\
\text { puts the clients more at } \\
\text { ease." }\end{array}$ & \\
\hline $\begin{array}{l}\text { "I am more aware of } \\
\text { different groups of } \\
\text { people." "My } \\
\text { openness has } \\
\text { increased." } \\
\text { "What changed was } \\
\text { my short- } \\
\text { sightedness." }\end{array}$ & $\begin{array}{l}\text { "I gained a deeper } \\
\text { insight into how } \\
\text { societal structures and } \\
\text { institution create } \\
\text { 'power' and } \\
\text { 'privilege' to } \\
\text { understand these } \\
\text { issues is to understand } \\
\text { society." }\end{array}$ & & \\
\hline \multicolumn{4}{|l|}{$\begin{array}{l}\text { "Increased awareness } \\
\text { into cultural } \\
\text { differences and the } \\
\text { experiences of others. } \\
\text { " }\end{array}$} \\
\hline $\mathrm{N}=13$ & $\mathrm{~N}=4$ & $\mathrm{~N}=3$ & $\mathrm{~N}=2$ \\
\hline
\end{tabular}

Note: One student said that there had been no change. Question stated: "Describe what, if any, change in your multicultural competence (i.e., awareness, knowledge, and skills) resulted from the class, and describe the meaning and significance of that change." 
Table 17.

Theoretical Coding Students' Self-Appraisals of Impact on Professional Services at 1-

Year Follow-up

\begin{tabular}{|c|c|c|c|c|}
\hline \multicolumn{3}{|c|}{$\begin{array}{c}\text { COUNSELOR } \\
\text { DEVELOPMENT }\end{array}$} & $\begin{array}{l}\text { EMPOWER- } \\
\text { MENT }\end{array}$ & $\begin{array}{l}\text { TRANFORMATIVE } \\
\text { STAKEHOLDER }\end{array}$ \\
\hline $\begin{array}{c}\text { Awarenes } \\
\text { s }\end{array}$ & Knowledge & Skills & & Profession \\
\hline $\begin{array}{l}\text { "I've } \\
\text { become } \\
\text { more } \\
\text { comfortable } \\
\text { with others' } \\
\text { differences." }\end{array}$ & $\begin{array}{l}\text { "I am learning to } \\
\text { incorporate a } \\
\text { more eclectic } \\
\text { cultural } \\
\text { approach." }\end{array}$ & $\begin{array}{l}\text { "I work with } \\
\text { clients in a more } \\
\text { sensitive manner." }\end{array}$ & $\begin{array}{l}\text { "I feel more } \\
\text { confident in my } \\
\text { competence to } \\
\text { serve my clients } \\
\text { in a multicultural } \\
\text { setting." }\end{array}$ & $\begin{array}{l}\text { "I have gone on to teach } \\
\text { courses dealing with the } \\
\text { issues of diversity." }\end{array}$ \\
\hline $\begin{array}{l}\text { "Made me } \\
\text { aware of } \\
\text { values and } \\
\text { scripts of } \\
\text { their culture } \\
\text { that every } \\
\text { client } \\
\text { brings." }\end{array}$ & $\begin{array}{l}\text { "I am more } \\
\text { conscious of the } \\
\text { complexity in } \\
\text { treatment } \\
\text { regarding cultural } \\
\text { differences." }\end{array}$ & $\begin{array}{l}\text { "I try to step into } \\
\text { my clients' shoes." } \\
\text { "Allows me to be } \\
\text { more empathic." }\end{array}$ & $\begin{array}{l}\text { "The quality of } \\
\text { my professional } \\
\text { activities has } \\
\text { definitely } \\
\text { benefited from } \\
\text { my increased } \\
\text { cultural } \\
\text { awareness." }\end{array}$ & $\begin{array}{l}\text { "I strive to incorporate the } \\
\text { lessons I've learned into } \\
\text { my career-how I interact } \\
\text { with colleagues and } \\
\text { students, the research } \\
\text { topics I choose." }\end{array}$ \\
\hline $\begin{array}{l}\text { "Conscious } \\
\text { efforts to } \\
\text { maintain a } \\
\text { more open- } \\
\text { minded } \\
\text { approach to } \\
\text { things." }\end{array}$ & $\begin{array}{l}\text { "I am more aware } \\
\text { of the narrowness } \\
\text { of past research } \\
\text { and problems } \\
\text { with the } \\
\text { assessments } \\
\text { utilized." }\end{array}$ & $\begin{array}{l}\text { "I recognize the } \\
\text { extent to which } \\
\text { perspectives can } \\
\text { differ culturally, } \\
\text { and I take more } \\
\text { care to actively } \\
\text { discuss such } \\
\text { issues." }\end{array}$ & $\begin{array}{l}\text { "This awareness } \\
\text { will have a great } \\
\text { impact on the } \\
\text { quality of my } \\
\text { professional } \\
\text { services to } \\
\text { clients, etc." }\end{array}$ & \\
\hline $\begin{array}{l}\text { "I convey } \\
\text { acceptance } \\
\text { and my } \\
\text { clients feel } \\
\text { more com- } \\
\text { fortable } \\
\text { because I'm } \\
\text { not stereo- } \\
\text { typing them. } \\
\text { "I } \\
\text { understand } \\
\text { where the } \\
\text { client is } \\
\text { coming } \\
\text { from." }\end{array}$ & $\begin{array}{l}\text { "I'm more aware } \\
\text { of the lack of } \\
\text { multicultural } \\
\text { knowledge in the } \\
\text { literature." }\end{array}$ & $\begin{array}{l}\text { "I am more } \\
\text { understanding, } \\
\text { non-judgmental, } \\
\text { and objective } \\
\text { when my clients } \\
\text { speak about their } \\
\text { life concerns." }\end{array}$ & $\begin{array}{l}\text { "The knowledge } \\
\text { I acquired will } \\
\text { have an impact, } \\
\text { but I have not yet } \\
\text { had an oppor- } \\
\text { tunity to work } \\
\text { with new groups } \\
\text { of people." }\end{array}$ & \\
\hline$N=11$ & $\mathrm{~N}=5$ & $\mathrm{~N}=7$ & $\mathrm{~N}=4$ & $\mathrm{~N}=2$ \\
\hline
\end{tabular}


Note: Two students said that there had been no change. Question stated: "Describe what, if any, impact the changes in your multicultural awareness knowledge, and skills have had on the quality of your professional services/activities in a multicultural context." 
Table 18.

Theoretical Coding Students' Self-Appraisals of Change in Involvement in Community/

\section{Profession at 1-Year Follow-up}

\begin{tabular}{|c|c|c|c|c|}
\hline \multicolumn{2}{|c|}{$\begin{array}{c}\text { COUNSELOR } \\
\text { DEVELOPMENT }\end{array}$} & \multirow[t]{2}{*}{$\begin{array}{l}\text { EMPOWER- } \\
\text { MENT }\end{array}$} & \multicolumn{2}{|c|}{$\begin{array}{l}\text { BECOMING A TRANSFORMATIVE } \\
\text { STAKEHOLDER }\end{array}$} \\
\hline Awareness & Knowledge & & $\begin{array}{c}\text { Community } \\
\text { (Local; Global) }\end{array}$ & Profession \\
\hline \multirow[t]{5}{*}{$\begin{array}{l}\text { I now know } \\
\text { to be more } \\
\text { attuned to } \\
\text { others' indi- } \\
\text { viduality, and } \\
\text { paradoxically, } \\
\text { those } \\
\text { characteristics } \\
\text { that bond } \\
\text { them to their } \\
\text { culture and } \\
\text { ethnicity." }\end{array}$} & $\begin{array}{l}\text { "I have a clearer } \\
\text { understanding of } \\
\text { the needs and } \\
\text { experiences of } \\
\text { others in our } \\
\text { community." }\end{array}$ & $\begin{array}{l}\text { "I used to feel } \\
\text { much more passive } \\
\text { and helpless in } \\
\text { changing things } \\
\text { around me...I now } \\
\text { feel more educated } \\
\text { and empowered to } \\
\text { contribute in the } \\
\text { small ways that I } \\
\text { can." }\end{array}$ & $\begin{array}{l}\text { "My awareness of the } \\
\text { hardships of living as an } \\
\text { immigrant was heightened, } \\
\text { so I did volunteer work for a } \\
\text { non-profit organization in } \\
\text { our community for which my } \\
\text { bilingual skill was of use." }\end{array}$ & $\begin{array}{l}\text { "There has been a huge } \\
\text { impact on my research } \\
\text { interests and activities } \\
\text {... am more interested } \\
\text { in discovering cultural } \\
\text { and racial differences } \\
\text { and how they impact } \\
\text { the generalizability of } \\
\text { research findings." }\end{array}$ \\
\hline & $\begin{array}{l}\text { "I now search } \\
\text { out talks, } \\
\text { performances, } \\
\text { etc., that } \\
\text { highlight } \\
\text { different cultural } \\
\text { histories and } \\
\text { lives." }\end{array}$ & $\begin{array}{l}\text { "The experience } \\
\text { has forever } \\
\text { changed my } \\
\text { thoughts about my } \\
\text { potential impact in } \\
\text { the mental health } \\
\text { field." }\end{array}$ & $\begin{array}{l}\text { "I have become more } \\
\text { involved with organizations } \\
\text { that try to bring awareness to } \\
\text { gay and women's issues. I } \\
\text { feel much more engaged } \\
\text { with my community." }\end{array}$ & $\begin{array}{l}\text { "I am more likely to } \\
\text { involve myself in } \\
\text { cultural education." } \\
\text { "In the classroom, I } \\
\text { encourage students to } \\
\text { relate and discuss } \\
\text { experiences about their } \\
\text { ethnicity or culture." }\end{array}$ \\
\hline & & $\begin{array}{l}\text { "I have more } \\
\text { interest and desire } \\
\text { to help improve } \\
\text { "others' lives." }\end{array}$ & $\begin{array}{l}\text { "Because I learned what is } \\
\text { happening in the community } \\
\text { with 'real' people, I decided } \\
\text { not to pursue a private } \\
\text { practice with largely high } \\
\text { functioning individuals." }\end{array}$ & $\begin{array}{l}\text { "I have frequently } \\
\text { attended seminars and } \\
\text { workshops on diversity } \\
\text { issues-for example, } \\
\text { how to incorporate } \\
\text { them into all of our } \\
\text { classes." }\end{array}$ \\
\hline & & & $\begin{array}{l}\text { "I keep informed about how } \\
\text { political and global issues } \\
\text { impact minority groups, and } \\
\text { take action in whatever way } \\
\text { possible." }\end{array}$ & $\begin{array}{l}\text { "I want to make an } \\
\text { impact on behalf of the } \\
\text { underserved women of } \\
\text { the world." }\end{array}$ \\
\hline & & & $\begin{array}{l}\text { "I influenced a community to } \\
\text { unite and come together to } \\
\text { save a program in the } \\
\text { organization." }\end{array}$ & \\
\hline $\mathrm{N}=1$ & $\mathrm{~N}=2$ & $\mathrm{~N}=3$ & $N=5$ & $\mathrm{~N}=7$ \\
\hline
\end{tabular}

Note: Seven students said that there had been no change or they currently had no professional involvement; one student was unsure if any change resulted from the class. Question stated: "Describe what, if any, change in your involvement in the community (local or global) and/or in the profession (e.g., affiliations with professional groups, conferences, etc.) resulted from the class, and describe the meaning and significance of that change." 
Table 19.

Theoretical Coding of Students' Self-Appraisals of Change in Quality of Services

Resulting from Involvement in Community/ Profession at 1-Year Follow-up

\begin{tabular}{|c|c|c|c|c|c|}
\hline \multicolumn{3}{|c|}{$\begin{array}{c}\text { COUNSELOR } \\
\text { DEVELOPMENT }\end{array}$} & \multirow[t]{2}{*}{$\begin{array}{l}\text { EMPOWER- } \\
\text { MENT }\end{array}$} & \multicolumn{2}{|c|}{$\begin{array}{c}\text { BECOMING A } \\
\text { TRANSFORMATIVE } \\
\text { STAKEHOLDER } \\
\end{array}$} \\
\hline Awareness & Knowledge & Skills & & $\begin{array}{c}\text { Community } \\
\text { (Local; Global) }\end{array}$ & Profession \\
\hline $\begin{array}{l}\text { "I have } \\
\text { become aware } \\
\text { of various } \\
\text { kinds of } \\
\text { people...dis- } \\
\text { crimination } \\
\text { isn't just a } \\
\text { white person } \\
\text { mistreating an } \\
\text { African } \\
\text { American." }\end{array}$ & $\begin{array}{l}\text { "I learned that } \\
\text { although } \\
\text { services [for a } \\
\text { certain group] } \\
\text { are available, } \\
\text { only a small } \\
\text { percentage can } \\
\text { actually benefit } \\
\text { from them." }\end{array}$ & $\begin{array}{l}\text { "I am a lot } \\
\text { more cautious } \\
\text { in drawing } \\
\text { conclusions } \\
\text { about my } \\
\text { clients and } \\
\text { their } \\
\text { families/ } \\
\text { situations." }\end{array}$ & $\begin{array}{l}\text { "I feel motivated } \\
\text { to empower clients } \\
\text { who are directly } \\
\text { being affected by } \\
\text { these issues." }\end{array}$ & $\begin{array}{l}\text { "I continue to be } \\
\text { involved with } \\
\text { organizations that are } \\
\text { trying to instigate } \\
\text { change in our } \\
\text { communities." }\end{array}$ & $\begin{array}{l}\text { "I will be } \\
\text { more } \\
\text { sensitive not } \\
\text { only in the } \\
\text { way I interact } \\
\text { with clients, } \\
\text { but in the } \\
\text { manner I } \\
\text { conduct } \\
\text { research." }\end{array}$ \\
\hline $\begin{array}{l}\text { "I am less } \\
\text { likely to make } \\
\text { assumptions; } \\
\text { my awareness } \\
\text { allows me to } \\
\text { 'see' } \\
\text { situations } \\
\text { others may } \\
\text { not." }\end{array}$ & $\begin{array}{l}\text { "I now } \\
\text { understand the } \\
\text { narrowness of } \\
\text { certain earlier } \\
\text { research and the } \\
\text { tools it used." }\end{array}$ & $\begin{array}{l}\text { "I ask more } \\
\text { questions and } \\
\text { listen more } \\
\text { carefully for } \\
\text { the meaning } \\
\text { of their } \\
\text { experiences." }\end{array}$ & $\begin{array}{l}\text { "Has helped me } \\
\text { interpersonally, } \\
\text { increased my } \\
\text { confidence and my } \\
\text { ability to network } \\
\text { with "other" } \\
\text { professionals." }\end{array}$ & $\begin{array}{l}\text { "Most of the impact } \\
\text { due to this change is } \\
\text { yet to come, but I } \\
\text { expect to work in a } \\
\text { variety of settings, } \\
\text { some of which will } \\
\text { involve care of the } \\
\text { neediest." }\end{array}$ & $\begin{array}{l}\text { "I feel more } \\
\text { of a } \\
\text { responsibility } \\
\text { to ensure that } \\
\text { my } \\
\text { professional } \\
\text { services } \\
\text { coincide with } \\
\text { my cultural } \\
\text { awareness." }\end{array}$ \\
\hline \multirow[t]{2}{*}{$\begin{array}{l}\text { "The trans- } \\
\text { formative } \\
\text { experience } \\
\text { broadened my } \\
\text { scope of } \\
\text { multi- } \\
\text { culturalism." }\end{array}$} & $\begin{array}{l}\text { "My } \\
\text { involvement } \\
\text { made me more } \\
\text { knowledgeable } \\
\text { about } \\
\text { international } \\
\text { issues." }\end{array}$ & $\begin{array}{l}\text { "I am better } \\
\text { able to } \\
\text { provide } \\
\text { services." }\end{array}$ & $\begin{array}{l}\text { "I can pass on my } \\
\text { sense of } \\
\text { empowerment to } \\
\text { my clients." }\end{array}$ & & \\
\hline & & $\begin{array}{l}\text { "I am more } \\
\text { sensitive.... } \\
\text { less likely to } \\
\text { make } \\
\text { assumptions } \\
\text { about the } \\
\text { meaning of a } \\
\text { downward } \\
\text { gaze." }\end{array}$ & & & \\
\hline$N=3$ & $N=3$ & $N=6$ & $N=3$ & $N=2$ & $\mathrm{~N}=2$ \\
\hline
\end{tabular}

Note: Of those students responding to the question, five said the question was not applicable to them. Question stated: "Describe what, if any, impact the change in your involvement in the community and/or in the profession has had on the quality of your services in a multicultural context." 
For the Research Analysis portion of the RDA, participants' pattern of responses across the Theoretical Coding Categories was analyzed. This was accomplished by calculating the percentage of responses across all questions that fell into each of the theoretical categories: Awareness, Knowledge, Skills, Empowerment, and Becoming a Transformative Stakeholder (both global/community and professional). Chi square analyses revealed that the pattern of responses across time was significantly different than would be expected by chance. As can be seen in the Table, the largest percentages of responses at all three times of assessment fell into the Awareness category. However, fewer than $1 \%$ had a goal of empowerment at pretest, whereas $27 \%$ of the responses were empowerment responses at post-test. At pretest, $25 \%$ expressed hopes for increased skills; at post-test only $1 \%$ thought skills were their most important gain, whereas $19 \%$ did at one-year follow-up. Finally, about $1 \%$ of the students had transformative goals at pretest and about the same percentage felt they had realized transformative goals at posttest. However, at the one-year follow-up, $17 \%$ of students identified transformative changes as the most salient result of the class. 
Table. 20

Percent of Responses in Each Category at Each Time of Assessment

\begin{tabular}{|c|c|c|c|c|c|c|c|c|c|c|}
\hline & \multicolumn{2}{|c|}{ Awareness } & \multicolumn{2}{|c|}{ Knowledge } & \multicolumn{2}{|c|}{ Skills } & \multicolumn{2}{|c|}{ Empowerment } & \multicolumn{2}{|c|}{ Transformative } \\
\hline & $\%$ & (n) & $\%$ & (n) & $\%$ & (n) & $\%$ & (n) & $\%$ & (n) \\
\hline Pretest & 42 & (15) & 17 & (6) & 25 & (9) & $>1$ & (2) & 1 & (4) \\
\hline Post-Test & 42 & (26) & 19 & (12) & 1 & (4) & 27 & (17) & $>1$ & (3) \\
\hline Follow & 37 & (28) & 17 & (14) & 19 & (16) & 14 & (12) & 17 & (13) \\
\hline Up & & & & & & & & & & \\
\hline
\end{tabular}

Note: Chi Square $=17.59, \mathrm{p}=.02$. 


\section{CHAPTER V}

\section{Discussion}

The purpose of this study was to gain knowledge about the impact and effectiveness of instructional practices used in teaching multicultural or diversity sensitivity courses at the graduate level, in particular a participatory approach to diversity training designated as Transformative Diversity Training (TDT). This was achieved by accomplishing two specific aims. The first aim of the study was to investigate and describe the way in which diverse students in a Transformative Diversity Training course evaluated their own change in awareness, knowledge, and skills for working with diverse clients, and how they evaluated their own efforts in transforming themselves, their work settings, and/or their communities toward more equitable practices. The second aim of the study was to assess whether the Transformative Diversity Training course accomplished its goals in (a) increasing students' cultural awareness, knowledge, and skills in enduring ways, and (b) empowering students to transform their work settings, communities, and/or the profession toward more equitable practices. Students' detailed descriptions of changes resulting from the course experiences suggested that the course goals were indeed accomplished.

A view of the trainee as a student coming from, living within, and preparing for professional service in a culturally pluralistic milieu prompted the development of the Transformative Diversity Training model and, subsequently, this examination of its effects. Previous research on the effects of diversity training for counselors has been conducted on programs primarily intended to increase majority white students' 
awareness of, and social action on behalf of, minority individuals, so the overall purpose of this study was to examine the impact of diversity training designed for minority students on a diverse population of students. The TDT course was built upon tested and enduring multicultural competencies of awareness, knowledge, and skills (Sue, Arredondo, \& McDavies, 1992), but encouraged the diverse (and predominantly minority) students to explore these competencies from the cultural reality in which they were embedded—namely, a multicultural community context.

The use of both qualitative and quantitative methodology, combined through Relational Data Analysis, permitted the aims of the study to be accomplished. Using qualitative methodology allowed the diverse trainees to identify and describe their multicultural experience (personally and professionally) in their own language. Their responses provided insights into how diverse students gain cultural competence in an increasingly multicultural and pluralistic community context. Using quantitative methodology allowed significant patterns of change over time to be selected. Thus, the participants in this study provided insights into how diverse students become empowered, transformative stakeholders in the community and the profession. Student Hopes for Change and Transformative Diversity Training Goals

As previously shown in Table 1, the TDT model included goals for the duration of the course. These included training group cohesion at the preliminary intervention phase; student gains in awareness, knowledge, and skills through the participatory learning phase; and personal empowerment and proactive participation in the community and the profession with the transformative activity phase. Student "hopes for change" that is, what students hoped to obtain from/through the course-were solicited before the 
onset of the course. These statements served as a baseline/bench mark for the change described by students at post TDT and follow-up. Conceptual coding revealed that the "students' hopes for change" were very much in line with the goals of the course. Most students expressed the desire to gain cultural awareness, general knowledge of other's cultures, and personal and professional development. These hopes for change are approximately parallel to the awareness, knowledge and skills (Sue, 1995) goals that were targeted through the participatory activities within the course. A few students also expressed a desire for Societal Change/Social Action, which foreshadowed the transformative aims and activities within the course. Thus, is would seem that going into the TDT course, the goals of both the course itself and the students were relatively well matched.

Change in Awareness, Knowledge, and Skills

As revealed through the post-TDT conceptual coding, the TDT course format did indeed achieve the goal of imparting multicultural competencies. As shown in Table 21, "Actual Change" conceptual coding categories can specifically matched with Sue's Multicultural Competencies (1998).

At both post-test and follow-up, the data also revealed that for a small subset of the students $(5 \%)$ there was no impact of the participatory activities on their multicultural competence, no impact on the quality of the professional services/activities and no change in their involvement in community or profession as a result of the overall class The reason for this was listed either as already being very much involved in multicultural aspects in personal, community and professional life before the TDT course, or had not had an opportunity to test for certain whether change did occur. 


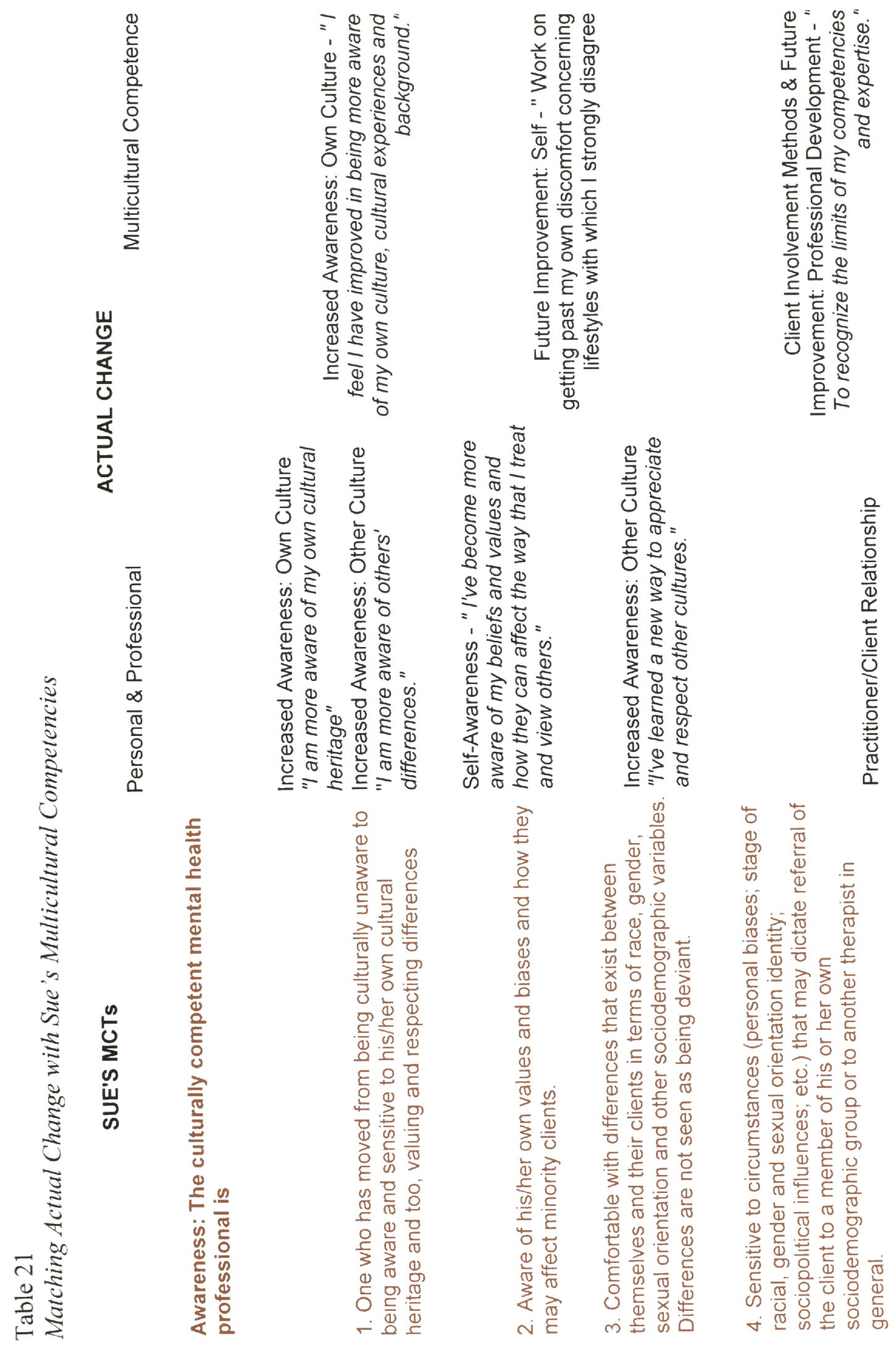



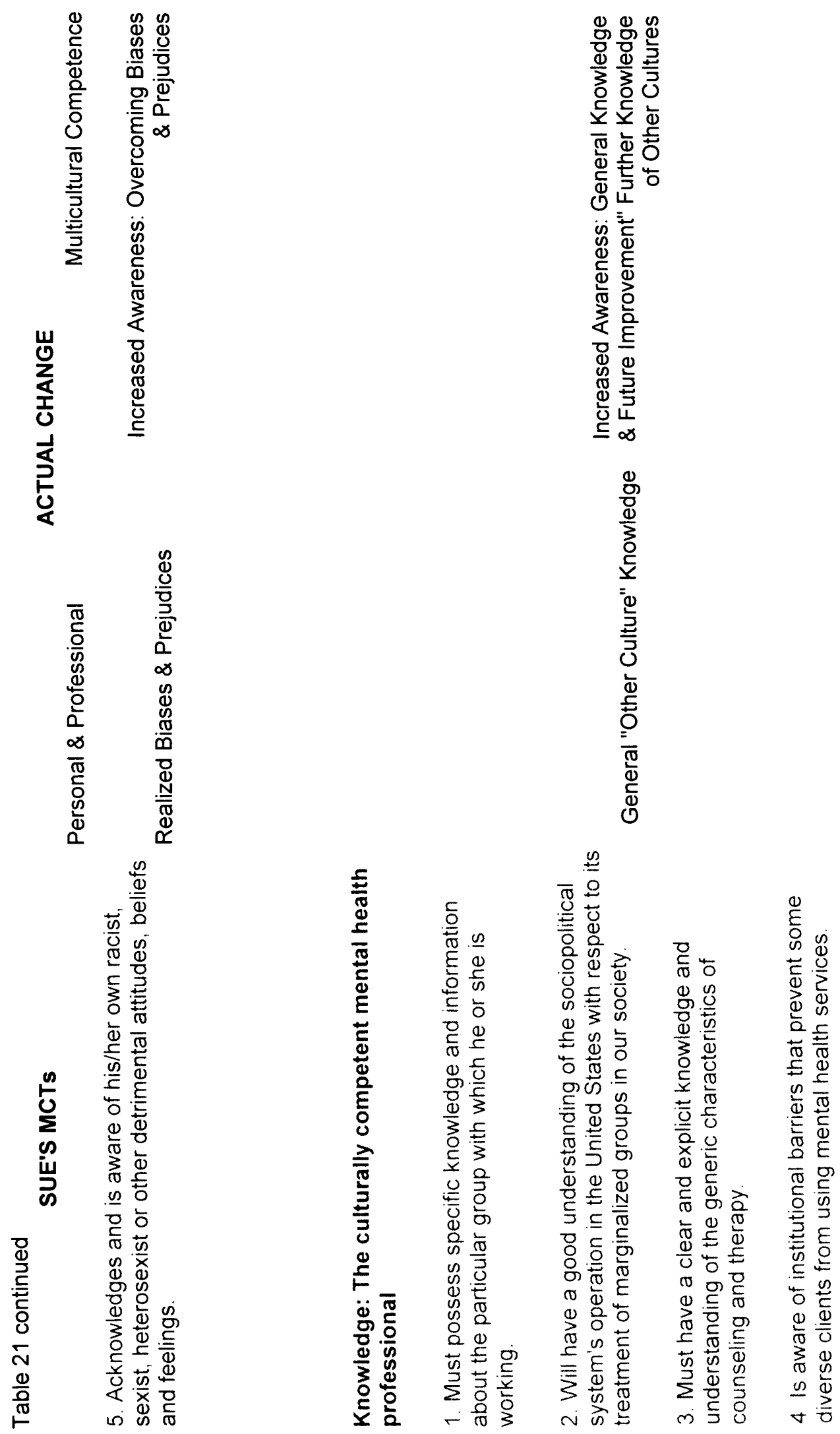


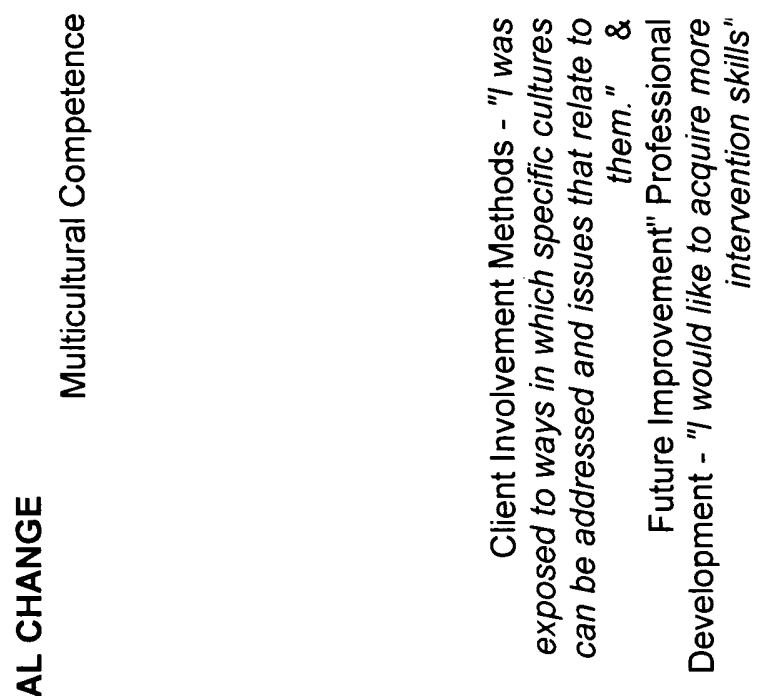

$\overline{0}$
$\frac{0}{0}$
$\frac{0}{0}$
0
$\frac{0}{0}$
$\frac{0}{0}$
$\infty$
$\overline{0}$
$\frac{0}{0}$
$\frac{0}{0}$
0

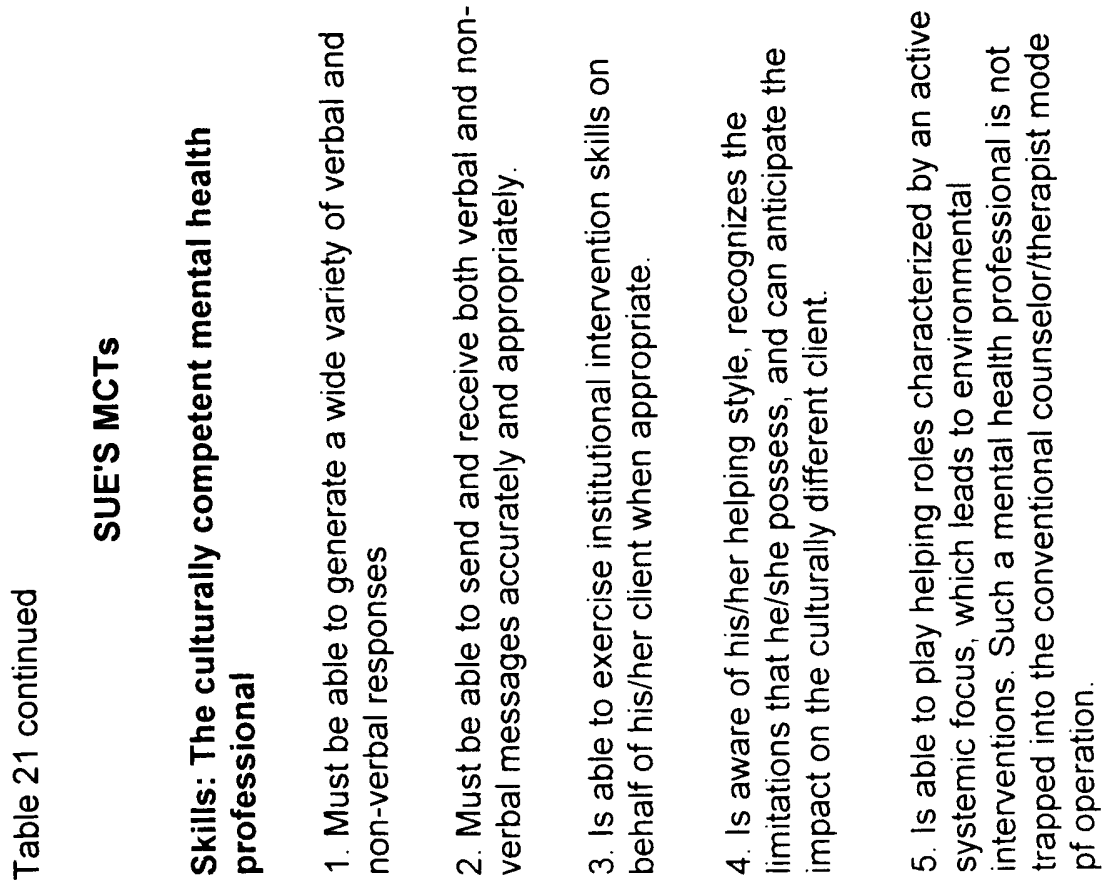


For the most part, the types of changes students attributed to experiences in the TDT course did carry forward to when students were assessed one year later. Students' follow-up responses also seemed to suggest that their understanding of the TDT course experiences were continuing to evolve and expand, and were still transforming them. Thus, for these diverse students, the participatory activities and transformative action activities included in the TDT course aided in their empowerment and personal growth, and facilitated, for some, a newfound role as a stakeholder in the community and the profession.

These results are consistent with the theoretical conceptions that provided the foundation for the TDT course. Participatory action was chosen as they primary mechanism through which the types of change that would be most appropriate for diverse students would occur (Montgomery, Contreras, \& Kurtines, 2001). Reason (1994) described the two primary objectives of participatory action as the production of "knowledge and action" directly useful to a community and "empowerment through consciousness raising," which were indeed reflected in the responses of the students. Participatory action accomplishes these objectives by promoting understanding, mutual involvement, change, and personal growth (Kidd \& Kral, 2005). The diverse students in the TDT course appeared to develop a frame of mind that included respect, genuineness, and openness to experience, all touted as necessary components to engage in participatory action. 
It would seem that TDT produced "conscientization," a term used by Paulo Friere (1982) to describe the developing awareness that occurs among people engaged in self-inquiry. I believe that this "conscientization" was empowering in and of itself. 


\section{Empowerment}

In addition to achieving increased awareness, knowledge, and skills related to multicultural competence, these gains and the overall TDT course itself appeared to facilitate empowerment by fostering individual transformation. This was revealed in the categories of Self-Improvement and Open-minded, in which students described being able to "think outside the box," "adopting a less judgmental stance," "being pushed out of my comfort zone," and "feeling empowered".

Writers in Counseling Psychology refer to empowerment as a process affecting the individual in relation to others, to the community and to society (e.g., McWhirter, 1994). Empowerment is conceptually distinct from autonomy, efficacy or general personal growth. It is a global process involving behavioral and cognitive components. Gutierrez (1998) emphasizes the cognitive components of empowerment and states that it involves a psychological transformation which requires the development of a new selfconcept. He states that there are three mutually reinforcing components of the empowered sense of self. They are (a) group identification (understanding areas of common experience and concern), (b) stratum consciousness involving a "realistic appraisal of the status and power of groups in society," and (c) self and collective efficacy which refers to "beliefs that one is capable as an individual or member of a group of making desired changes to one's life" (pp. 6). Having the skills to create change is not enough; people must believe that they are indeed capable of using such skills effectively. It would seem from the nature of responses received that students did indeed progress, and are continuing to progress, through these mutually reinforcing components of the empowered sense of self. 
It should be noted however, that how empowerment actually takes place will vary across individuals and across time as a result of the multitude and variety of power relationships in society. Both Solomon $(1976,1987)$ and Pinderhughes $(1983)$ state that empowerment must involve the recognition of the way power operates within society and how individuals and communities are affected by the way power is used. The scope and nature of empowerment also depends on the context within which empowerment occurs. What empowers some individuals may not do the same for others. Because this sample was comprised of diverse students, many of whom had immigrated to the United States and many of whom were first generation Americans, an examination of empowerment that students felt across time and attributed to the course experiences was of particular interest.

Finally, the empowerment process represents a continuum, rather than a dichotomy (McWhirter, 1994). There is no specific beginning and no end states of empowerment. This indeed seems to be the case as evidenced by responses and categories obtained for the diverse students who experiences TDT course.

\section{Becoming a Transformative Stakeholder}

The knowledge generation component of the course and the participatory activities seemed to be inextricably linked to action and thus carried forward into the transformative activities. Students were not just interested in simply knowing about a problem, but rather wished to generate collectively developed action. This interest became clear enough to become a distinct category of response in the post-TDT course conceptual coding, and was labeled "Societal Change/Social Action." At the follow-up, 
the category of Social Action was more elaborate and was a salient result of the course for even more individuals.

This result is consistent with the call to social justice that has been sounded throughout professional associations for counseling (Lee, 1995), psychology (Vera and Speight, 2003), mental health (Schlesinger \& Gray, 1999), and feminist therapy (Worell \& Johnson, 1997). Major contributors to a recent forum on social justice sponsored by The Counseling Psychologist (2003) called on counseling psychologists to recognize that multicultural competence cannot be achieved without a commitment to social justice. This commitment would require the counseling psychologists extend their professional activities beyond counseling and psychotherapy to advocacy and intervention at the community and policy levels. Goodman et al. (2004), conceptualized the social justice work of counseling psychologist as scholarship and professional action designed to change societal values, structures, policies and practices, such that disadvantaged or marginalized groups gain increased access to the tools necessary for self-determination. Social action represents a means to achieve social justice.

Inherent within the format of the TDT course, specifically through the participatory activities and as expressed by students and shown in conceptual coding, the TDT course allowed for "conscientization" (Friere, 1982); increased professional knowledge base; and problem posing identification at community level as well as within self and professionally. This process of self-inquiry/self reflection (self-awareness) professional awareness, and awareness of environmental dynamics coupled with transformative activities (action) set the stage for the development of characteristics common to both the concepts of social action and empowerment. 
According to Lee (1998), the concept of social action must be considered within the context of a counselor's awareness of self both as a person and a professional; interpersonal awareness: which involves entering a client's reality in a non-judgmental manner and systemic awareness -which entails being able to perceive accurately the environmental influences on client development and provide skills to intercede at the environmental level to challenge systemic barriers that block optimal mental health(Cook, 1972; Gunnings \& Simkins, 1972; Katz, 1985; Lee, Armstrong \& Brydges, 1996). Within the definition of empowerment it suggests that empowerment is a complex process that encompasses self-reflection and action, awareness of environmental power dynamics that may impact upon psychosocial development, and the development of skills to promote community enhancement (McWhirter, 1997). Thus it would seem that the two concepts social action and empowerment share many similar characteristics and thus may possibly interact to contribute to the overall development of the counselor trainee as well as to the development of each construct within the counselor trainee once provided with a catalyst - in this case the TDT course..

As the $\mathrm{f}$ ace of the US changes and diversity becomes more a part of everyday life and context, the need for minority students to become transformative stakeholders within the profession seems even more crucial. It is only through the awareness and actions of those individuals embedded within the context of multiculturalism, that is, coming directly from and/or a product of diversity can we really have a chance for true and lasting change that can benefit us all. 
Transforming the Profession

Whether we address diversity issues in one class or in many, counselor educators engage in multi-faceted interventions with students. We hope for change: change in our students' (and our own) ways of understanding, feeling, practicing counseling, living as citizens in our communities, and participating in the profession. We hope our students, both non-majority and majority, will choose greater sensitivity to diversity and greater cultural competence in providing services. Furthermore, we hope they will also choose to increase their proactive participation in our profession. As educators and mentors of future practitioners, our goal is to engage counselors proactively in dialogues and endeavors that enhance the level of sensitivity to diversity in individual counselors, in the helping professions, and, ultimately, in the countries and communities in which we all live.

Of course, students have their own goals with respect to diversity issues. They also have their own preferred ways of learning. Although this is true in any class, the importance of students' perspectives is heightened when the basic goal of the curriculum is to promote respectful approaches to difference. The irony is not lost on our students if we insist that they adopt our version of cultural competence, through our preferred educational process, whatever those may be. Thus, the curriculum for diversity training needs to parallel the skillful respect for individuality and difference that we hope to nurture in our students. The process of fostering students' growth in awareness of cultural diversity is parallel to the process of fostering student's growth in skillful and respectful counseling. Many of the methods for supporting clients' growth processes are helpful for facilitating a classroom climate in which the students' cultural competence can grow. In 
this way, individuals' diverse voices will be heard, adding to the richness and the equity of our communities and our profession.

\section{Study Limitations}

As with all studies, there are limitations. For this study, self-report measures were utilized, thus we used counselor trainees' self-perceived efficacy in multicultural competencies and issues that may have been positively or negatively biased. For example, people with little multicultural training tend to be less aware of their lack of knowledge and thus may be less able to make an adequate assessment of their cultural competence (i.e. over-reporting their competencies). Additionally, we did not take into account social desirability, self-enhancement motives, and possible misinterpretation of items on the instruments.

This study did not include a comparison control group. Similar studies in the future could include graduate students enrolled in a course employing one of the more common formats for teaching multicultural competency, in order to see whether the TDT course format resulted in different student perceptions of short- and long-term change. Another comparison group might usefully include majority white students. Because this sample included a vast majority of minority students, is it most representative of student populations from other diverse campuses in urban communities in the US, and not of student populations that are from predominantly white majority communities.

Nevertheless, because minority trainees are a vastly understudied group, this study makes an important contribution of knowledge. 
Finally, limitations in the concept of "multicultural competence"-the key construct examined in this study-must be acknowledged. In trying to study a concept such as multicultural competence, "what remains elusive is a collectively agreed upon operationalization that comprehensively and accurately captures the quintessence of the construct cultural competence” (Ridley, Baker, \& Hill, 2001, pp. 823). At best, cultural competence seems to describe (a) a goal that represents ideal or exemplary practices for maximizing effectiveness with diverse people, (b) a set of mental health counseling skills that can be taught or trained, and (c) a functional developmental sequence (Snarey \& Bell, 2003) that unfolds from awareness to knowledge and skills, creating the empowerment needed to bring about personal transformation and participation in the community and profession as a stakeholder with justice aims. Clearly, cultural competence remains a concept that is difficult to translate into training goals or to operationalize for study.

\section{Suggestions for Future Research}

Despite these challenges, Arredondo and Arciniega (2001) and many others have insisted that research is required in order to identify how exactly counselor trainees become aware and accepting of themselves as racial and cultural beings; how they become more aware of their biases, preconceived notions, and personal limitations; how they come to appreciate and incorporate in therapy the worldviews and perspectives of their clients; and how the multicultural competencies are integrated into specific treatment practices.

Another key question that has been raised is whether clients perceive counselors who have had multicultural training to be more culturally competent. For example, 
Atkinson, Casas, and Abrey (1992) have noted that it is not clear if counseling trainees' exposure to multicultural topics actually increases counselor competence such that clients notice observable competency related behaviors, or if training experiences allow the counselors to demonstrate interest in a culture because they are familiar with it, and this results in better counselor-client rapport due to mechanisms present in any counseling encounter. Additionally, research that probed the question, "Is clients' definition of cultural competency similar to that set forth by D.W. Sue et al. (1992)?" would also be noteworthy in the field of multicultural competency training. This might be a particularly interesting question to explore in a diverse community where many combinations of client-counselor cultural backgrounds would be not only possible, but common.

In conclusion, research helping the profession achieve its goal of "guidance for all" has just begun. As Sue wrote in a recent American Psychologist essay (November, 2003) research that seeks to answer any of the following questions would also add a wealth of knowledge to understanding multicultural competence.

1) How can culturally competent providers be identified?

2) What measures of cultural competence are there?

3) What characteristics are important in cultural competency?

4) How should providers and mental health administrators be trained?

This study sought to add to our knowledge about how diverse providers of counseling and future members of the profession should be trained. In doing so, this study brings the viewpoints of minority trainees-a group which has heretofore been largely ignoredinto the realm of study, with hopes that their actions as stakeholders in our profession will help to transform it into one that is more broad, equitable, and inclusive. 
American Psychological Association (2002). Guidelines on Multicultural Education, Training, Research, Practice, and Organizational Change for Psychologists. Washington, DC: APA.

Ancis, J. R. (Ed.) (2003). Culturally Responsive Practice. In Culturally Responsive Interventions. Brunner-Routledge.

Arredondo, P., \& Arciniega, G.M. (2001). Strategies and Techniques for Counselor Training based on the Multicultural Counseling Competencies. Journal of Multicultural Counseling and Development, 29, 263-273.

Arthur, N., (2000, April). Predictive Characteristics of Multicultural Counseling Competence. Paper presented at the Annual Conference of the American Educational Research Association, New Orleans, LA.

Arthur, N., \& Achenbach, K. (2002). Developing multicultural counselling competencies through experiential learning. Counsellor Education and Supervision, 42(1), 2-15.

CCPT (1998). Council of Counseling Psychology Training Programs 1996 Survey of Doctoral Training Programs.

Chiang, Y. Y. (2000). How the International Students Office helps students from different cultures: A comprehensive report. Unpublished manuscript.

Constatine, M.G. \& Sue, D.W. (Eds.). (2005). Strategies for building multicultural competence in mental health and educational settings. Hoboken, NJ: John Wiley and Sons Inc.

Constantine, M.G., Landanv, N., Inman, A.G., and Ponterotto, J.G. (1996). Students' perception of multicultural training in counselling psychology programs. Journal of Multicultural Counseling and Development, 24, 241-253.

Cooper, A.R. , \& Hodgetts, J. A. (2000). The Guardianship Program of Dade County: An investigation of cultural awareness. Unpublished manuscript.

D'Andrea, M. \& Daniels, J. (1994). The different faces of racism in higher education. Thought \& Action, 10, 73-89.

D'Andrea, M., Daniels, J., \& Heck, R. (1991). Evaluating the impact of multicultural counseling training. Journal of Counseling and Development, 70, 143-150. 
D'Andrea, M., \& Daniels, J. (1995). Promoting multiculturalism and organizational change in the counseling profession. In J. Ponterotto, J. M. Casas, L. A. Suzuki, C. M. Alexander (eds.), Handbook of multicultural counseling, (pp. 17-33), Thousand Oaks: Sage.

Diaz, E. (1990). Barriers to minorities in the field of psychology and strategies for change. In Stricker, G., Davis-Russell, E., Bourg, E., Duran, E., Hammond, W. R., McHolland, J., Polite, K., \& Vaughn, B. E. (Eds.), Toward ethnic diversification in psychology education and training. Washington, D.C.: American Psychological Association.

Evans, K. M., \& Foster, V. A. (2000). Relationships among multicultural training, moral development, and racial identity development of white counseling students. In Counseling and Values, 45, 39-48.

Fouad, N. A. (1999). Diversity and the public interest. Division 17 Newsletter (American Psychological Association, Division of Counseling Psychology), 20 (2), 3-5.

Freire, P. (1970/1983). Pedagogy of the oppressed. New York: Continuum.

Goh, M. (2005). Cultural competence and master therapist; an inextricable relationship. Journal of Mental Health Counseling, 27(1), 71-87.

Goodman, L.A., Liang, B., Helms, J.E., Lalta, R.E., Sparks, E., \& Weintraub, S.R. (2004). Training counseling psychologists as social justice agents: feminist and multicultural principles in action. Counseling Psychologist, 36(6), 793-837.

Heid, L.S., \& Parish, M.T. (1998) Relating authentically in a global community: A Process of personal transformation. Proceedings of the Seventh International Conference, Sydney, Australia.

Heppner, M. J., \& O’Brien, K. M. (1994). Multicultural counselor training: Students' perceptions of helpful and hindering events. Counselor Education and Supervision, 34, 4-18.

Holcomb-McCoy, C.C. (1999). Multicultural counseling training: A preliminary study.

Ivey, A. E. (1995). Psychotherapy as liberation. In Ponterotto, J. G., Casas, J. M., Suzuki, L. A., \& Alexander, C. M. (Eds.), Handbook of multicultural counseling (pp. 53-72). Thousand Oaks: Sage.

Kidd, S. A., \& Kral, M. J. (2005). Practicing a participatory action research. Journal of Counseling Psychology, 52(2), 187-195. 
LaRoche, M. J., \& Maxie, A. (2003). Ten considerations in addressing cultural differences in psychotherapy. Professional Psychology: Research and Practice. 34(2), 180-186.

Lee, C. C. \& Walz, G. R. (1998). Social action: A mandate for counselors. Washington, DC: American Counseling Association and ERIC Counseling \& Student Services Clearinghouse.

McAuliffe, G., Montgomery, M. J., Contreras, R., \& Marbley, A. F., Kurtines, W. M., \& Eriksen, K. (2002). Activities for increasing multicultural awareness. In McAuliffe, G.; \& Eriksen, K. (Eds.), Teaching strategies for constructivist and developmental counselor education (pp. 79-116). Westport, CT: Bergin \& Garvey.

McWhirter, E.H. (1994). Counseling for Empowerment. Virginia: American Counseling Association.

Montgomery, M. J., Contreras, R., \& Kurtines, W. M. (2001). Participatory learning activities for transforming diversity training. Eriksen, K., \& McAuliffe, G. (Eds.), Classroom Strategies for Constructivist and Developmental Counselor Education. Westport, CT: Greenwood.

Montgomery, M. J., \& Kottler, J. (2004). The developing counselor. In D. Comstock (Ed.), Diversity and development: Critical contexts that shape our lives and relationships, pp. 129-158. New York: Wadsworth.

Montgomery, M., Marbley, A. F, Contreras, R., \& Kurtines, W. (2000). Transforming diversity training in counselor education. In McAuliffe, G., \& Eriksen, K. (eds.), Preparing counselors and therapists: Creating constructivist and developmental programs (pp. 148-169). Washington, D. C.: Donning Publishers.

Montgomery, M. J., Marbley, A. F., Contreras, R., \& Kurtines, W. M. (2000). . Diversity training as personal $\mathrm{b}$ and social transformation. Paper presented in Valdez, J. (Chair), Overcoming resistance, achieving transformationinnovations in teaching multicultural counseling skills. Symposium conducted at the meeting of the American Psychological Association, Washington, DC.

Norcross, J.C., Hodges, M., \& Castle, R.H. (2002). Psychologists conducting psychotherapy in 2001: A Study of the Division 29 membership. Psychotherapy: Theory/Research/Practice/Training, 39(1), 97-102.

Parker, W. M., Moore, M. A., \& Neimeyer, G. J. (1998). Altering white racial identity and interracial comfort through multicultural training. Journal of Counseling \& Development, 78, 302-310. 
Ponterotto, J.G. (2002). Qualitative Research Methods: The fifth force in psychology. Counseling Psychologist, 30(3), 394-406.

Pope-Davis, D., Reynolds, A.L., Dings, J.G., \& Nielson, D. (1995). Examining Multicultural Competencies of Graduate Students in Psychology. Professional Psychology: Research and Practice, 26(3), 322-329.

Pope-Davis, D.B., Liu, W.M., Toporek, R.L., \& Brittan-Powell, L.S. (2001). What's missing from multicultural competency research: review, introspection and recommendations. Cultural Diversity and Ethnic Minority Psychology, 7(2), 121138.

Ridley, C. R. (1995). Overcoming unintentional racism in counseling and therapy: A practitioner's guide to intentional intervention. Thousand Oaks: Sage.

Schlesinger, M., \& Gray, B. (1999). Institutional change and its consequences for the delivery of mental health services. In A. Horwitz \& T. Scheid (Eds.), A Handbook for the study of mental health: Social contexts, theories, and systems (pp. 427-448). New York: Cambridge University Press.

Sevig, T. \& Etzkorn, J. (2001) Transformative Training: A Year-Long Multicultural Counseling Seminar for Graduate Students.Journal of Multicultural Counseling and Development, 29, 57-72.

Snarey, J. R., \& Bell, D. (2003). Distinguishing Structural and Functional Models of Human Development: A Response to "What Transits in an Identity Status Transition?" Identity, 3, pp. 221-230.

Steward, R.J., Neil, D.M., Breland, A, \& Miller, M. (1999, April). Negative Outcomes of Diversity Training: What Can We Do? Paper presented at the Great lakes regional Counseling Psychology Conference, Columbus, $\mathrm{OH}$.

Steward, R. J. (1998, April). PAR: A theoretic model for self-assessment and practice toward multicultural counseling competence. In Integrating theory, research training, and practice toward multicultural competence. Symposium conducted at the American Counseling Association World Conference, Indianapolis, Indiana.

Steward, R. J., Morales, P. C., Bartell, P. A., Miller, M., \& Weeks, D. (1998). The multiculturally responsive versus the multiculturally reactive: A study of perceptions of counselor trainees. Journal of Multicultural Counseling and Development, 26, 13-27. 
Steward, R., Wright, D., Jackson, J. D., \& Jo, H. I. (1998). The relationship between multicultural counseling training and the evaluation of culturally sensitive and culturally insensitive counselors. Journal of Multicultural Counseling and Development, 26, 205-217.

Stuart, R.B. (2004). Twelve practical suggestions for achieving multicultural competence. Professional Psychology: Research and Practice, 35(1), 3-9.

Sue, D.W. (2003). In defense of cultural competency in psychotherapy and treatment. American Psychologist, Nov., 964-970.

Sue, D. W., Arredondo, P., \& McDavis, R. J. (1992). Multicultural counseling competencies and standards: A call to the profession. Journal of Multicultural Counseling and Development, 20, 64-88.

Sue, D. W., Bernier, J. E., Durran, A., Feinberg, L., Pedersen, P., Smith, E. J., \& Vasquez-Nuttal, E. (1982). Position paper: Cross-cultural counseling competencies. The Counseling Psychologist, 10, 45-52.

Sue, D. W., \& Sue, D. (1977). Barriers to effective cross-cultural counseling. Journal of Counseling Psychotherapy, 24, 420-429.

Sue, D. W., \& Sue, D. (1990). Counseling the culturally different: Theory and practice (2nd ed.). New York: John Wiley.

Toporek, R.L., \& Reza, J.V. (2001). Context as a critical dimension of Multicultural Counseling: Articulating Personal, Professional and Institutional Competence. Journal of Multicultural Counseling and Development, 29, 13-30.

Tomlinson-Clark, S. (2000). Assessing outcomes in a multicultural training course: A qualitative study. Counselling Psychology Quarterly, 13, 221-231.

Vinson, T. S., \& Neimeyer, G. J. (2000). The relationship between racial identity development and multicultural counseling competency. Journal of Multicultural Counseling and Development, 28, 177-192.

Warring, D.F., Keim, J.S., \& Rau, R. (1998). Multicultural training for students and its impact. Action in Teacher Education, 20, 56-63.

Worell, J., \& Johnson, N. (1997). Shaping the future of feminist psychology and practice. Washington, DC: American Psychological Association. 
Zerbe-Enns, C., \& Sinacore, A.L.(Eds.). (2005). Teaching and Social Justice: Integrating Multicultural and Feminist Theories in the classroom. Washington DC: American Psychological Association. 


\section{Demographic Information}

1. Gender (circle one): Male Female

2. Age: years

3. Please check all ethnic identifiers you feel describe you:

White, not of Hispanic origin

Black, not of Hispanic origin

Haitian

Jamaican

Cuban

Hispanic/Latino, please specify:

Other Caribbean, please specify:

Asian or Pacific Islander

American Indian

Other, please specify:

4. Were you born in the United States (circle one):

Yes

No

If no, where were you born?

5. Was your mother born in the United States (circle one):

If no, where was she born?

Yes

No

6. Was your father born in the United States (circle one):

Yes

No

If no, where was he born?

7. If you were not born in the United States, are you here permanently or temporarily?

8. What was the first language(s) you learned to speak?

9. What other languages do you speak fluently?

10. How would you best describe your yearly income? (If you depend on family members for

support, please include their yearly income.) (circle one):

below $\$ 30,000 \quad \$ 30,000$ to $\$ 50,000 \quad \$ 50,000$ to $\$ 100,000$ more than $\$ 100,00$ 


\section{THE EFFECTS OF TRANSFORMATIVE DIVERSITY TRAINING SURVEY}

1. What, if any, changes in multicultural competence (i.e., awareness, knowledge, and/or skills) resulted from the in-class participatory activities (e.g., readings, discussions, participatory learning experiences, etc.)?

- How significant or important are these changes to you?

- Why are they significant or meaningful to you?

2. Have the changes in your multicultural awareness, knowledge, and/or skills had an impact on the quality of your professional services/activities in a multicultural context? (Professional services and activities might include teaching, service to clients, service to community agencies, scholarly projects or products, etc). Please elaborate.

3. What, if any, changes in your involvement in the community (local or global) and/or in the profession (e.g., affiliation with professional groups, presenting at conferences, taking on a new professional role, taking on particular projects) resulted from the class activities and transformative project?

- How significant or important is this community/professional involvement you?

- Why is it significant or meaningful to you?

4. Has your involvement in the community and/or in the profession had an impact on the quality of the professional services/activities you offer (now or in the future) in a multicultural context? Please elaborate. 
5. What changes, if any, would you suggest for future sections of the course that could better increase students' multicultural awareness, knowledge, and skills, and increase students' involvement in the community and the profession? 


\section{APPENDIX B}

Procedures for Conducting Relational Data Analysis [RDA] Conceptual Analysis

This appendix provides a more detailed description of the procedures used for conducting Relational Data Analysis Conceptual Analysis based on work done by Kurtines, Montgomery, Lewis-Arango, and Kortsch (2004). The basic task of the conceptual analysis phase is to identify all the categories for the Response Content Units (RCU's) based on the similarities and difference in the properties of their content. The conceptual coders who generate the initial set of content categories should be theoretically "neutral" in that the process of grouping the RCUs should be done based on identifiable properties of the RCUs using the explicit verbal content of the respondent. For this phase, in other words, the groupings should not be done because of preconceived "theoretical" categories. Theoretical coding (and the use of theoretical justification) is conducted at a later phase of analysis. The only basis for grouping RCUs during the Conceptual Analysis is because the respondents used the same or similar verbal content in their narrative description. We call this task Content Category Identification.

\section{Using Open Coding to Identify Content Categories}

\section{Data Preparation}

The first step in preparing for open coding is to enter the Macro Interview Responses (MIR) onto the RDA standard card format. In this study, MIRs were the student responses to the "Effects of Diversity Training Survey." 
After the Macro Interview Responses are entered into the RDA standard card format and sorted, the coders are assembled for the coding session. Kurtines et al. (2004) have mainly used undergraduate coders who are not knowledgeable about the research agenda in general or the specific research hypotheses in particular. In this study we followed similar procedures. The coding procedures are generally concrete and specific and have been successfully used by both psychology undergraduates and non-psychology undergraduates, and students at every level (freshman through seniors).

Once the coders are assembled, they are provided with an orientation that includes a general explanation of the goals of coding (i.e., to identify and classify answers to interview questions into groups or categories) and a brief overview of the process that are to be used (i.e., by sorting cards containing a transcription of various segments of the interviewee's answers to the questions). For this study, undergraduate coders were introduced to conceptual coding as follows: The principle investigator printed approximately 20 clip-art pictures (of food, fruits, vegetables, drinks, flowers, people performing tasks) and pasted them onto $4 \times 6$ index cards. The questions "What do you do in your spare time?" and "What do you think about food?" were printed on two larger index cards.

Two sets of 12-15 index cards were printed with one set containing the first question - "What do you do in your spare time?" followed by a response, for example, "Nothing", "I work in my garden" etc. The second set of index card each contained the question "What do you think about food?" followed by a response, for example "I don't think about food", "We need food to survive." The recruited undergraduate students were 
initially asked to create groups/ categories from the set of clip art images given, with the stipulation that they had to use all the cards and that they had to agree on the names of the groups/categories and provide a description for the groups/ categories created.

Once they completed this task they were then presented with one of the index cards that had a question only printed on it only and were told that a group of people were asked this question and instead of giving their response either verbally or in writing, they provided their answer in the form of the pictures. The students were then asked to again create groups/categories with the cards in front of them, but this time keeping in mind the context of the question asked; in other words, to create categories that are somehow relevant to the question asked. Again they were given the stipulations of having to use all the cards, to agree upon the category/group name and to provide a description of each category/group created.

Upon completion of this task, the students were then given the index card with both a study question and a response (MIR) and asked to again create categories, this time from the verbal responses to the "same" question posed on each card. They were informed that they would be watched performing this task. Before the undergraduates could complete the task they were stopped and introduced to the method of constant comparison and informed that for subsequent tasks, categorization had to be done utilizing the method of constant comparison.

Once the method of constant comparison was demonstrated, the students completed the assigned task again with the same stipulations as before but with the addition of highlighting the most salient RCU in the MIR - the aspects of the response 
that helped them decide on the category name and/or the category in which the response would be placed. They were then provided with a brief explanation of:

(1) What a Response Content Unit is -- the properties of the content (i.e., the ideas, incidents, examples, persons, events, things, actions/interactions, etc.) that make up the phrases and sentences interviewees use in answering the interview questions and probes.

(2) What a property is - the distinguishing attribute, quality, or characteristics of whatever it is that the phrases and sentences describe (i.e., the ideas, incidents, examples, persons, events, things, actions/interactions, etc.).

(3) What a category is - Response Content Units that share one or more nonoverlapping (unique) properties.

It was explained to the coders that they would be consensually making all of the decisions concerning what are considered RCUs, what defines their properties, and the categories to which they will be assigned. Open discussion of the process was encouraged and they are encouraged to raise issues, ask questions, and seek clarification.

The process of coding began when the investigator turned over the first (and usually the shortest) card and gave the coders "hands on" experience with the first several cards to be coded. In the process of sorting the first few cards, the concepts of RCUs, properties, and categories were again reviewed, and coders were again encouraged to raise issues, ask questions, and seek clarification.

The first MIR card in response to the question about students' hopes for change from the course, for example, might contain only a single RCU (e.g. "Things I can do in 
everyday life to bring about change" or "Learn more about cultural diversity issues such as values, customs". Coders would be asked to see if they can tentatively (and consensually) identify (describe) the property (or properties) of this unit (e.g., wanting to make a change in society, general cultural awareness etc.) and tentatively (and consensually) identify the content of the category that this response unit belongs to based on the specific categories. The categories would be identified based on the content properties (e.g., properties-“make a difference in society," "gain in general knowledge of other cultures"). Once a tentative category is identified and a tentative description of its property or properties provided, the next card is turned over.

The second card may once again have only a single response unit (e.g. "awareness of cultural issues." Or "Greater opportunity to mature as a person"). Coders are asked to compare this response content unit (and its properties) to the category that now exists (e.g., "Cultural Awareness."). If the second card contains the "awareness of cultural issues." response unit, the coders might agree to classify it as belonging to the "Cultural Awareness category." If, on the other hand, the second card contains the "Greater opportunity to mature as a person" response unit, the coders might agree that it does not belong to the "Cultural Awareness category" and, on the basis of their discussion of the properties of the response unit, tentatively identify a new content category, (e.g. "personal development, "self-improvement").

At this point, student coders for this study were informed to notify the investigator if they were unclear on the methodology. The groups/categories created at this phase were also an indicator of how well the students understood the methodology. Once it was 
determined that the undergraduates had a good grasp of the methodology, they were given their task of coding the response for this study.

Provide Coders with Guidelines for Interpretation and Classification

Once the process of coding begins and coders have some experience with the actual data to be coded, the guidelines for the interpretation of the participants' description of the properties of the RCUs were reviewed. Coders were informed that their interpretation of the participants' description of the properties of the RCUs should make as little use of inference about the subjective meaning and significance of the response to the participants as possible. That is, the aim was to identify the content categories that are in the data set (the actual response of the participants), and the interpretation of the subjective meaning and significance of the content should be based on the explicit content of the responses using the most conservative criteria possible.

For example, if in response to hopes for change question, the participant stated, "Become more aware of people who are different from me," it would be possible to challenge this description as belonging to the "Cultural Awareness" category by stating that it infers self-improvement, personal development. However, because this has not been explicitly stated, the conclusion that the student is seeking self-improvement would be an inference not justified on the basis of the content of their response. Consequently, the guideline provided to the coders is that they are to follow the most conservative criteria in interpreting the participants' description of the properties of the RCUs. They are instructed to code the responses on the basis of the explicit content contained in the $\mathrm{RCU}$, and avoid making inferences about the subjective meaning and significance of the content not explicitly stated by the participants. That is, in the tradition of qualitative 
research, the coders are expected to generate interpretations of the meaning and significance of participants' response data, but they are also expected not to "over interpret" in ways not justified by the data. Thus, in the absence of evidence to the contrary, if a participant makes an explicit statement that she/he would like to become more aware of other cultures/culturally aware, it was be coded in the "Cultural Awareness category."

Providing Coders with Guidelines for Formulating Category

As coders gained experience with the actual data to be coded, the aim of the grouping process - to come up with the smallest number of groups (categories) of RCUs that share at least one property in common that is not shared with RCUs of other categories (groups) - is reviewed. They were also instructed that when they had successfully identified two (or more) categories (groups) (e.g., Category A, Category B, Category $\mathrm{C}$, etc.) that define qualitatively different (non-overlapping) categories of RCUs, they had to verbally describe the properties that each category of RCUs shared in common, and the properties that they did not share in common with other categories of RCUs.

It was explained that these property descriptions were intended to provide the criteria for classifying particular RCUs as belonging (or not belonging) to specific categories. Coders were further provided with prototypical statements to serve as models in articulating or formulating the property descriptions in order to ensure that the classification of the content of the categories are based on explicit information contained in the data set (i.e., the actual response of the participants) and that the interpretation of 
the subjective meaning and significance of the content was based on the explicit content of the responses using the most conservative criteria possible. These statements were:

(1) A RCU classified as belonging to Category A should make an explicit reference to a specific property that defines the category (e.g., an RCU classified as belonging to the "Cultural Awareness" category should make explicit reference to gaining in awareness of other cultures).

(2) The RCUs classified as belonging to Category B should make an explicit reference to a specific property that defines the category (e.g., the RCU classified as belonging to the "Social Action" category should make explicit reference to wanting to make a change in society). 